\title{
Neuronal Network Excitability in Alzheimer's Disease: The Puzzle of Similar versus Divergent Roles of Amyloid $\beta$ and Tau
}

\author{
Syed Faraz Kazim, ${ }^{1}$ Joon Ho Seo, ${ }^{1}$ Riccardo Bianchi, ${ }^{2}$ Chloe S. Larson, ${ }^{1}$ Abhijeet Sharma, ${ }^{1}$ \\ Robert K. S. Wong, ${ }^{2}$ Kirill Y. Gorbachev, ${ }^{1}$ and Ana C. Pereira ${ }^{1,3}$
}

https://doi.org/10.1523/ENEURO.0418-20.2020

\begin{abstract}
${ }^{1}$ Department of Neurology and Nash Family Department of Neuroscience, Friedman Brain Institute, Icahn School of Medicine at Mount Sinai, New York, NY 10029, ${ }^{2}$ The Robert F. Furchgott Center for Neural and Behavioral Science, and Department of Physiology and Pharmacology, State University of New York (SUNY) Downstate Medical Center, Brooklyn, NY 11203, and ${ }^{3}$ Ronald M. Loeb Center for Alzheimer's Disease, Icahn School of Medicine at Mount Sinai, New York, NY 10029
\end{abstract}

\begin{abstract}
Alzheimer's disease (AD) is the most frequent neurodegenerative disorder that commonly causes dementia in the elderly. Recent evidence indicates that network abnormalities, including hypersynchrony, altered oscillatory rhythmic activity, interneuron dysfunction, and synaptic depression, may be key mediators of cognitive decline in $A D$. In this review, we discuss characteristics of neuronal network excitability in $A D$, and the role of $A \beta$ and tau in the induction of network hyperexcitability. Many patients harboring genetic mutations that lead to increased $A \beta$ production suffer from seizures and epilepsy before the development of plaques. Similarly, pathologic accumulation of hyperphosphorylated tau has been associated with hyperexcitability in the hippocampus. We present common and divergent roles of tau and $A \beta$ on neuronal hyperexcitability in AD, and hypotheses that could serve as a template for future experiments.
\end{abstract}

Key words: amyloid $\beta$; neuronal excitability; seizures; tau

\section{Significance Statement}

Abnormal neuronal network excitability may lead to hypersynchrony, aberrant oscillatory rhythmic activity and interneuron dysfunction, which may contribute to cognitive decline in Alzheimer's disease (AD). The main goals of this review are the following: (1) to provide an overview of the current knowledge on the association between abnormal network dysfunction and AD; (2) discuss the role of pathologic $A \beta$ and tau on neuronal hyperexcitability; and (3) present potential hypotheses that can be tested for future studies, which could lead to more effective strategies to prevent, diagnose, and manage AD and related disorders.

\section{Introduction}

\section{Alzheimer's disease (AD): health care burden and neuropathology \\ $A D$ is an age-dependent chronic progressive neurode- generative disorder, and is the leading cause of dementia worldwide (Ballard et al., 2011; Cornutiu, 2015; Alzheimer's Association, 2019). It is the sixth leading cause of mortality in the United States and affects $\sim 5.8$

million Americans (Alzheimer's Association, 2019). Worldwide, $A D$ and related dementias affect $\sim 47$ million people (Prince, 2015). In the year 2019, the total health care expenditure for $A D$ and related dementias in United States was nearly 290 billion dollars, making it one of the costliest chronic diseases (Alzheimer's Association, 2019). To date, there is no effective disease-modifying therapy for AD.

The authors declare no competing financial interests.

Author contributions: S.F.K., J.H.S., R.B., C.S.L., A.S., R.K.S.W., K.Y.G., and A.C.P. wrote the paper. 
Histopathologically, AD is characterized by two major lesions: amyloid as diffuse and neuritic plaques composed of amyloid $\beta(\mathrm{A} \beta)$ peptide, and neurofibrillary tangles (NFTs) composed of abnormally hyperphosphorylated tau protein (Glenner and Wong, 1984; Grundke-lqbal et al., 1986a,b). Besides $A \beta$ plaques and NFTs, impairments in adult hippocampal neurogenesis and synaptic plasticity, profound synaptic loss, and neurodegeneration are also major features of AD (Terry et al., 1991; Selkoe, 2002; Scheff and Price, 2003; Scheff et al., 2007; Li et al., 2008; Demars et al., 2010; Shruster et al., 2010; Mu and Gage, 2011). The hippocampal formation in the brain is the hub of learning and memory (Neves et al., 2008; Battaglia et al., 2011), and entorhinal cortex (EC), within the hippocampal formation, is one the first brain regions to be affected by $A D$ pathology (Braak and Braak, 1991, 1995, 1996). Despite the dramatic advances in understanding the molecular pathology underlying neurodegeneration in $A D$ during the past few decades, current knowledge of the physiological basis of memory loss in $A D$ is limited.

\section{Network dysfunction in AD}

Network abnormalities and their contribution to cognitive dysfunction in $A D$ have been reviewed before (Palop and Mucke, 2010a,b, 2016; Zott et al., 2018; Busche and Hyman, 2020; Jun et al., 2020). Network hypersynchrony, altered oscillatory rhythmic activity, interneuron dysfunction, and synaptic depression may be key mediators of cognitive deficits in AD (Palop and Mucke, 2010a,b, 2016). Emerging evidence suggests that brain network alterations begin even decades before the symptomatic onset of AD (Busche and Konnerth, 2016; Nakamura et al., 2017). Besides, recent studies have provided evidence that abnormal neuronal network activities could contribute to the spread of pathology across functionally connected brain circuitry in AD (Wu et al., 2016; Schultz et al., 2018). It can thus be speculated that early brain network dysfunction not only contributes to cognitive dysfunction but also to disease progression in AD.

A.C.P. is supported by National Institutes of Health Grants R01AG064020 and R01AG063819, the Paul B. Beeson Emerging Leaders Career Development Award in Aging K76AG054772, the BrightFocus Foundation, the DANA Foundation, the Alzheimer's Drug Discovery Foundation, the Alzheimer's Association, the Bernard L. Schwartz Award for Physician Scientist, and seed money from Icahn School of Medicine at Mount Sinai. S.F.K. was supported by a doctoral fellowship from Neural and Behavioral Science Program, School of Graduate Studies, State University of New York (SUNY) Downstate Medical Center and SUNY Downstate/New York State Institute for Basic Research (NYSIBR) Program in Developmental Neuroscience, when initial ideas related to the discussion and perspectives presented in manuscript were generated and a part of this review was written.

Acknowledgements: We thank the support from the Neural and Behavioral Science Graduate Program and the Department of Physiology and Pharmacology, SUNY Downstate Medical Center.

Correspondence should be addressed to Ana C. Pereira at ana.pereira@ mssm.edu.

https://doi.org/10.1523/ENEURO.0418-20.2020

Copyright (C) 2021 Kazim et al.

This is an open-access article distributed under the terms of the Creative Commons Attribution 4.0 International license, which permits unrestricted use, distribution and reproduction in any medium provided that the original work is properly attributed.
Brain activity in humans can be evaluated by employing functional magnetic resonance imaging (fMRI), positron emission tomography (PET), single-photon emission computed tomography (SPECT), electroencephalography (EEG), or local field potentials (LFPs) recordings (Palop and Mucke, 2016). In healthy individuals, cognitive tasks increase $\mathrm{fMRl}$ signals in particular brain regions (e.g., the hippocampus during learning) but also lead to a profound large-scale deactivation in brain regions that are jointly referred to as the default mode network (DMN; Raichle et al., 2001; Boyatzis et al., 2014; Palop and Mucke, 2016). The DMN includes several brain regions such as the precuneus, posterior cingulate cortex, lateral and inferior parietal cortex, and regions of the temporal and medial prefrontal cortex (Raichle et al., 2001). A consistent fMRI signature of $A D$, specifically during the early stages of the disease, is hippocampal hyperactivation and reduced deactivation of DMN components during memory encoding tasks (Bookheimer et al., 2000; Dickerson et al., 2005; Celone et al., 2006; Trivedi et al., 2008; Filippini et al., 2009; Sperling et al., 2009; Quiroz et al., 2010; Bakker et al., 2012, 2015; Sepulveda-Falla et al., 2012; Kunz et al., 2015). Early hippocampal hyperactivation was traditionally thought of as a compensatory mechanism for emerging cognitive dysfunction in early AD (Dickerson et al., 2004; Kunz et al., 2015). However, recent evidence points toward a primary pathogenic role of this early hippocampal hyperactivity, and it may play a major role in cognitive decline in AD (Putcha et al., 2011; Bakker et al., 2012, 2015). This will be discussed in detail in later (see below, Seizures and neuronal network hyperexcitability in AD: a late-onset consequence of neurodegeneration or an early component of $\mathrm{AD}$ pathophysiology contributing to cognitive impairment? and Beneficial effect of levetiracetam, an antiepileptic drug, on cognition in $A D$ patients and mouse models: evidence for the role of neuronal network hyperexcitability in cognitive impairment?).

Neural oscillations (or brain rhythms) are rhythmic fluctuations of electrical activity in the CNS that emerge because of the physiological properties of different types of neural cells and their interactions (Buzsáki et al., 2012, 2013). Normal neuronal synchrony underlies the generation of oscillatory brain rhythms that promote cognitive functions including memory. Oscillations, from lowest to highest frequencies, are classified into $\delta, \theta, \alpha, \beta, \gamma$, and sharp-wave ripples (SWRs). $\gamma$ Oscillations, in particular, are of interest because of their proposed role in organization of functional neural circuits and formation of functional neuronal assemblies, contributing to sensory processing, attention, and memory (Fries, 2015; Lundqvist et al., 2016). Accumulating evidence shows that $\gamma$ power as well as interareal $\gamma$ coherence is severely affected in AD patients (Stam et al., 2002; Koenig et al., 2005; Guillon et al., 2017). More recently, Jun and his colleagues demonstrated that remapping capabilities of CA1 cells and grid cells are severely affected by expression of human mutant gene of APP (APP-knockin; APP$\mathrm{KI})$. The authors found that CA1 neurons from APP-KI mice exhibited reduced firing peaks and less spatial tuning, with lower mean spatial information compared with those of wild-type (WT) CA1 neurons. To investigate the impact of 
human $\mathrm{A} \beta$ precursor protein (hAPP) on remapping of $\mathrm{CA} 1$, the authors recorded from CA1 neurons while WT and APP$\mathrm{KI}$ mice were subjected to two different environments. While WT CA1 neurons showed distinct firing patterns with respect to their environment, APP-KI CA1 neurons showed no changes in firing patterns between the environments. Further analyses revealed that fast $\gamma$ oscillations, but not slow $\gamma$ oscillations, were found to be diminished in APP-KI mice (Jun et al., 2020). Also, reduced $\gamma$ is observed in several AD mouse models, remarkably even at the presymptomatic stage (Verret et al., 2012; laccarino et al., 2016). Recent studies have demonstrated reduction of disease pathology by induction of $\gamma$ oscillations via sensory stimulation ( $\gamma$ entrainment using sensory stimulus or GENUS) in AD mouse models (Adaikkan et al., 2019; Martorell et al., 2019). Similarly, alterations in other brain rhythms such as hippocampal SWRs and $\theta$ oscillations have also been implicated in AD and will be discussed in detail in later (see High-frequency oscillations or SWRs, epilepsy, and tau; and Phosphorylation of tau reduces hippocampal excitability).

Neural network synchrony and brain oscillatory rhythms are governed by the activity of inhibitory GABAergic interneurons (Buzsáki and Draguhn, 2004). Certain types of inhibitory interneurons such as parvalbumin-positive $\left(\mathrm{PV}^{+}\right)$ or vasoactive intestinal polypeptide-positive (VIP ${ }^{+}$) cells fire mainly during brain states that promote memory encoding (Lapray et al., 2012; Fu et al., 2014). Inhibitory interneuron dysfunction has been linked to network abnormalities in AD (Lapray et al., 2012; Fu et al., 2014; Palop and Mucke, 2016). It was found that impairments of inhibitory interneurons contribute to network hypersynchrony, altered oscillatory rhythms, and behavioral deficits in hAPP-J20 mouse model of AD (Verret et al., 2012). In fact, accumulating evidence implicates inhibitory interneuron dysfunction as a potential common mediator of altered brain rhythms and cognitive impairment in several neuropsychiatric disorders (Sohal et al., 2009; Chao et al., 2010; Marin, 2012; Verret et al., 2012). Recent studies show that modulating the interneuron function ameliorates altered brain rhythms and cognitive impairments in $A D$ and other neurologic disorders (Verret et al., 2012; Hunt et al., 2013; Tong et al., 2014; Dargaei et al., 2018; Martinez-Losa et al., 2018).

In experimental rodent models, high $A \beta$ levels were shown to cause synaptic loss, decrease glutamatergic synaptic transmission and long-term potentiation (LTP), and increase long-term depression (LTD; Hsia et al., 1999; Mucke et al., 2000; Kim et al., 2001; Walsh et al., 2002; Kamenetz et al., 2003; Hsieh et al., 2006; Li et al., 2009; Mucke and Selkoe, 2012). Because of several proposed shared underlying mechanisms, synaptic depression and aberrant excitatory network activity have been hypothesized to be the two faces of the same coin contributing to network dysfunction in AD (Palop and Mucke, $2010 a, b) . A \beta$ was reported to block neuronal glutamate uptake at synapses, resulting in glutamate spillover and aberrant activation of extrasynaptic or perisynaptic GluN2B-containing NMDA receptors (NMDARs) and metabotropic glutamate receptors (mGluRs), ultimately leading to enhanced LTD (Hsieh et al., 2006; Li et al., 2009).
A $\beta$-induced NMDAR-dependent and mGluR-dependent LTD can be mimicked by employing the glutamate reuptake inhibitor threo- $\beta$-benzyloxyaspartate (TBOA), which can also induce synchronized epileptiform discharges in WT brain slices (Campbell et al., 2014). Thus, $A \beta$-induced neuronal network hyperexcitability and synaptic depression in $A D$ may be interlinked through common mediator pathways (Palop and Mucke, 2010a,b, 2016).

\section{Seizures and epilepsy in AD}

It has long been known that $A D$ patients are at increased risk of developing seizures and epilepsy (Friedman et al., 2012; Vossel et al., 2013, 2017). Earlyonset familial AD (EOFAD), caused by genetic mutations in APP, presenilin 1 (PSEN1), and presenilin 2 (PSEN2), is associated with a remarkable 87-fold higher seizure incidence compared with the general population (Amatniek et al., 2006; Cloyd et al., 2006). In contrast, the late-onset sporadic $A D$ is associated with a 3-fold rise in seizure incidence (Amatniek et al., 2006; Cloyd et al., 2006). Also, AD severity was reported to correlate with seizure occurrence. In prospective studies of mild neurocognitive dysfunction because of probable $A D$, seizures were found to occur in $0.5-16 \%$ of patients (Hauser et al., 1986; Romanelli et al., 1990; Amatniek et al., 2006); however, in more advanced, institutionalized $A D$ patients, the incidence of seizures ranged from $9 \%$ to $64 \%$ (Sulkava, 1982; Risse et al., 1990; McAreavey et al., 1992).

\section{Seizures and neuronal network hyperexcitability in AD: a late-onset consequence of neurodegeneration or an early component of $A D$ pathophysiology contributing to cognitive impairment?}

A widely prevalent classical notion was that dementia and seizures exemplify two primarily independent disorders, a supportive argument being that not every individual with generalized seizures goes on to develop progressive cognitive dysfunction. Nonetheless, epilepsy does interfere with cognitive development in temporal lobe epilepsy (TLE) individuals with hippocampal sclerosis (Helmstaedter and Elger, 2009). Thus, despite AD being widely known as a risk factor for seizures, seizures in AD were thought to be a consequence of neurodegeneration (Scarmeas et al., 2009). However, during the last decade, several mouse model studies have challenged this notion, and have suggested a different view regarding the relationship between epileptic seizures and AD: instead of being a complication of AD, epileptiform activity including both convulsive and non-convulsive seizures may represent a primary disturbance and contribute to network dysfunction, cognitive impairment, and disease progression in AD (Leonard and McNamara, 2007; Palop et al., 2007; Palop and Mucke, 2009, 2016; Noebels, 2011; Chin and Scharfman, 2013; Vossel et al., 2013). It has been proposed that both the recurrent seizure activity and compensatory homeostatic responses to this seizure activity may interfere with normal neuronal and synaptic functions essential for learning and memory (Leonard and McNamara, 2007; Palop and Mucke, 2009, 2016; Noebels, 2011; Scharfman, 2012a,b; Chin and Scharfman, 
2013). Seizures, epileptiform activity, and hippocampal neuronal network hyperactivity were reported in the mild cognitive impairment $(\mathrm{MCl})$ and early stages of $A D$ in humans (Bakker et al., 2012; Vossel et al., 2013). In fact, in MCl and AD patients, cognitive decline began five to seven years earlier in those with epilepsy than in those without, further strengthening the idea of a possible causal association between network hyperexcitability and memory impairment (Vossel et al., 2013). Also, AD patients with subclinical epileptiform activity were found to have an early onset of cognitive decline (Vossel et al., 2013). Additionally, in A $\beta$-based $A D$ transgenic mice, epileptiform activity and neuronal network hyperexcitability have been reported much before the development of $A \beta$ plaques and overt cognitive impairment (Del Vecchio et al., 2004; Westmark et al., 2010; Bezzina et al., 2015; Kazim et al., 2017; Zott et al., 2019). Also, neural hyperactivity was reported to increase tau release and spread, critical processes in the progression of AD pathology (Pooler et al., 2013; Wu et al., 2016). Neuronal activity was also found to regulate the brain regional vulnerability to A $\beta$ deposition (Bero et al., 2011). These data provide strong evidence of a potential role of neuronal network hyperexcitability in cognitive deficit and disease progression in $A D$, and further studies in this field may yield potential therapeutic strategies for $A D$.

\section{Beneficial effect of levetiracetam, an antiepileptic drug, on cognition in AD patients and mouse models: evidence for the role of neuronal network hyperexcitability in cognitive impairment?}

Remarkably, reduction of hippocampal hyperactivity by treatment with an antiepileptic drug, levetiracetam (in low dose), was found to improve memory task performance in MCl patients (Bakker et al., 2012, 2015). Another recent study reported a beneficial effect of low dose levetiracetam in early AD patients by inducing a pattern in brain oscillations of decreased coherence in the lower frequency bands and increased coherence in the higher frequency bands (Musaeus et al., 2017). Additionally, several studies on rodent models of $A D$ and aging have demonstrated beneficial effects of levetiracetam treatment not only on learning and memory impairments but also on disease pathology and disease-associated neurogenic and synaptic failure (Koh et al., 2010; Sanchez et al., 2012; Devi and Ohno, 2013; Shi et al., 2013; Das et al., 2018; Fu et al., 2019).

Targeting hippocampal hyperactivity, peripheral administration of low-dose levetiracetam in aged impaired rats improved cognitive function in two separate hippocampus-dependent spatial reference memory tasks (Koh et al., 2010). Similarly, another study reported that pretraining administration of levetiracetam reduced memory dysfunction in aged C57BL/6 mice in the contextual fear conditioning task (Devi and Ohno, 2013). Acute levetiracetam immediately following training also rescued contextual memory decline in aged mice, however, administration $3 \mathrm{~h}$ after training interval had no effect (Devi and Ohno, 2013). These data showed that suppressing hyperexcitability with acute levetiracetam around the time of acquisition or during early consolidation may be sufficient to reverse memory decline associated with aging (Devi and Ohno, 2013).

Levetiracetam was found not only to reduce abnormal spike activity (on subdural EEG recordings) but chronic treatment with levetiracetam also reversed hippocampal remodeling, behavioral abnormalities, synaptic dysfunction, and learning and memory impairments in hAPP-J20 mice (Sanchez et al., 2012). Nonetheless, levetiracetam did not affect $\mathrm{A} \beta$ deposition in hAPP-J20 mice, and the behavioral and molecular abnormalities reversed within $35 \mathrm{~d}$ after the end of levetiracetam treatment. Contrarily, another study showed that chronic levetiracetam treatment not only alleviated behavioral deficits but also reduced amyloid plaques in APPswe/PS1dE9 transgenic mice (overexpressing the Swedish mutation of APP together with PS1 deleted in exon 9; Shi et al., 2013). Levetiracetam increased $A \beta$ clearance, upregulated $A \beta$ transport and autophagic degradation, and inhibited $\mathrm{A} \beta$ generation and suppressed $\gamma$-secretase activity (Shi et al., 2013). Another study reported that levetiracetam treatment not only reduced network hypersynchrony in human tau transgenic mice (htau-A152T) but also rapidly and persistently reversed brain dysrhythmia, thus ameliorating network dysfunction (Das et al., 2018). A recent study reported that early seizure activity accelerated depletion of hippocampal neural stem cells and impaired spatial discrimination in hAPP-J20 mice, and treatment with levetiracetam restored neurogenesis and improved performance in a neurogenesis-associated spatial discrimination task in this $A D$ mouse model (Fu et al., 2019).

Overall, the rescue of cognitive dysfunction by antiepileptic drug, levetiracetam, in human $A D$ patients and in aging and $A D$ rodent models, provides an indirect evidence for the role of neuronal network hyperexcitability in memory impairment associated with the disease. Neuronal network hyperexcitability may interfere with encoding or consolidation of memory, and an antiepileptic drug treatment could ameliorate this memory dysfunction by suppressing hyperexcitability.

\section{Neuronal network hyperexcitability in AD mouse models: roles of $A \beta$ and tau}

The role of $A \beta$ in enhancing neuronal network excitability in AD mouse models is well characterized (Palop et al., 2007; Palop and Mucke, 2010a,b, 2016; Noebels, 2011; Scharfman, 2012a,b; Chin and Scharfman, 2013; Born et al., 2014; Bezzina et al., 2015; Born, 2015; Kazim et al., 2017; Zott et al., 2019). However, the role of tau, the other major neuropathological hallmark of AD besides $A \beta$ and a better correlate of cognitive impairment in $A D$ (Nelson et al., 2012), in neuronal network excitability remains unclear with different studies reporting conflicting roles, i.e., enhancement versus suppression (Roberson et al., 2007; García-Cabrero et al., 2013; Holth et al., 2013; Angulo et al., 2017; Hatch et al., 2017; Mondragón-Rodríguez et al., 2018a; Busche et al., 2019). Furthermore, recent studies indicate that experimental models that use expression of both $\mathrm{A} \beta$ and tau are more physiologically relevant. Indeed, current understanding of AD pathophysiology is that $A \beta$ initiates a cascade of pathologic events that lead 
to tau misfolding and aggregation. Ultimately, tau spreads throughout the cortex, resulting in neurodegeneration and cognitive deficits (Busche and Hyman, 2020).

In this paper, we review the relevant literature to date and offer perspectives on the similar versus divergent roles of $\mathrm{A} \beta$ and tau in neuronal network excitability in $\mathrm{AD}$.

\section{A $\beta$ Induces Neuronal Network Hyperexcitability in AD, Even before the Development of Plaques}

Seizures and epilepsy as a co-morbidity in familial AD patients harboring mutations which lead to increased A $\beta$ production

Seizures and epilepsy are a frequent co-morbidity in individuals with EOFAD which is caused by autosomal dominant mutations in APP, PSEN1, or PSEN2 genes, resulting in increased $A \beta$ production and altered $A \beta_{42} /$ $\mathrm{A} \beta_{40}$ ratio (Noebels, 2011; Guerreiro and Hardy, 2014; Born, 2015). PSEN1 mutations are the most common cause of EOFAD ( 185 mutations PSEN1 mutations identified; Campion et al., 1999; Janssen et al., 2003). Only 33 APP mutations and 13 PSEN2 mutations have been identified as yet (Campion et al., 1999; Janssen et al., 2003; Bekris et al., 2010; Guerreiro and Hardy, 2014). In EOFAD, disease onset is typically at a younger age $(<65$ years of age) and disease progression is more aggressive as compared with sporadic, late-onset AD.

Seizures have been reported in many PSEN1 mutations carriers. For example, convulsive seizures were described in $37-58 \%$ patients with PSEN1 E280A mutation (Larner and Doran, 2006). The S107F mutation, one of the most aggressive PSEN1 mutation pedigrees, was reported to lead to cognitive dysfunction by 26-27 years of age and tonicclonic seizures in two of the three affected family members (Snider et al., 2005). Patients with other PSEN1 mutations, M146L (Morelli et al., 1998), M223V (Houlden et al., 2001), or L235P (Campion et al., 1996) mutations, developed memory impairment in their $30 \mathrm{~s}$ and exhibited seizures and myoclonus.

Mutations in APP and PSEN2, the other two genes that cause familial $A D$, were also associated with seizures. Seizures were described in $31 \%$ (20 out of 64 ) patients in a case series with N141I PSEN2 mutation (Jayadev et al., 2010). Epileptic seizures were also reported in families with other PSEN2 mutations, for instance, M239V (Marcon et al., 2004) and T430M (Ezquerra et al., 2003) mutations. APP mutations have also been linked with epileptic seizures, for example, T714I (Edwards-Lee et al., 2005), T714A (Lindquist et al., 2008), and V7171G (Kennedy et al., 1993) mutations.

Seizures are also common in patients who carry extra copies of APP. In one study, seizures were reported in $57 \%$ of affected individuals with dementia carrying APP duplication (Cabrejo et al., 2006). Seizures and epilepsy are also more frequently observed in DS individuals (who carry APP overexpression by virtue of trisomy 21 and who universally develop $A D$ neuropathological hallmarks and dementia by age 40-55). In one study of 96 down syndrome (DS) cases, $84 \%$ were found to develop seizures (Lai and Williams, 1989). In another study of 191 DS adults aged 19-69, 9.4\% had epilepsy and the prevalence increased with age; $46 \%$ of patients older than 50 had epilepsy (McVicker et al., 1994).

Taken together, these studies suggest that familial forms of $A D$ characterized by abnormal $A \beta$ processing and deposition, a final common pathway in all of these genetic causes of $A D$, are specifically associated with high occurrence of seizures and epilepsy (Friedman et al., 2012; Born, 2015).

\section{Neuronal network hyperexcitability in hAPP/A $\beta$ mouse models of $A D$}

Many $A \beta$-based transgenic mouse models exist that exhibit AD-like behavioral phenotype (Elder et al., 2010; Hall and Roberson, 2012; Webster et al., 2014). Most of the $\mathrm{A} \beta$-based $\mathrm{AD}$ transgenic mouse models carry one or more APP mutations found in EOFAD (Campion et al., 1999). Several transgenic APP-overexpression AD mouse models have been found to exhibit neuronal network hyperexcitability (epileptiform activity, behavioral seizure, or increased seizure susceptibility) including Tg2576 (hAPP Swedish mutation, Prp promoter; Hsiao et al., 1996; Westmark et al., 2008, 2010; Corbett et al., 2013; Bezzina et al., 2015; Chan et al., 2015; Duffy et al., 2015; Kam et al., 2016; Ciccone et al., 2019), hAPP-J20 (hAPP Swedish and Indiana mutations, PDGF- $\beta$ promoter; Palop et al., 2007; Sanchez et al., 2012; Verret et al., 2012; MartinezLosa et al., 2018), APP23 (hAPP Swedish mutation, Thy-1 promoter; Lalonde et al., 2005), APP23xPS45 (hAPP Swedish and PSEN1 mutations, Thy-1 promoter; Busche et al., 2008, 2012), APdE9 (hAPP Swedish and PSEN1: deltaE9 mutations, Prp promoter; Minkeviciene et al., 2009; Ziyatdinova et al., 2011, 2015; Gurevicius et al., 2013; Nygaard et al., 2015; Reyes-Marin and Nuñez, 2017), APP/TTA (hAPP Swedish and Indiana mutations, CamKIl $\alpha$ promoter; Born et al., 2014), TgCRND8 (hAPP Swedish and Indiana mutations, Prp promoter; Jolas et al., 2002; Del Vecchio et al., 2004), 3xTg-AD (hAPP Swedish, htau P301L, and PSEN1:M146V mutations, Thy-1 promoter; Davis et al., 2014; Nygaard et al., 2015; Frazzini et al., 2016; Kazim et al., 2017), and 5XFAD (hAPP Swedish, Florida, and London mutations and two PSEN1 (M146L, L286V) mutations, Thy-1 promoter (Siwek et al., 2015). Recent studies suggest the existence of a feed-forward induction loop between $\mathrm{A} \beta$ and neuronal network hyperexcitability as it was shown that neural activity modulates $A \beta$ production (Cirrito et al., 2008; Bero et al., 2011). Table 1 summarizes main findings of studies evaluating neuronal network hyperexcitability in $\mathrm{A} \beta$ mouse models of $\mathrm{AD}$.

\section{Neuronal network hyperexcitability in hAPP/A $\beta$ mice at advanced stages of disease pathology and cognitive impairment}

In 2007, a landmark study was published which showed the presence of spontaneous epileptiform discharges in hAPP-J20 mice [harboring hAPP Swedish (KM670/ $671 \mathrm{NL}$ ) and hAPP Indiana (V717F) mutations; transgene expression being driven by the PDGF- $\beta$ promoter; Fig. 
Table 1: Studies evaluating neuronal network excitability in hAPP/A $\beta$ mouse models of AD

\begin{tabular}{|c|c|c|c|c|}
\hline $\begin{array}{l}\text { Author(s) and publi- } \\
\text { cation year }\end{array}$ & $\begin{array}{l}\text { Mouse model/transgene(s)/ } \\
\text { promoter }\end{array}$ & Age/stage of pathology & $\begin{array}{l}\text { Neuronal net- } \\
\text { work excitabil- } \\
\text { ity status }\end{array}$ & Experimental paradigm/neuronal network excitability observation(s) \\
\hline \multicolumn{5}{|c|}{ Studies assessing neuronal network hyperexcitability in hAPP/A $\beta$ mice at advanced stages of $A \beta$ plaque pathology and cognitive impairment } \\
\hline Palop et al. (2007) & $\begin{array}{l}\text { hAPP-J20 } \\
\text { (hAPP Swedish and Indiana) } \\
\text { PDGF- } \beta \text { promoter }\end{array}$ & $\begin{array}{l}\text { 4-7 months, } \mathrm{A} \beta \text { plaques } \\
\text { deposition, cognitive im- } \\
\text { pairment, synaptic deficit }\end{array}$ & Increased & $\begin{array}{l}\text { Experimental paradigm: in vivo chronic video EEG recordings; PTZ-induced seizure } \\
\text { susceptibility; in vitro mIPSCs and fEPSPs recordings. } \\
\text { Findings: frequent epileptiform activity including spikes and SWDs and increased } \\
\text { PTZ-induced seizure susceptibility in hAPP-J20 mice. Reduced LTP and PPF in } \\
\text { hippocampal perforant pathway in hAPP-J20 mice slices. Increased dentate gran- } \\
\text { ule cells mIPSCs frequency in hAPP-J20 mice. Remodeling of inhibitory circuits } \\
\text { and altered NPY expression in dentate gyrus of hAPP-J20 mice. }\end{array}$ \\
\hline Verret et al. (2012) & $\begin{array}{l}\text { hAPP-J20 } \\
\text { (hAPP Swedish and Indiana) } \\
\text { PDGF- } \beta \text { promoter }\end{array}$ & $\begin{array}{l}\text { 4-7 months, } \mathrm{A} \beta \text { plaques } \\
\text { deposition, cognitive im- } \\
\text { pairment, synaptic deficit }\end{array}$ & Increased & $\begin{array}{l}\text { Experimental paradigm: in vivo chronic video EEG recordings. } \\
\text { Findings: spontaneous epileptiform discharges observed during reduced } \gamma \text { oscilla- } \\
\text { tory activity (generated by inhibitory PV cells) in hAPP-J20 mice. Decreased levels } \\
\text { of the interneuron-specific and PV cell-predominant voltage-gated sodium chan- } \\
\text { nel subunit } \mathrm{Na}_{\mathrm{v}} 1.1 \text {. Restoring } \mathrm{Na}_{\mathrm{v}} 1.1 \text { level in hAPP-J20 mice increased inhibitory } \\
\text { synaptic activity and } \gamma \text { oscillations and reduced hyperexcitability and cognitive } \\
\text { deficits. }\end{array}$ \\
\hline Sanchez et al. (2012) & $\begin{array}{l}\text { hAPP-J20 } \\
\text { (hAPP Swedish and Indiana) } \\
\text { PDGF- } \beta \text { promoter }\end{array}$ & $\begin{array}{l}\text { 4-6 months, } A \beta \text { plaques } \\
\text { deposition, cognitive im- } \\
\text { pairment, synaptic deficit }\end{array}$ & Increased & $\begin{array}{l}\text { Experimental paradigm: in vivo chronic video EEG recordings; fEPSPs in acute hip- } \\
\text { pocampal slices. } \\
\text { Findings: spontaneous epileptiform activity in hAPP-J20 mice. Chronic treatment } \\
\text { with levetiracetam reversed abnormal spiking activity, hippocampal remodeling, } \\
\text { behavioral abnormalities, synaptic dysfunction, and deficits in learning and mem- } \\
\text { ory in hAPP-J20 mice. }\end{array}$ \\
\hline $\begin{array}{l}\text { Martinez-Losa et al. } \\
\qquad(2018)\end{array}$ & $\begin{array}{l}\text { hAPP-J20 } \\
\text { (hAPP Swedish and Indiana) } \\
\text { PDGF- } \beta \text { promoter }\end{array}$ & $\begin{array}{l}\text { 7-8 months, } \mathrm{A} \beta \text { plaques } \\
\text { deposition, cognitive im- } \\
\text { pairment, synaptic deficit }\end{array}$ & Increased & $\begin{array}{l}\text { Experimental paradigm: in vivo EEG recordings in freely moving mice. } \\
\text { Findings: epileptiform spikes on cortical EEG in hAPP-J20 mice. } \mathrm{Na}_{\mathrm{v}} 1.1 \text {-overex- } \\
\text { pressing, interneuron transplants enhanced reduced network hypersynchrony and } \\
\text { improved cognitive functions in hAPP-J20 mice. }\end{array}$ \\
\hline $\begin{array}{l}\text { Minkeviciene et al. } \\
\text { (2009) }\end{array}$ & $\begin{array}{l}\text { APdE9 } \\
\text { (hAPP Swedish and PSEN1: } \\
\quad \text { deltaE9) Prp promoter }\end{array}$ & $\begin{array}{l}3 \text { and } 4.5 \text { months, substantial } \\
\text { number } \mathrm{A} \beta \text { plaques ob- } \\
\text { served in cortex, hippo- } \\
\text { campus, and amygdala }\end{array}$ & Increased & $\begin{array}{l}\text { Experimental paradigm: in vivo video EEG recordings; patch clamp electrophysiol- } \\
\text { ogy; extracellular field recordings in brain slices. } \\
\text { Findings: unprovoked seizures in APdE9 mice. Hyperexcitability in neocortical layer } \\
2 / 3 \text { pyramidal cells in APdE9 mice on patch clamp recordings. A } \beta \text { protofibrils in- } \\
\text { duced neuronal network hyperexcitability in acute brain slices. }\end{array}$ \\
\hline $\begin{array}{l}\text { Ziyatdinova et al. } \\
\qquad(2011)\end{array}$ & $\begin{array}{l}\text { APdE9 } \\
\text { (hAPP Swedish and PSEN1: } \\
\quad \text { deltaE9) Prp promoter }\end{array}$ & $\begin{array}{l}\text { 4-5 months, } A \beta \text { plaques in } \\
\text { the neocortex and } \\
\text { hippocampus }\end{array}$ & Increased & $\begin{array}{l}\text { Experimental paradigm: in vivo video EEG recordings. } \\
\text { Findings: spontaneous electrographic epileptiform discharges. Antiepileptic drugs } \\
\text { that block sodium chan-nels, including carbamazepine, phenytoin, and valproic } \\
\text { acid suppressed epileptiform activity in APdE9 mice with increased amyloid } \\
\text { pathology. }\end{array}$ \\
\hline $\begin{array}{l}\text { Gurevicius et al. } \\
\qquad(2013)\end{array}$ & $\begin{array}{l}\text { APdE9 } \\
\text { (hAPP Swedish and PSEN1: } \\
\quad \text { deltaE9) Prp promoter }\end{array}$ & $\begin{array}{l}4 \text { months; } \mathrm{A} \beta \text { plaques in the } \\
\text { neocortex and } \\
\text { hippocampus }\end{array}$ & Increased & $\begin{array}{l}\text { Experimental paradigm: in vivo EEG recordings from the hippocampus, cerebral cor- } \\
\text { tex, and thalamus during movement, quiet waking, non-rapid eye movement } \\
\text { sleep, and REM sleep. } \\
\text { Findings: cortical EEG power was higher in APdE9 mice than in WT mice over a } \\
\text { broad frequency range }(5-100 \mathrm{~Hz}) \text { and during all } 4 \text { behavioral states. Thalamic } \\
\text { EEG power was also increased but in a narrower range }(10-80 \mathrm{~Hz}) \text {. While power } \\
\text { and } \theta-\gamma \text { modulation were preserved in the APdE9 hippocampus, REM sleep-re- } \\
\text { lated phase shift of } \theta-\gamma \text { modulation was altered. }\end{array}$ \\
\hline $\begin{array}{l}\text { Ziyatdinova et al. } \\
\qquad(2015)\end{array}$ & $\begin{array}{l}\text { APdE9 } \\
\text { (hAPP Swedish and PSEN1: } \\
\quad \text { deltaE9) Prp promoter }\end{array}$ & $\begin{array}{l}\text { 4-5 months, } A \beta \text { plaques in } \\
\text { the neocortex and } \\
\text { hippocampus }\end{array}$ & Increased & $\begin{array}{l}\text { Experimental paradigm: in vivo video EEG recordings. } \\
\text { Findings: spontaneous epileptiform discharges. Antiepileptic drug valproic acid re- } \\
\text { duced the amount of epileptiform activity, but the effect disappeared after treat- } \\
\text { ment discontinuation. }\end{array}$ \\
\hline Nygaard et al. (2015) & $\begin{array}{l}\text { APdE9 } \\
\text { (hAPP Swedish and PSEN1: } \\
\quad \text { deltaE9) Prp promoter }\end{array}$ & $\begin{array}{l}10 \text { months, } \mathrm{A} \beta \text { plaques in } \\
\text { the cortex and } \\
\text { hippocampus }\end{array}$ & Increased & $\begin{array}{l}\text { Experimental paradigm: in vivo video EEG recordings. } \\
\text { Findings: epileptiform activity in the form of SWDs in APdE9 mice. SWDs correlated } \\
\text { with spatial memory impairment in these mice. Brivaracetam (a chemical analog } \\
\text { of levetiracetam) reduced SWDs and reversed memory impairments in in APdE9 } \\
\text { mice. }\end{array}$ \\
\hline $\begin{array}{c}\text { Reyes-Marin and } \\
\text { Nuñez (2017) }\end{array}$ & $\begin{array}{l}\text { APdE9 } \\
\text { (hAPP Swedish and PSEN1: } \\
\quad \text { deltaE9) Prp promoter }\end{array}$ & $\begin{array}{l}\text { 4-9 months, } A \beta \text { plaques in } \\
\text { the cortex and } \\
\text { hippocampus }\end{array}$ & Increased & $\begin{array}{l}\text { Experimental paradigm: in vivo video EEG recordings; PTZ-induced seizure suscepti- } \\
\text { bility. } \\
\text { Findings: higher incidence of epileptiform-like discharges, i.e., seizure events (interic- } \\
\text { tal spikes, sharp waves, or polyspikes) in APdE9 than in the controls. Also, APdE9 } \\
\text { mice showed a lower latency to PTZ-evoked seizure events than in the control an- } \\
\text { imals. A correlation was also found between the frequency of epileptiform-like dis- } \\
\text { charges and the number of A } \beta \text { plaques. }\end{array}$ \\
\hline & & & & \\
\hline
\end{tabular}


Table 1: Continued

\begin{tabular}{|c|c|c|c|c|}
\hline $\begin{array}{l}\text { Author(s) and publi- } \\
\text { cation year }\end{array}$ & $\begin{array}{l}\text { Mouse model/transgene(s)/ } \\
\text { promoter }\end{array}$ & Age/stage of pathology & $\begin{array}{l}\text { Neuronal net- } \\
\text { work excitabil- } \\
\text { ity status }\end{array}$ & Experimental paradigm/neuronal network excitability observation(s) \\
\hline Busche et al. (2008) & $\begin{array}{l}\text { APP23xPS45 } \\
\left(\text { hAPP }{ }_{751} \text { Swedish and }\right. \\
\quad \text { PSEN1-Gly384 } \rightarrow \text { Ala384, } \\
\quad \text { G384A) } \\
\text { Thy-1 promoter }\end{array}$ & $8-10$ months, $A \beta$ plaques & Increased & $\begin{array}{l}\text { Experimental paradigm: in vivo two-photon } \mathrm{Ca}^{2+} \text { imaging of neurons in layer } 2 / 3 \text { of } \\
\text { the cortex. } \\
\text { Findings: clusters of hyperactive neurons were found in the vicinity of } \mathrm{A} \beta \text { plaques. }\end{array}$ \\
\hline Busche et al. (2012) & $\begin{array}{l}\text { APP23xPS } 45 \\
\text { (hAPP }_{751} \text { Swedish and } \\
\quad \text { PSEN1-Gly384 } \rightarrow \text { Ala384, } \\
\quad \text { G384A) } \\
\text { Thy-1 promoter }\end{array}$ & $6-7$ months, $A \beta$ plaques & Increased & $\begin{array}{l}\text { Experimental paradigm: in vivo two-photon } \mathrm{Ca}^{2+} \text { imaging of } \mathrm{CA} 1 \text { pyramidal neurons } \\
\text { in the hippocampus. } \\
\text { Findings: hyperactive neurons were found to be located exclusively in the vicinity of } \\
\quad \mathrm{A} \beta \text { plaques in the hippocampus of transgenic mice. }\end{array}$ \\
\hline Lalonde et al. (2005) & $\begin{array}{l}\text { APP23 } \\
\text { (hAPP } 751 \text { Swedish) } \\
\text { Thy-1 promoter }\end{array}$ & 24 months, $\mathrm{A} \beta$ plaques & Increased & $\begin{array}{l}\text { Experimental paradigm: behavioral seizures evaluation. } \\
\text { Findings: } 41 \% \text { of APP23 mice exhibited tonic-clonic seizures; } 24 \% \text { displayed myo- } \\
\text { clonic jumping. }\end{array}$ \\
\hline Jolas et al. (2002) & $\begin{array}{l}\text { TgCRND8 } \\
\text { (hAPP } 695 \text { Swedish and } \\
\quad \text { Indiana) } \\
\text { Prp promoter }\end{array}$ & 5 months, $A \beta$ plaques & Increased & $\begin{array}{l}\text { Experimental paradigm: in vitro hippocampal electrophysiology recordings; evoked } \\
\text { EPSCs and IPSCs; PTZ-induced seizure threshold. } \\
\text { Findings: increased synaptic excitability and increased maximum amplitude of } \\
\text { evoked mEPSCs; consistently lower dose of PTZ was required to elicit myoclonic } \\
\text { activity (preseizure signs) in TgCRND8 mice compared with controls. }\end{array}$ \\
\hline Siwek et al. (2015) & $\begin{array}{l}\text { 5XFAD } \\
\text { (hAPP Swedish, Florida, and } \\
\text { London plus PSEN1: } \\
\text { M146L and L286V) Thy-1 } \\
\text { promoter }\end{array}$ & $\begin{array}{l}16.5 \text { months, } \mathrm{A} \beta \text { plaques } \\
\text { throughout hippocampus } \\
\text { and cortex }\end{array}$ & Increased & $\begin{array}{l}\text { Experimental paradigm: in vivo video EEG recordings from the cortex and the hippo- } \\
\text { campus. } \\
\text { Findings: aberrant hyperexcitability in } 5 \times F A D \text { mice evidenced as ictal-like dis- } \\
\text { charges, such as spikes, polyspikes, and spike-waves. }\end{array}$ \\
\hline Davis et al. (2014) & $\begin{array}{l}\text { 3xTg-AD } \\
\text { (hAPP Swedish. htau P301L, } \\
\quad \text { and hPSEN1: M146V) } \\
\text { Thy-1.2 promoter }\end{array}$ & $17-18$ months, $A \beta$ plaques & Increased & $\begin{array}{l}\text { Experimental paradigm: in vivo hippocampal electrophysiology recordings. } \\
\text { Findings: increased synaptic excitability in DG and CA1. }\end{array}$ \\
\hline Nygaard et al. (2015) & $\begin{array}{l}\text { 3xTg-AD } \\
\text { (hAPP Swedish. htau P301L, } \\
\quad \text { and hPSEN1: M146V) } \\
\text { Thy-1.2 promoter }\end{array}$ & $\begin{array}{l}8-10 \text { months, } \mathrm{A} \beta \text { plaques, } \\
\text { cognitive impairment }\end{array}$ & Increased & $\begin{array}{l}\text { Experimental paradigm: in vivo video EEG recordings from the cortex. } \\
\text { Findings: SWDs in } 3 \times \mathrm{Tg}-\mathrm{AD} \text { mice which correlated with spatial memory } \\
\text { impairments. }\end{array}$ \\
\hline Chan et al. (2015) & $\begin{array}{l}\operatorname{Tg} 2576 \\
\text { (hAPP Swedish), Prp } \\
\quad \text { promoter }\end{array}$ & $\begin{array}{l}12-14 \text { months, } \mathrm{A} \beta \text { plaques, } \\
\text { cognitive impairment }\end{array}$ & Increased & $\begin{array}{l}\text { Experimental paradigm: electrical amygdala kindling with implanted electrodes and } \\
\text { behavioral seizures evaluation. } \\
\text { Findings: } \operatorname{Tg} 2576 \text { mice exhibited increased susceptibility to kindling and seizure-as- } \\
\text { sociated death. }\end{array}$ \\
\hline \multicolumn{5}{|c|}{ Studies evaluating neuronal network hyperexcitability in hAPP/A $\beta$ mice at early stages of $\mathrm{A} \beta$ pathology before plaque deposition and/or cognitive impairment } \\
\hline $\begin{array}{l}\text { Westmark et al. } \\
\qquad(2008)\end{array}$ & $\begin{array}{l}\text { Tg2576 } \\
\text { (hAPP Swedish), Prp } \\
\quad \text { promoter }\end{array}$ & $\begin{array}{l}2 \text { months, before } A \beta \text { plaques } \\
\text { deposition and cognitive } \\
\text { impairment }\end{array}$ & Increased & $\begin{array}{l}\text { Experimental paradigm: PTZ-induced seizure susceptibility assessment. } \\
\text { Findings: increased susceptibility to PTZ-induced seizures in Tg2576 mice. }\end{array}$ \\
\hline $\begin{array}{l}\text { Westmark et al. } \\
\text { (2010) }\end{array}$ & $\begin{array}{l}\text { Tg2576 } \\
\text { (hAPP Swedish), Prp } \\
\quad \text { promoter }\end{array}$ & $\begin{array}{l}3 \text { weeks, before } \mathrm{A} \beta \text { plaques } \\
\text { deposition and cognitive } \\
\text { impairment }\end{array}$ & Increased & $\begin{array}{l}\text { Experimental paradigm: audiogenic seizure susceptibility evaluation. } \\
\text { Findings: increased susceptibility to audiogenic seizures in Tg2576 mice as com- } \\
\text { pared with WT controls. The audiogenic seizure susceptibility in Tg2576 mice } \\
\text { could be suppressed by passive immunization with an anti-APP/A } \beta \text { antibody or } \\
\text { by blockade of mGluR5 with the selective antagonist, MPEP. }\end{array}$ \\
\hline Corbett et al. (2013) & $\begin{array}{l}\text { Tg2576 } \\
\text { (hAPP Swedish), Prp } \\
\quad \text { promoter }\end{array}$ & $\begin{array}{l}5-7 \text { months, before } \mathrm{A} \beta \text { pla- } \\
\text { ques deposition }\end{array}$ & Increased & $\begin{array}{l}\text { Experimental paradigm: in vivo EEG recordings. } \\
\text { Findings: presence of SWDs and abnormal EEG patterns in Tg2576 mice; these mice } \\
\text { also exhibited longer durations of higher frequency brain activity, suggesting in- } \\
\text { creased synchrony. }\end{array}$ \\
\hline Bezzina et al. (2015) & $\begin{array}{l}\text { Tg2576 } \\
\text { (hAPP Swedish), Prp } \\
\quad \text { promoter }\end{array}$ & $\begin{array}{l}\text { 1.5-2 months, before } A \beta \text { pla- } \\
\text { ques deposition and cog- } \\
\text { nitive impairment }\end{array}$ & Increased & $\begin{array}{l}\text { Experimental paradigm: electrical amygdala kindling with implanted electrodes and } \\
\text { behavioral seizures evaluation. } \\
\text { Findings: } \operatorname{Tg} 2576 \text { mice exhibited increased susceptibility to kindling and seizure-as- } \\
\text { sociated death. }\end{array}$ \\
\hline Duffy et al. (2015) & $\begin{array}{l}\text { Tg2576 } \\
\text { (hAPP Swedish), Prp } \\
\quad \text { promoter }\end{array}$ & $\begin{array}{l}\text { 2-4 months, prior to } \mathrm{A} \beta \text { pla- } \\
\text { ques deposition; soluble } \\
\mathrm{A} \beta_{40} \text { and } \mathrm{A} \beta_{42} \text { detecta- } \\
\text { ble; impairment in object } \\
\text { location, an EC-depend- } \\
\text { ent cognitive task. }\end{array}$ & (Continued) & $\begin{array}{l}\text { Experimental paradigm: ex vivo EC recordings. } \\
\text { Findings: increased excitability in EC recordings in slices from Tg2 } 276 \text { mice. }\end{array}$ \\
\hline
\end{tabular}


Table 1: Continued

\begin{tabular}{|c|c|c|c|c|}
\hline $\begin{array}{l}\text { Author(s) and publi- } \\
\text { cation year }\end{array}$ & $\begin{array}{l}\text { Mouse model/transgene(s)/ } \\
\text { promoter }\end{array}$ & Age/stage of pathology & $\begin{array}{l}\text { Neuronal net- } \\
\text { work excitabil- } \\
\text { ity status }\end{array}$ & Experimental paradigm/neuronal network excitability observation(s) \\
\hline Kam et al. (2016) & $\begin{array}{l}\text { Tg2576 } \\
\text { (hAPP Swedish), Prp } \\
\quad \text { promoter }\end{array}$ & $\begin{array}{l}5 \text { weeks, prior to } A \beta \text { plaques } \\
\text { deposition and cognitive } \\
\text { impairment }\end{array}$ & Increased & $\begin{array}{l}\text { Experimental paradigm: in vivo video EEG recordings. } \\
\text { Findings: synchronized large amplitude potentials resembling interictal spikes in epi- } \\
\text { lepsy were observed in Tg2576 mice. }\end{array}$ \\
\hline Ciccone et al. (2019) & $\begin{array}{l}\text { Tg2576 } \\
\text { (hAPP Swedish), Prp } \\
\quad \text { promoter }\end{array}$ & $\begin{array}{l}3 \text { months, before } \mathrm{A} \beta \text { plaques } \\
\text { deposition }\end{array}$ & Increased & $\begin{array}{l}\text { Experimental paradigm: extracellular fEPSP activity elicited by the proconvulsant } \\
\text { drug 4-aminopyridine (4-AP) in acute hippocampal slices from 3-month-old WT } \\
\text { and Tg2576 slices. } \\
\text { Findings: significantly higher number of electrical discharges, occurring with similar } \\
\text { amplitude but shorter intervals, was observed in Tg2576 in comparison to WT hip- } \\
\text { pocampal slices after 4-AP application. }\end{array}$ \\
\hline $\begin{array}{l}\text { Del Vecchio et al. } \\
\qquad(2004)\end{array}$ & $\begin{array}{l}\text { TgCRND8 } \\
\text { (hAPP }_{695} \text { Swedish and } \\
\quad \text { Indiana) } \\
\text { Prp promoter }\end{array}$ & $\begin{array}{l}6-8 \text { weeks, before } \mathrm{A} \beta \text { pla- } \\
\text { ques deposition }\end{array}$ & Increased & $\begin{array}{l}\text { Experimental paradigm: PTZ-induced seizure susceptibility evaluation. } \\
\text { Findings: increased susceptibility to PTZ-induced seizures in TgCRND8 mice. }\end{array}$ \\
\hline Fontana et al. (2017) & $\begin{array}{l}\text { PS2APP } \\
\text { (hAPP Swedish and hPSEN2: } \\
\text { N141l) } \\
\text { Thy1 (hAPP) and Prp } \\
\text { (hPSEN2) promoters }\end{array}$ & $\begin{array}{l}3 \text { months, before } \mathrm{A} \beta \text { plaques } \\
\text { deposition and cognitive } \\
\text { impairment }\end{array}$ & Increased & $\begin{array}{l}\text { Experimental paradigm: in vivo spontaneous LFPs in DG. } \\
\text { Findings: network hypersynchronicity was observed in the DG of PS2APP mice. }\end{array}$ \\
\hline Busche et al. (2012) & $\begin{array}{l}\text { APP23xPS45 } \\
\left(\text { (hAPP }_{751} \text { Swedish and }\right. \\
\quad \text { PSEN1-Gly384 } \rightarrow \text { Ala384, } \\
\quad \text { G384A) } \\
\text { Thy-1 promoter }\end{array}$ & $\begin{array}{l}1.5 \text { months, before } \mathrm{A} \beta \text { pla- } \\
\text { ques deposition and cog- } \\
\text { nitive impairment }\end{array}$ & Increased & $\begin{array}{l}\text { Experimental paradigm: in vivo two-photon calcium imaging of the hippocampal CA1 } \\
\text { neurons. } \\
\text { Findings: selective increase in hyperactive neurons in hippocampus of APP23xPS } 45 \\
\text { mice before } \mathrm{A} \beta \text { plaques deposition suggesting that soluble species of A } \beta \text { may } \\
\text { underlie this impairment. Acute treatment with the } \gamma \text {-secretase inhibitor LY- } \\
411575 \text { reduced soluble } A \beta \text { levels and rescued the neuronal dysfunction. }\end{array}$ \\
\hline Davis et al. (2014) & $\begin{array}{l}\text { 3xTg-AD } \\
\text { (hAPP Swedish. htau P301L, } \\
\quad \text { and hPSEN1: M146V) } \\
\text { Thy-1.2 promoter }\end{array}$ & $\begin{array}{l}\text { 4-6 months, before } \mathrm{A} \beta \text { pla- } \\
\text { ques deposition }\end{array}$ & Increased & $\begin{array}{l}\text { Experimental paradigm: in vivo hippocampal electrophysiology recordings. } \\
\text { Findings: synaptic hyperexcitability in DG and CA1. }\end{array}$ \\
\hline Kazim et al. (2017) & $\begin{array}{l}\text { 3xTg-AD } \\
\text { (hAPP Swedish. htau P301L, } \\
\quad \text { and hPSEN1: M146V) } \\
\text { Thy-1.2 promoter }\end{array}$ & $\begin{array}{l}3 \text { weeks, before } \mathrm{A} \beta \text { plaques } \\
\text { deposition and cognitive } \\
\text { impairment }\end{array}$ & Increased & $\begin{array}{l}\text { Experimental paradigm: audiogenic seizure susceptibility; ex vivo hippocampal CA3 } \\
\text { intracellular recordings after } \mathrm{GABA}_{\mathrm{A}} \text { blockade with bicuculline. } \\
\text { Findings: increased audiogenic seizure susceptibility and prolonged epileptiform dis- } \\
\text { charges after bicuculline application in hippocampal CA3 intracellular recordings } \\
\text { in } 3 \times \mathrm{Tg}-\mathrm{AD} \text { mice. }\end{array}$ \\
\hline Fu et al. (2019) & $\begin{array}{l}\text { hAPP-J20 } \\
\text { (APP Swedish and Indiana) } \\
\text { PDGF- } \beta \text { promoter }\end{array}$ & $\begin{array}{l}1 \text { and } 2 \text { months, before } \mathrm{A} \beta \\
\text { plaques deposition and } \\
\text { cognitive impairment }\end{array}$ & Increased & $\begin{array}{l}\text { Experimental paradigm: in vivo EEG recordings. } \\
\text { Findings: epileptic spikes at } 1 \text { month of age with robust seizure activity at } 2 \text { months } \\
\text { of age. }\end{array}$ \\
\hline
\end{tabular}

4-AP, 4-aminopyridine; $\mathrm{A} \beta$, amyloid $\beta$; DG, dentate gyrus; EC, entorhinal cortex; EEG, electroencephalogram; fEPSPs, field EPSPs; hAPP, human amyloid $\beta$ precursor protein; hPSEN, human presenilin; LFPs, local field potentials; LTP. Long-term potentiation; mEPSCs, miniature EPSCs; mGluR5, metabotropic glutamate receptor 5; mIPSCs, miniature IPSCs; MPEP, 2-methyl-6-(phenylethynyl)pyridine hydrochloride; PDGF, platelet-derived growth factor; Prp, prion protein; PTZ, phenylenetetrazole; PV, parvalbumin; REM, rapid eye movement; SWDs, spike-wave discharges; WT, wild type.

$1 A, B$; Palop et al., 2007]. The study brought into focus the question that $A D$ transgenic mice may be undergoing spontaneous intermittent episodes of generalized nonconvulsive seizures without the investigators being aware of the phenomenon. Palop et al. (2007) continually monitored neuronal activity in cortical and hippocampal networks by video EEG recordings in four- to sevenmonth-old hAPP-J20 mice, which have $\mathrm{A} \beta$ plaques in the hippocampus and neocortex and demonstrate behavioral and synaptic deficits. They reported the presence of frequent epileptiform activity including spikes and sharp waves, and intermittent unprovoked seizures involving neocortex and hippocampus that were not accompanied by tonic or clonic motor activity (Fig. 1A; Palop et al., 2007). Additionally, increased susceptibility to phenylenetetrazole (PTZ)-induced seizures was observed in hAPPJ20 mice as compared with WT controls (Fig. 1B; Palop et al., 2007). Also, epileptic activity led to compensatory inhibitory remodeling of the hippocampal circuitry to counteract network activity imbalances (Palop et al., 2007). GABAergic sprouting, enhanced synaptic inhibition, and synaptic plasticity deficits in the dentate gyrus were also observed in hAPP-J20 mice (Palop et al., 2007). It was proposed that both the recurrent seizure activity and compensatory homeostatic responses to this seizure activity may interfere with normal neuronal and synaptic functions essential for learning and memory (Leonard and McNamara, 2007; Palop et al., 2007; Palop and Mucke, 2009, 2010a,b, 2016; Noebels, 2011; Scharfman, 2012a, b; Chin and Scharfman, 2013).

A subsequent study from the same group further confirmed the presence of spontaneous epileptiform activity and network hypersynchrony on cortical EEG recordings in four- to seven-month-old hAPP-J20 mice (Verret et al., 2012). Primarily, the spontaneous epileptiform discharges were observed during reduced $\gamma$ oscillatory activity (important for learning and memory). As this oscillatory rhythm is generated by inhibitory PV cells, it was 
A

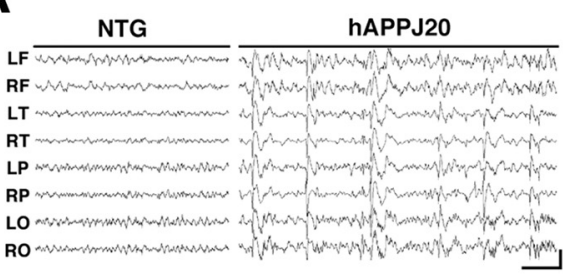

C

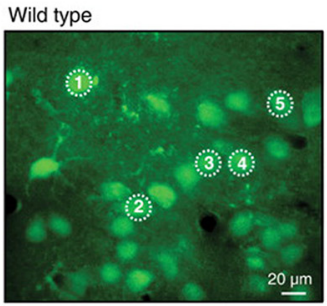

APP23xPS45

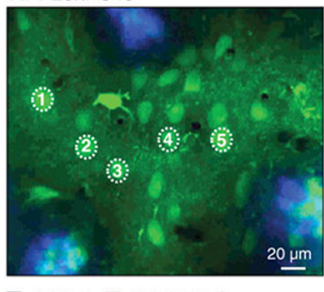

$\square$-OGB-1, $\square-T h i o f l a v i n-S$

E

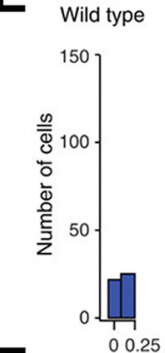

$\mathbf{F}$

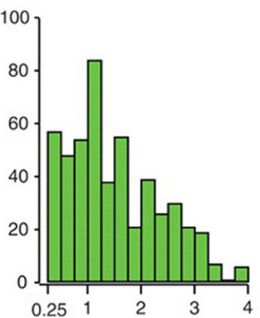

APP23xPS45
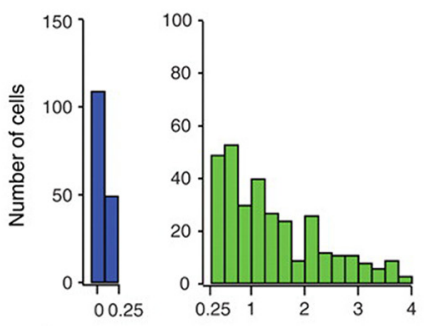

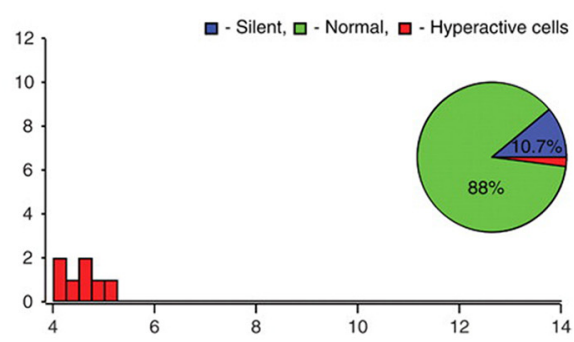

B

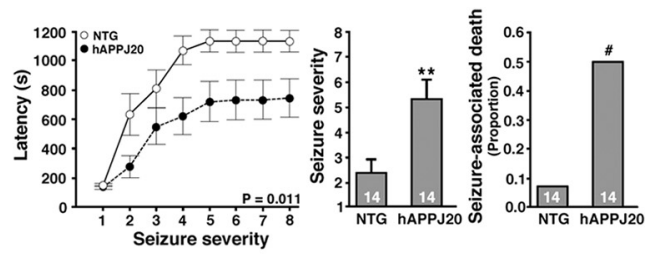

D
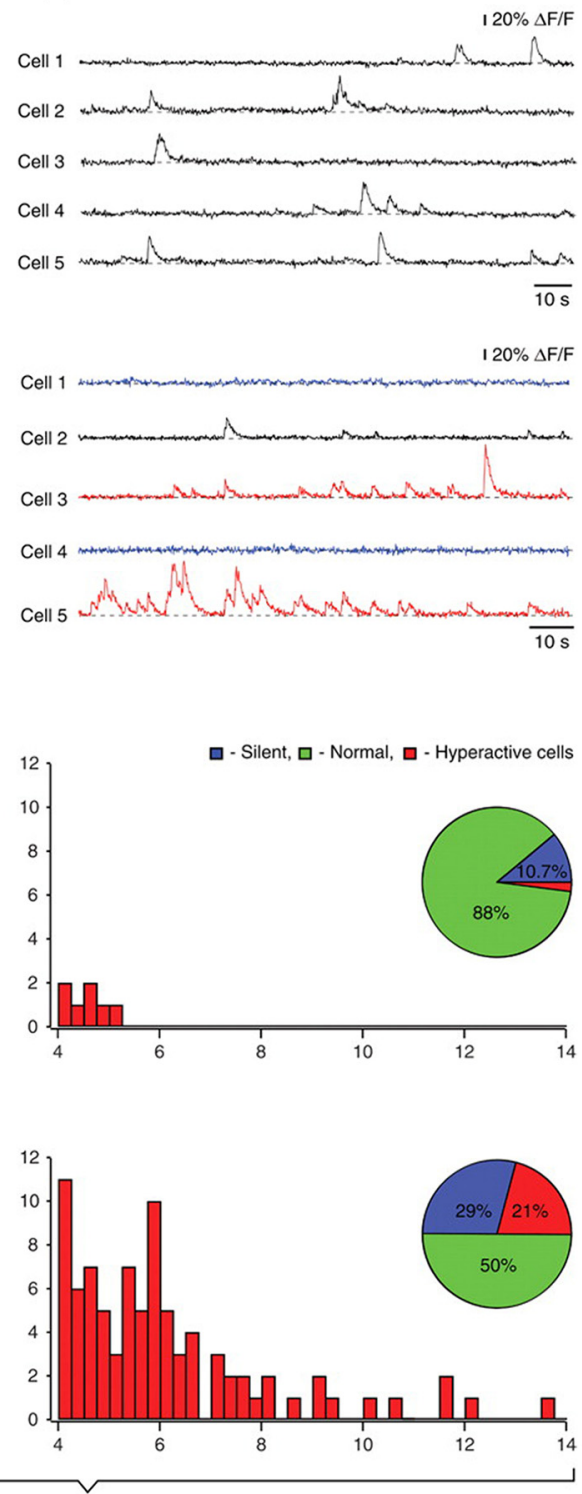

Frequency (transients / min)

Figure 1. Neuronal network hyperexcitability at advanced stages of pathology in hAPP/A $\beta$ mouse models of AD. $\boldsymbol{A}, \boldsymbol{B}, \mathrm{Aberrant}$ synchronous neuronal network activity, spontaneous nonconvulsive seizures, and increased susceptibility to PTZ-induced seizures in four- to seven-month-old hAPP-J20 mice. Reproduced from Palop et al. (2007) with permission from Elsevier. A, Chronic cortical EEG recordings performed in freely moving, untreated hAPP-J20 mice, and non-transgenic (NTG) controls. L, left; R, right; F, frontal; $\mathrm{T}$, temporal; P, parietal; O, posterior-parietal, indicate the position of recording electrodes. In contrast to NTG mice, which showed normal EEG activity (left), hAPP-J20 mice exhibited frequent (5-50/min) generalized cortical epileptiform (interictal) spike discharges (right). Calibration: $1 \mathrm{~s}$ and $400 \mathrm{mV}$. B. Mice were injected intraperitoneally with PTZ (GABA $A_{A}$ antagonist), behavior was videorecorded, and seizure severity was scored off-line. Compared with NTG controls, hAPP-J20 mice had shorter latencies to reach a given seizure severity (left), greater overall seizure severity (center), and more seizure-associated deaths (right); ${ }^{* *} p<0.01$ versus NTG by Student's $t$ test; $\# p<0.05$ by Fisher's exact test. Quantitative data represent mean \pm SEM. C-F, Clusters of hyperactive 
continued

neurons near amyloid plaques in APP23xPS45 mice. In vivo two-photon calcium imaging from layer $2 / 3$ cortical neurons. Reproduced with permission from Busche et al. (2008). $\boldsymbol{C}, \boldsymbol{D}$, Spontaneous $\mathrm{Ca}^{2+}$ transients (D) recorded in vivo in the corresponding neurons of the frontal cortex shown in $\boldsymbol{C}$ in a WT (top) and a APP23xPS45 (bottom) mouse. Traces in $\boldsymbol{D}$, bottom, are color-coded to mark neurons that were either inactive during the recording period (blue) or showed an increased frequency of Ca ${ }^{2+}$ transients (red). $\boldsymbol{E}, \boldsymbol{F}$, Histograms showing the frequency distribution of $\mathrm{Ca}^{2+}$ transients in WT and APP23xPS45 mice (in both cases $n=564$ cells). There is a substantial increase in the amount of silent and hyperactive neurons in APP23xPS45 mice. (Insets) Pie charts showing the relative proportion of silent, normal, and hyperactive neurons in WT $(n=10)$ and APP23xPS45 $(n=20)$ mice.

hypothesized that network dysfunction in hAPP-J20 mice might arise from impaired PV cells (Verret et al., 2012). In fact the study found that hAPP-J20 mice and AD patients had decreased levels of the interneuron-specific and PV cell-predominant voltage-gated sodium channel subunit $\mathrm{Na}_{v} 1.1$ (Verret et al., 2012). Restoring $\mathrm{Na}_{v} 1.1$ level in hAPP-J20 mice by $\mathrm{Na}_{v} 1$.1-BAC expression increased inhibitory synaptic activity and $\gamma$ oscillations and reduced hyperexcitability, cognitive deficits, and premature mortality. Thus, it was concluded that reduced $\mathrm{Na}_{v} 1.1$ levels and PV cell dysfunction critically mediate abnormalities in oscillatory brain rhythms, network synchrony, and memory in hAPP-J20 mice, and possibly in AD (Verret et al., 2012). A recent study further corroborated this as $\mathrm{Na}_{v} 1.1-$ overexpressing, interneuron transplants (derived from the embryonic medial ganglionic eminence) were found to enhance behavior-dependent $\gamma$ oscillatory activity, reduce network hypersynchrony, and improve cognitive functions in hAPP-J20 mice (Martinez-Losa et al., 2018).

Another study in four- to six-month-old hAPP-J20 mice provided evidence for the causal relationship between neuronal network hyperexcitability and cognitive dysfunction (Sanchez et al., 2012). The antiepileptic drug levetiracetam was found to effectively reduce abnormal spike activity detected by EEG (Sanchez et al., 2012). Chronic treatment with levetiracetam also reversed hippocampal remodeling, behavioral abnormalities, synaptic dysfunction, and deficits in learning and memory in hAPP-J20 mice (Sanchez et al., 2012). These data supported the hypothesis that aberrant network activity contributes causally to synaptic and cognitive deficits in $A \beta$ mice. Nonetheless, it is imperative to note here that behavioral and molecular abnormalities recurred within $35 \mathrm{~d}$ after end of levetiracetam treatment in hAPP-J20 mice (Sanchez et al., 2012), suggesting that a chronic persistent treatment of network hyperexcitability may be required to ameliorate $A D$-associated cognitive dysfunction.

Previously, in six- to eight-month-old double transgenic APP23xPS45 mice [harboring the 751 isoform of hAPP Swedish (KM670/671NL) and PSEN1 (Gly384 $\rightarrow$ Ala384, G384A) mutations under the control of Thy-1 promoter; cognitively impaired at this age], in vivo two-photon $\mathrm{Ca}^{2+}$ imaging in layer $2 / 3$ cortical neurons revealed clusters of hyperactive neurons near $A \beta$ plaques (Fig. $1 C-F$; Busche et al., 2008). While the study found a decrease in neuronal activity in $29 \%$ of layer $2 / 3$ cortical neurons, remarkably $21 \%$ of neurons displayed an unexpected increase in the frequency of spontaneous $\mathrm{Ca}^{2+}$ transients (Busche et al., 2008). These hyperactive neurons were found exclusively in the vicinity of the plaques of A $\beta$-depositing APP23xPS45 mice (Busche et al., 2008). It was reported that not only did hyperactive neurons fire more frequently, they also did this in a correlated manner, thus increasing the risk for seizurelike activity (Busche et al., 2008). The hyperactivity appeared to be because of a relative decrease in synaptic inhibition (Busche et al., 2008). The study suggested that an anatomic remodeling of both excitatory and inhibitory synaptic inputs gave rise to the observed changes in neuronal function (Busche et al., 2008), this was in congruence with the finding of inhibitory interneuron remodeling reported in the hippocampus of amyloid plaques bearing hAPP-J20 mice demonstrating spontaneous epileptiform activity (Palop et al., 2007). Another study from the same group (Busche et al., 2012) reported the presence of hyperactive neurons near $\mathrm{A} \beta$ plaques in the hippocampus in six- to seven-month-old APP23xPS45 mice. A marked increase in the fractions of both silent and hyperactive neurons was observed in the hippocampus of plaque depositing APP23xPS45 mice (Busche et al., 2012), as previously also found in the cortex (Busche et al., 2008). Also, the hyperactive neurons were found to be located exclusively in the vicinity of plaques in transgenic mice, whereas both silent and normal neurons were distributed throughout the hippocampus (Busche et al., 2012). A recent study from the same group employing in vivo two-photon $\mathrm{Ca}^{2+}$ imaging reported that hyperactivation in $A \beta$ mouse models is initiated by the suppression of glutamate reuptake (Zott et al., 2019). The astroglial excitatory amino-acid transporter 2 (EAAT2; also termed GLT-1 in mice) is the predominant glutamate transporter in mammalian brain, being responsible for over $90 \%$ of glutamate uptake (Danbolt et al., 1992; Haugeto et al., 1996). A $\beta$ was found to interfere with EAAT2-mediated glutamate uptake, thus providing a mechanism for $\mathrm{A} \beta$-mediated neuronal network hyperexcitability in AD (Li et al., 2009; Zott et al., 2019).

We have reported that treatment with the glutamate modulator riluzole, which has been shown to increase EAAT2 expression (Banasr et al., 2010; Hunsberger et al., $2015,2016)$ besides other mechanisms of actions, can prevent age-related cognitive decline through clustering of dendritic spines (Pereira et al., 2014), strengthening neural communication (Govindarajan et al., 2006; Larkum and Nevian, 2008). Furthermore, we have shown that riluzole rescues age and AD-gene expression profile (Pereira et al., 2017). More recently, we have published that riluzole prevents hippocampal-dependent spatial memory decline in an early-onset and aggressive mouse model of $A D(5 X F A D)$ and reversed many of the gene expression changes in immune pathways (Okamoto et al., 2018), and specifically microglia-related genes thought to be critical mediators of AD pathophysiology (Streit, 2004; Butovsky et al., 2014; Colonna and Wang, 2016), including a recently identified unique population of disease-associated microglia (DAM; Keren-Shaul et al., 2017). 
In a study of 3- and 4.5-month-old APdE9 mice [harboring hAPP Swedish (KM670/671NL) and PSEN1:deltaE9 mutations; transgene expression being driven by the Prp promoter], neuronal hyperexcitability culminating in epileptiform activity in the presence of $A \beta$ plaques was reported (Minkeviciene et al., 2009). In video EEG recordings, at least one unprovoked seizure was detected in $65 \%$ of APdE9 mice, of which $46 \%$ had multiple seizures and $38 \%$ had a generalized seizure, whereas none of the WT mice had seizures (Minkeviciene et al., 2009). In a subset of APdE9 mice, seizure phenotype was associated with a loss of calbindinD28k immunoreactivity in dentate granular cells and ectopic expression of neuropeptide $Y$ (NPY) in mossy fibers (Minkeviciene et al., 2009). In APdE9 mice, persistently decreased resting membrane potential in neocortical layer $2 / 3$ pyramidal cells and dentate granule cells was observed which could be responsible for neuronal network hyperexcitability as identified by patch-clamp electrophysiology (Minkeviciene et al., 2009). Bath application of $A \beta$ protofibrils was found to induce significant membrane depolarization of pyramidal cells and increased the activity of excitatory cell populations as measured by extracellular field recordings in the rodent brain slices, confirming the pathogenic significance of $A \beta$ in neuronal network hyperexcitability (Minkeviciene et al., 2009). Another study in four-monthold APdE9 mice further confirmed increased cortical and thalamic excitability (Gurevicius et al., 2013). A subsequent study demonstrated that sodium channel blocking antiepileptic drugs (carbamazepine, valproic acid, or phenytoin) could suppress epileptiform activity in APdE9 mice with increased amyloid pathology (Ziyatdinova et al., 2011). Another study later found that while valproic acid treatment of APdE9 mice, at the stage when amyloid plaques are beginning to develop and epileptiform activity is detected, reduced the amount of epileptiform activity, but the effect disappeared after treatment discontinuation, and no consistent long-term effects were observed (Ziyatdinova et al., 2015). This is in congruence with the data from hAPP-J20 mice where abnormalities returned after discontinuation of levetiracetam treatment, as mentioned earlier (Sanchez et al., 2012). Epileptiform-like discharges, i.e., seizure-related events consisting of interictal spikes, sharp wave discharges or polyspikes were also observed in cortical EEG recordings of four- to nine-month-old APdE9 mice (Reyes-Marin and Nuñez, 2017). Also, a lower latency to PTZ-evoked seizure events was found in APdE9 mice compared with WT controls (Reyes-Marin and Nuñez, 2017). Importantly, a correlation between the frequency of epileptiform-like discharges and the number of $\mathrm{A} \beta$ plaques was reported (Reyes-Marin and Nuñez, 2017). Another study also reported the presence of epileptiform activity in the form of spike wave discharges in 8- to 10-month-old APdE9 mice; spike wave discharges correlated with spatial memory impairment in these mice (Nygaard et al., 2015). Interestingly, while antiepileptics ethosuximide and brivaracetam (a chemical analog of levetiracetam) both reduced spike-wave discharges in APdE9 mice, brivaracetam, but not ethosuximide, reversed impairments in spatial memory (Nygaard et al., 2015).

Several other studies in hAPP/A $\beta$ mouse models of $A D$ have identified enhanced seizure susceptibility and/or spontaneous epileptiform activity at advanced stages of the $\mathrm{A} \beta$ pathology and cognitive deficit. Increased seizure activity was found in 24-month-old APP23 mice [harboring the 751 isoform of hAPP Swedish (KM670/671 NL) mutation under the control of Thy-1 promoter] with extensive A $\beta$ plaque pathology (Lalonde et al., 2005). Increased synaptic excitability and increased maximum amplitude of evoked miniature EPSCs (mEPSCs) was reported in the hippocampus of $A \beta$ plaques bearing 20-week-old TgCRND8 mice [hAPP695 with the Swedish mutation (KM670/671NL) and Indiana mutation (V717F) under the control of the hamster prion (PrP) gene promoter; thioflavin S-positive amyloid deposits at three months; dense cored plaques and neuritic pathology by five months; Jolas et al., 2002]. Cortical hyperexcitability was also reported in $\sim 72$-week (16.5-month)-old 5XFAD mice [harboring three hAPP mutations: Swedish (KM670/671NL), Florida (1716V), and London (V717I) mutations and two PSEN1 (M146L, L286V) mutations under the control of Thy-1 promoter; plaques are found throughout the hippocampus and cortex by six months; Siwek et al., 2015]. Employing in vivo electrophysiology, increased hippocampal excitability was reported in 17- to 18-month-old 3xTg-AD mice [harboring hAPP Swedish (KM670/671NL), hPSEN1 M146V, and htau P301L mutations under control of Thy 1.2 promoter; these mice develop $\mathrm{A} \beta$ plaques and $\mathrm{NFT}$-like pathologies in a progressive and age-dependent manner, starting at $\sim 9$ and $\sim 12$ months; Davis et al., 2014]. Another study in 8- to 10-month-old 3xTg-AD mice reported the presence of spike wave discharges which correlated with spatial memory impairment in these mice (Nygaard et al., 2015). An increased susceptibility to kindling and seizure-associated death was also reported in aged (12- to 14month-old) Tg2576 mice [harboring hAPP Swedish mutation (KM670/671NL), under the control of prion protein promoter; numerous parenchymal $A \beta$ plaques are evident by $11-$ 13 months of age; Chan et al., 2015].

\section{Early-onset neuronal network hyperexcitability in $A \beta$ - based mouse models of $A D$, much before $A \beta$ plaques and overt cognitive impairment: the role of intraneuronal hAPP/A $\beta$ and soluble $A \beta$}

Several hAPP/A $\beta$ mouse model studies have documented the presence of early-onset neuronal network hyperexcitability manifesting as epileptiform activity and seizure susceptibility, much before $\mathrm{A} \beta$ plaques deposition and overt cognitive impairment (Fig. 2). These studies suggest the potential role of transgenic APP and intraneuronal $A \beta$ in neuronal network hyperexcitability before plaque deposition. Early onset of hypersynchronous activity and expression of a chronic seizures' marker was reported in Tg2576 mice (Bezzina et al., 2015). No memory dysfunction has been reported in these mice at 1.52 months, and they develop $A \beta$ plaques by $11-13$ months of age (Jacobsen et al., 2006; D'Amelio et al., 2011; Stewart et al., 2011). Spontaneous epileptiform activity and an increased susceptibility to PTZ-induced seizures was observed in Tg2576 mice as early as 1.5 months of age (Fig. 2A-C; Bezzina et al., 2015). Additionally, higher ectopic expression of NPY in the mossy fibers was found at three months of age in these mice (Bezzina et al., 2015), 
A

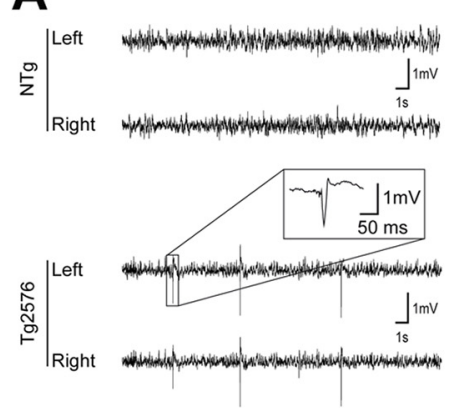

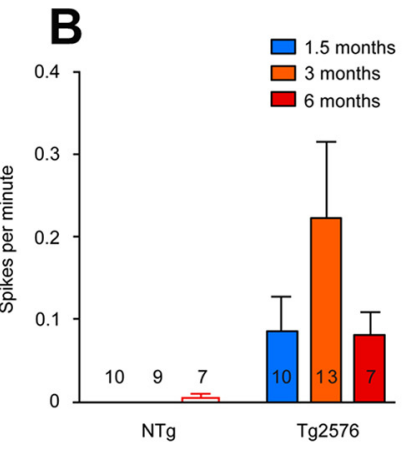

D
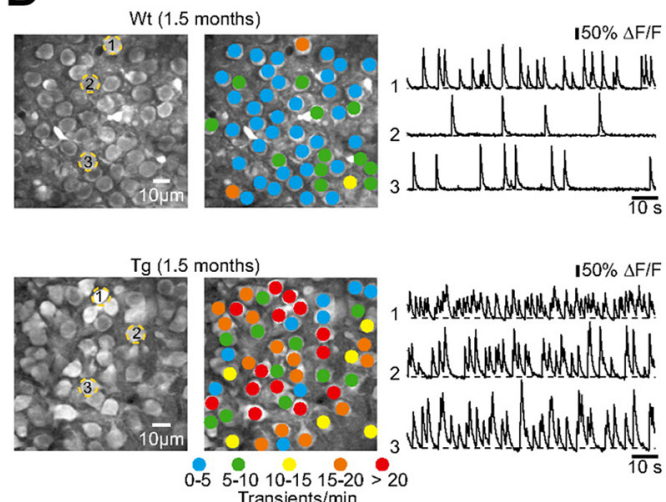

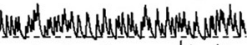

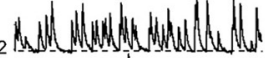

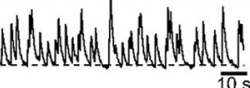

F

WT

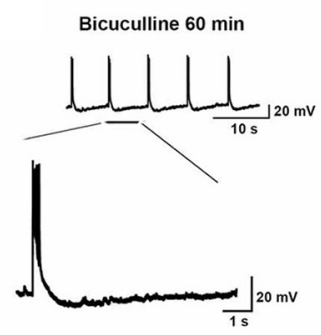

H

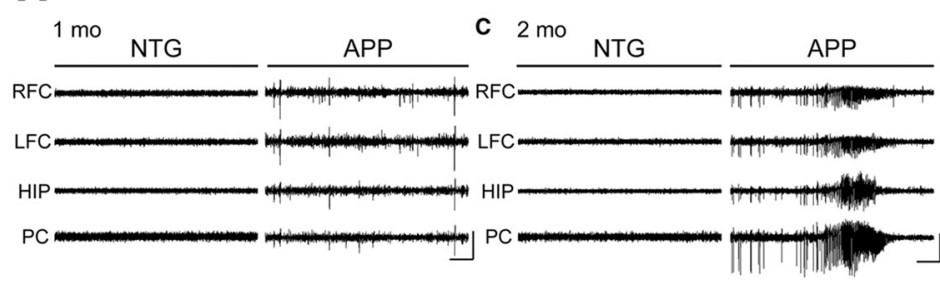

C

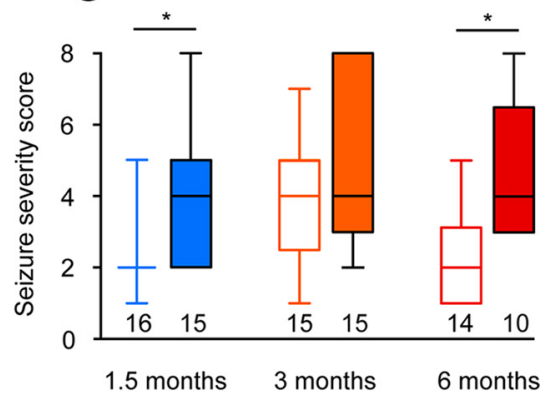

E

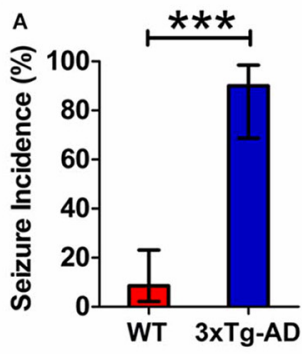

G

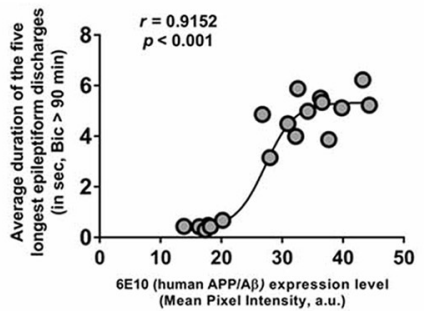

I

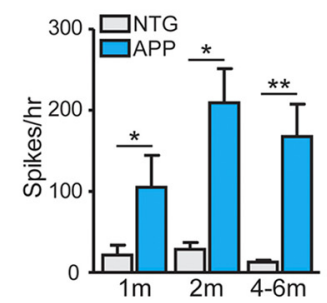

Figure 2. Early-onset neuronal network hyperexcitability in hAPP/A $\beta$ mouse models of AD. $\boldsymbol{A}-\boldsymbol{C}$, Tg2576 mice exhibit spontaneous epileptiform activity and high susceptibility to pharmacologically induced seizures as young as 1.5 months of age. Reproduced with permission from Bezzina et al. (2015). A, Representative EEG traces from non-transgenic (NTg; top) and Tg2576 (bottom) mice from left and right parietal cortices. Note that only transgenic animals displayed sharp, high-voltage spikes that characterize epileptiform activity (inset). B, Quantitative analysis of the frequency of interictal spikes (mean \pm SEM). Two-way ANOVA shows a significant genotype effect $(p=0.013)$ but no age effect $(p=0.4091)$ and no interaction $(p=0.3865)$. Numbers over the horizontal axis indicate the number of mice used in each experimental group. $\boldsymbol{C}$, Seizure severity score of 1.5-, 3-, and 6-month-old Tg2576 male mice and NTg age-matched littermates. Whiskers boxes represent the interquartile distribution. Number of mice in each group is indicated below the boxes. Tg2576 mice exhibit more severe seizures than NTg at 1.5 and 6 months of age (Dunn's tests: $p<0.05$ for Tg2576 vs NTg at 1.5 and 6 months old). Note that only transgenic animals exhibit lethal seizures. Numbers over the horizontal axis indicate the number of mice used in each experimental group. $\boldsymbol{D}$, Early hyperactivity of hippocampal neurons of 1.5-month-old APP23xPS45 mice (an age when no plaques are detectable). Reproduced with permission from Busche et al. (2012). Left, CA1 neurons imaged in 


\section{continued}

vivo in a WT and a transgenic mouse, respectively. Center, Activity maps in which hue is determined by the frequency of spontaneous $\mathrm{Ca}^{2+}$ transients, overlaid with the anatomic image (left). Right, Spontaneous $\mathrm{Ca}^{2+}$ transients of the corresponding neurons marked (left). E-G, Early-onset seizure susceptibility and epileptiform activities in three-week-old 3xTg-AD mice (much before plaques and overt cognitive impairment). Reproduced with permission from Kazim et al. (2017). E, Incidence of convulsive seizures after audiogenic stimulation was markedly higher in three-week-old 3xTg-AD mice (blue bar) compared with WT mice (red bar). The data are presented as percent incidence with 95\% confidence interval and compared using exact logistic regression stratified by litter; ${ }^{* \star *} p<0.001$, compared with WT. WT $(n=35)$ and 3xTg-AD $(n=20)$ mice. $\boldsymbol{F}$, Ictal-like epileptiform discharges in CA3 pyramidal cells of hippocampal slices from three-week-old 3xTg-AD mice. Left, CA3 intracellular recording from a WT slice after bicuculline addition $(50 \mu \mathrm{M})$. Within $20 \mathrm{~min}$, bicuculline induced rhythmic, short epileptiform discharges $(\leq 1.5 \mathrm{~s}$ in duration) that were ongoing for at least $1 \mathrm{~h}$ of continuous recording. Membrane potential at the beginning of recording: $-60 \mathrm{mV}$. Right, CA3 intracellular recording from a 3xTg-AD slice after bicuculline. Bicuculline first induced short synchronized epileptiform discharges that were similar to those in WT slices. However, continuous perfusion with bicuculline induced prolonged epileptiform (ictal-like) discharges ( $>1.5 \mathrm{~s}$ ) in $3 x T g-A D$ slice. Membrane potential at the beginning of recording: $-65 \mathrm{mV}$. G, Positive correlation of intraneuronal human APP/A $\beta$ expression in CA3 neurons and ictal-like activity in CA3 region. Correlation analyses revealed a positive relationship between intraneuronal human APP/A $\beta$ immunoreactivity in the CA3 neurons (analyzed by 6E10, human APP/A $\beta$ ) and average duration of the five longest epileptiform discharges recorded during a 5-min period after $90 \mathrm{~min}$ of bicuculline application in the CA3 region of hippocampal slices from the same mice. Data from Saline-3xTg-AD $(n=9)$ and 6E10-3xTg-AD $(n=9)$ was pooled together to evaluate the correlation. The sigmoidal curve based on nonlinear regression is also shown. $\boldsymbol{H}, \boldsymbol{I}$, Early-onset epileptic activity in one- and twomonth-old hAPP-J20 mice. Reproduced with permission from Fu et al. (2019). $\boldsymbol{H}$, Representative EEG traces from NTg and hAPPJ20 mice at one and two months of age, with epileptiform spikes at one month of age and a seizure at two months of age in hAPPJ20 mice. Electrodes were in left and right frontal cortices (LFC and RFC), hippocampus (HIP), and parietal cortex (PC). Scale bars: $1 \mathrm{mV}, 10 \mathrm{~s}$. I, The number of epileptic spikes per hour in NTg or hAPP-J20 mice at one, two, and four to six months of age $(n=3-5$ mice per genotype and age).

suggesting that chronic seizures occur at very early stages in the course of the disease, and that their incidence likely increases with age among the Tg2576 population. Another study reported increased susceptibility to audiogenic seizures as early as threeweeks of age in Tg2576 mice as compared with WT controls (Westmark et al., 2010). This early-onset audiogenic seizure susceptibility in Tg2576 mice could be suppressed by passive immunization with an anti-APP/A $\beta$ antibody or by blockade of mGluR5 with the selective antagonist, 2-methyl-6-(phenylethynyl)pyridine hydrochloride (MPEP; Westmark et al., 2010). Additionally, a study also found increased susceptibility to PTZ-induced seizures in two-month-old Tg2576 mice (Westmark et al., 2008). Another study in Tg2576 mice, using video EEG recordings, reported synchronized, large amplitude potentials resembling interictal spikes in epilepsy at just five weeks of age, long before memory impairments or $\mathrm{A} \beta$ plaques deposition, suggesting epileptiform activity as a biomarker for early detection of AD (Kam et al., 2016). Also, a study in two- to fourmonth-old Tg2576 mice (before $A \beta$ plaques deposition) reported increased excitability in the $E C$, one of the first regions to display neuropathology in $A D$ (Duffy et al., 2015).

A study in five- to seven-month-old Tg2576 mice (still before $A \beta$ plaques deposition) reported the presence of spike wave discharges and abnormal EEG patterns; these mice also exhibited longer durations of higher frequency brain activity, suggesting increased synchrony (Corbett et al., 2013). The Tg2576 mice with epileptiform activity exhibited increased $\mathrm{Na}_{\mathrm{v}} \beta 2$ cleavage and increased total levels of $\mathrm{Na}_{v} 1.1 \alpha$ (Corbett et al., 2013). Interestingly, the magnitude of alterations in sodium channel subunits was associated with aberrant EEG activity and impairments in the Morris water maze task (Corbett et al., 2013). As mentioned earlier, in hAPP-J20 mice, decreased levels of $\mathrm{Na}_{\mathrm{v}} 1.1 \alpha$, only in $\mathrm{PV}^{+}$interneurons, were found which led to impaired interneuron function and aberrant neuronal activity that could be normalized by overexpressing $\mathrm{Na}_{v} 1.1 \alpha$ in interneurons (Verret et al., 2012). While Corbett and colleagues (Corbett et al., 2013) found increased rather than decreased total levels of $\mathrm{Na}_{\mathrm{v}} 1.1 \alpha$ in Tg2576 mice, the surface $\mathrm{Na}_{\mathrm{v}} 1.1 \alpha$ levels were in fact reduced (Corbett et al., 2013). Overall, both studies reported a decrease in the levels of functional Nav1.1 $\alpha$ in APP mice cortex (Verret et al., 2012; Corbett et al., 2013). Interestingly, $\mathrm{Na}_{\mathrm{v}} 1.1$-null mice were shown to exhibit spontaneous seizures and a significant reduction in $\mathrm{Na}^{+}$ currents in isolated GABAergic interneurons, but not in pyramidal cells from hippocampus, suggesting that loss of $\mathrm{Na}_{v} 1.1$ might specifically decrease inhibitory function, thereby prompting hyperexcitability (Yu et al., 2006). Thus, $\mathrm{Na}_{v} 1.1$ hypofunction could be a possible mechanism of neuronal network hyperexcitability in AD. A recent study also found that selective overexpression of another sodium channel subunit, $\mathrm{Na}_{v} 1.6$, is responsible for the aberrant neuronal activity observed in hippocampal slices from three-month-old Tg2576 mice (Ciccone et al., 2019). Furthermore, the $\mathrm{Na}_{v} 1.6$ channels were identified as a determinant of the hippocampal neuronal hyperexcitability induced by $\mathrm{A} \beta 42$ oligomers (Ciccone et al., 2019).

A study in preplaque (six- to eight-week-old) TgCRND8 mice, another hAPP/A $\beta$ mouse model of $A D$, demonstrated an increased sensitivity to PTZ-induced seizures with a more severe seizure type in transgenic mice over age-matched littermate controls (Del Vecchio et al., 2004). A lower threshold and more severe seizure type in TgCRND8 mice before plaque deposition suggested that this genotype difference might be because of $A \beta$ toxicity rather than plaque formation (Del Vecchio et al., 2004). In PS2APP mice [harboring hAPP Swedish (KM670/671NL) and PSEN2:N141I mutations; transgene expression being driven by the Thy 1 and Prp promoter; overt $A \beta$ deposition at approximately sixmonths, with heavy plaque load in 
the hippocampus, frontal cortex, and subiculum at 10 months; cognitive impairment at eight months], a study employing in vivo recordings of LFP activity in the dentate gyrus, uncovered network hypersynchronicity as early as three months, when intracellular accumulation of $A \beta$ (and not plaques) was observable (Fontana et al., 2017). An in vivo two-photon calcium imaging study in the hippocampal CA1 neurons in young (1.5-month-old) APP23xPS45 mice reported a selective increase in hyperactive neurons already before the formation of plaques, suggesting that soluble species of $A \beta$ may underlie this impairment (Fig. $2 D$; Busche et al., 2012). Acute treatment with the $\gamma$-secretase inhibitor $L Y-411575$ reduced soluble $A \beta$ levels and also rescued the neuronal dysfunction (Busche et al., 2012). Furthermore, direct application of soluble $A \beta$ could induce neuronal hyperactivity in WT mice (Busche et al., 2012). Thus, hippocampal hyperactivity was identified as a very early functional impairment in $A D$ transgenic mice and soluble $A \beta$ was reported to be crucial for hippocampal hyperactivity (Busche et al., 2012).

Previously, we detected the presence of early-onset neuronal network hyperexcitability at three weeks of age, much before $A \beta$ plaque pathology and cognitive deficit, in 3xTg-AD mice (Fig. 2E-G; Kazim et al., 2017). The earliest cognitive deficits reported in 3xTg-AD mice are by two to three months of age (Davis et al., 2013; Stevens and Brown, 2015). However, most studies show cognitive impairment in 3xTg-AD by approximately five months of age (Oddo et al., 2003a; Billings et al., 2005). Increased susceptibility to audiogenic seizures and epileptiform discharges were observed in the hippocampal CA3 region in three-week-old 3xTg-AD mice (Fig. 2E,F; Kazim et al., 2017). In congruence with a previous study in Tg2576 mice (Westmark et al., 2010), passive immunization with an anti-APP/A $\beta$ antibody or blockade of mGluR5 with MPEP suppressed early-onset neuronal network hyperexcitability in 3xTg-AD mice. While no amyloid plaques are present at this age in 3xTg-AD mice, they exhibit intraneuronal APP/A $\beta$ expression; remarkably, epileptiform discharge duration positively correlated with intraneuronal transgenic hAPP/A $\beta$ expression in the CA3 region of the hippocampus (Fig. 2G; Kazim et al., 2017). Another study in four- to six-month 3xTg-AD mice, an age where there is intraneuronal APP/A $\beta$ expression but no plaques, reported the presence of synaptic hyperexcitability (Davis et al., 2014), which could be a major contributor to episodic memory deficit observed at young age in these mice (Davis et al., 2013). The familial AD mouse models which carry human APP mutation(s) and display early-onset epileptiform activity and seizure susceptibility have increased expression of intraneuronal human APP and A $\beta$ before extracellular $A \beta$ deposition and amyloid plaque formation (Oddo et al., 2003a,b; Billings et al., 2005; Lithner et al., 2011; Stargardt et al., 2015). In human AD brains, intraneuronal $A \beta$ accumulation precedes plaque formation (Gyure et al., 2001; Bossers et al., 2010). In AD transgenic mice, intraneuronal $A \beta$ deposition was described to contribute to cognitive impairment before amyloid plaque stage (Oddo et al., 2003b; Billings et al., 2005), and aberrant network excitability may be a mechanism of this cognitive deficit. Similar to $A \beta, A P P$ may also be a mediator of neuronal network hyperexcitability in AD patients and transgenic mice. Interestingly, genetic suppression of transgenic APP in a human APP mouse model of AD [tetracycline-responsive APP-transgenic mice (APP/TTA, where TTA stands for tetracyclinecontrolled transactivator protein)] was shown to rescue hypersynchronous network activity (Born et al., 2014). Also, individual peptides generated from APP processing may play a role in neuronal network hyperexcitability as hyperexcitability and seizure susceptibility was previously reported in mice overexpressing APP intracellular domain (AICD; Vogt et al., 2011). However, because of the intrinsic relationship of APP and A $\beta$ in familial AD mouse models, dissecting out the differential impact of APP overexpression versus intraneuronal $A \beta$ deposition before plaque pathology on neuronal network hyperexcitability in hAPP/A $\beta$ mice has been experimentally daunting. Additionally, besides hAPP/A $\beta$, other pathogenic factors could also play a role in earlyonset neuronal network hyperexcitability in AD. For instance, a study employing electrophysiological recordings in hippocampal primary neuronal cultures from embryonic (E16-E18) 3xTg-AD mice reported a causative link between the development of hyperexcitability, increased spontaneous synaptic activity, and the reactive oxygen species-dependent appearance of conglomerates of dysfunctional $\mathrm{K}_{\mathrm{v}} 2.1$ potassium channels (Frazzini et al., 2016).

A recent study reported epileptic spikes as early as one month of age with robust seizure activity at two months of age, before $A \beta$ plaques deposition and overt memory dysfunction in hAPP-J20 mice (Fig. 2H,l; Fu et al., 2019). Interestingly, it was found that as early seizure activity appears, adult hippocampal neurogenesis initially increases at two months of age, however with recurrent seizure activity, a deficit in adult hippocampal neurogenesis was observed at 3, 7, and 14 months in hAPP-J20 mice (Fu et al., 2019). Adult hippocampal neurogenesis is known to play an essential role in learning and memory (Aimone et al., 2006, 2010; Sahay et al., 2011). It was proposed that the seizure activity that occurs early in disease progression in hAPP-J20 mice aberrantly stimulates neural stem cell division and accelerates depletion of the neural stem cell pool (Aimone et al., 2006, 2010; Sahay et al., 2011). At 3-3.5 months of age, when the level of neurogenesis in hAPP-J20 mice first becomes markedly reduced, deficit in a spatial discrimination memory task was found in these mice (Fu et al., 2019). This was in agreement with the previous data which showed that adult-born hippocampal neurons are critical for spatial discrimination (Sahay et al., 2011). Remarkably, chronic treatment with levetiracetam, which effectively reduces spikes and seizures in hAPP-J20 mice (Sanchez et al., 2012), normalized neurogenesis and improved spatial discrimination memory in hAPP-J20 mice, thus providing a causal link between early-onset network hyperexcitability much before $\mathrm{A} \beta$ plaques and cognitive deficit via recurrent epileptic activity-induced aberrant adult hippocampal neurogenesis (Fu et al., 2019). These data challenge the old concept that neuronal network hyperexcitability is a compensatory mechanism following $A D$-related neurodegeneration and reflect an effort of the brain that cannot keep pace with cognitive 
Table 2: Summary of studies analyzing neuronal network excitability in tau mouse models

\begin{tabular}{|c|c|c|c|c|}
\hline $\begin{array}{l}\text { Author(s) and publi- } \\
\text { cation year }\end{array}$ & Mouse model/transgene(s) & Age/stage of pathology & $\begin{array}{l}\text { Neuronal network } \\
\text { excitability status }\end{array}$ & $\begin{array}{l}\text { Experimental paradigm/neuronal network excitability observa- } \\
\text { tion(s) }\end{array}$ \\
\hline Rocher et al. (2010) & $\begin{array}{l}\text { rTg4510 } \\
\text { (htau P301L) }\end{array}$ & $\begin{array}{l}8.5 \text { months, NFTs and } \\
\text { neurodegeneration }\end{array}$ & Increased & $\begin{array}{l}\text { Experimental paradigm: in vitro whole cell patch clamp record- } \\
\text { ings of layer } 3 \text { frontal cortex pyramidal neurons. } \\
\text { Findings: increased action potential firing rates and a signifi- } \\
\text { cantly depolarized resting membrane potential in transgenic } \\
\text { mice slices, independent of NFTs. }\end{array}$ \\
\hline Hoover et al. (2010) & $\begin{array}{l}\text { rTg } 4510 \\
\text { (htau P301L) } \\
\text { Rat hippocampal neurons trans- } \\
\quad \text { fected with } \mathrm{h} \tau \mathrm{P} 301 \mathrm{~L}\end{array}$ & $\begin{array}{l}\text { rTg4510 cultured hippocampal neu- } \\
\text { rons from E18: DIV 22-30, de- } \\
\text { creased excitatory glutamate } \\
\text { receptor levels. } \\
\text { Rat hippocampal neurons trans- } \\
\text { fected with h } \tau \text { P301L: DIV 22-30, } \\
\text { increased phospho-tau }\end{array}$ & Decreased & $\begin{array}{l}\text { Experimental paradigm: in vitro hippocampal neurons electro- } \\
\text { physiology, mEPSCs recording. } \\
\text { Findings: reduced mEPSCs frequency and amplitude both in } \\
\text { rTg4510 cultured hippocampal neurons and rat hippocampal } \\
\text { cultured neurons transfected with } \mathrm{h} \tau \mathrm{P} 301 \mathrm{~L} \text {. }\end{array}$ \\
\hline Crimins et al. (2011) & $\begin{array}{l}\text { rTg4510 } \\
\text { (htau P301L) }\end{array}$ & $\begin{array}{l}9 \text { months, NFTs and } \\
\text { neurodegeneration }\end{array}$ & Increased & $\begin{array}{l}\text { Experimental paradigm: in vitro whole cell patch clamp record- } \\
\text { ings of layer } 3 \text { frontal cortex pyramidal neurons. } \\
\text { Findings: increased spontaneous synaptic activity (increased } \\
\text { frequency of sEPSCs). }\end{array}$ \\
\hline Crimins et al. (2012) & $\begin{array}{l}\text { rTg4510 } \\
\text { (htau P301L) }\end{array}$ & $\begin{array}{l}<4(1-3) \text { mo and }>8(9-13) \text { mo; } \\
\text { soluble hyperphosphorylated tau } \\
\text { species at }<4 \text { months, NFTs and } \\
\text { neurodegeneration at }>8 \text { months }\end{array}$ & Increased & $\begin{array}{l}\text { Experimental paradigm: in vitro whole cell patch clamp record- } \\
\text { ings of layer } 3 \text { frontal cortex pyramidal neurons. } \\
\text { Findings: increased excitability both in early and advanced tau- } \\
\text { opathy. Depolarized resting membrane potential, an in- } \\
\text { creased depolarizing sag potential and increased action } \\
\text { potential firing rates-all indicative of hyperexcitability. } \\
\text { Hyperexcitability reversed by suppression of human mutant } \\
\text { tau transgene. }\end{array}$ \\
\hline $\begin{array}{l}\text { Menkes-Caspi et al. } \\
\qquad(2015)\end{array}$ & $\begin{array}{l}\text { rTg4510 } \\
\text { (htau P301L) }\end{array}$ & $\begin{array}{l}3 \text { months, accumulation of hyper- } \\
\text { phosphorylated and misfolded } \\
\text { tau in cortex; } 5 \text { months, patho- } \\
\text { logic tau and NFTs in cortex }\end{array}$ & Decreased & $\begin{array}{l}\text { Experimental paradigm: in vivo intracellular recordings from } \\
\text { frontal cortex in anesthetized mice, In vivo extracellular re- } \\
\text { cordings/LFPs in awake behaving mice. } \\
\text { Findings: reduced activity both of single neocortical pyramidal } \\
\text { cells and of the neocortical network including decreased fir- } \\
\text { ing rates and altered firing patterns. }\end{array}$ \\
\hline Witton et al. (2016) & $\begin{array}{l}\text { rTg4510 } \\
\text { (htau P301L) }\end{array}$ & $\begin{array}{l}\text { 7-8 months, NFTs and } \\
\text { neurodegeneration }\end{array}$ & Increased & $\begin{array}{l}\text { Experimental paradigm: in vivo hippocampal CA1 electrophysi- } \\
\text { ology recordings, both single-unit and LFPs. } \\
\text { Findings: increased propensity of excitatory pyramidal neurons } \\
\text { in hippocampus to fire action potentials in a phase locked } \\
\text { manner during SWRs; inhibitory interneurons were less likely } \\
\text { to fire phase-locked spikes during SWRs. }\end{array}$ \\
\hline Hatch et al. (2017) & $\begin{array}{l}\text { rTg4510 } \\
\text { (htau P301L, 13-fold higher human } \\
\text { tau expression as compared with } \\
\quad \text { endogenous tau) } \\
\text { pR5 } \\
\text { (htau P301L, at lower level than } \\
\text { rTg4510, 0.7-fold higher human } \\
\text { tau as compared with endoge- } \\
\text { nous tau) }\end{array}$ & $\begin{array}{l}\text { rTg4510: } 1-2 \text { months, early stage } \\
\text { tauopathy before overt tau hyper- } \\
\text { phosphorylation and synaptic im- } \\
\text { pairment } \\
\text { 4-6 months, mid-stage with exten- } \\
\text { sive tau hyperphosphorylation } \\
\text { and impairment of synaptic activ- } \\
\text { ity and spatial memory } \\
\text { 12-14 months, late stage with syn- } \\
\text { aptic loss and neurodegeneration } \\
\text { PR5: } 15-17 \text { months, tau pathology in } \\
\text { hippocampus }\end{array}$ & Decreased & $\begin{array}{l}\text { Experimental paradigm: in vitro whole cell patch clamp record- } \\
\text { ings from hippocampal CA1 pyramidal neurons. } \\
\text { Findings: reduced action potential firing rate because of a de- } \\
\text { polarization shift in action potential generation and reduced } \\
\text { action potential amplitude at all ages in the CA1 pyramidal } \\
\text { neurons of P301L mice. pR5 mice CA1 pyramidal neurons } \\
\text { showed less severe action potential impairment compared } \\
\text { with rTg4510, including action potential depolarization shift } \\
\text { and reduced action potential amplitude. }\end{array}$ \\
\hline Busche et al. (2019) & $\begin{array}{l}\text { rTg4510 } \\
\text { (htau P301L) } \\
\text { rTg21221 } \\
\text { (htau overexpression) }\end{array}$ & $\begin{array}{l}\text { rTg4510: 6-12 months, tau aggrega- } \\
\text { tion and NFTs } \\
\text { 3-4 months; soluble tau. } \\
\text { rTg21221: } 6-12 \text { months, human tau } \\
\text { overexpression. }\end{array}$ & Decreased & $\begin{array}{l}\text { Experimental paradigm: in vivo two-photon } \mathrm{Ca}^{2+} \text { imaging of } \\
\text { neurons in layer } 2 / 3 \text { of the cortex. } \\
\text { Findings: strong reduction in cortical activity as reflected by in- } \\
\text { creased number of silent neurons in both 6- to } 12 \text { - and 3- to } \\
\text { 4-month-old rTg } 4510 \text { mice. Reduction in cortical activity in } \\
\text { 6- to } 12 \text {-month-old rTg2210 mice. Reducing tau in 3- to 4- } \\
\text { month-old rTg4510 mice decreased the number of silent } \\
\text { neurons. }\end{array}$ \\
\hline $\begin{array}{l}\text { Van Erum et al. } \\
\qquad(2020)\end{array}$ & $\begin{array}{l}\text { tau58/4 } \\
\text { (htau P301S) }\end{array}$ & $\begin{array}{l}3 \text { months, htau and phospho-tau in } \\
\text { the frontal cortex and pons } \\
\text { (Continued) }\end{array}$ & Increased & $\begin{array}{l}\text { Experimental paradigm: video EEG recordings; PTZ-induced } \\
\text { seizure susceptibility. }\end{array}$ \\
\hline
\end{tabular}


Table 2: Continued

\begin{tabular}{|c|c|c|c|}
\hline $\begin{array}{l}\text { Author(s) and publi- } \\
\text { cation year }\end{array}$ & Mouse model/transgene(s) & Age/stage of pathology & $\begin{array}{l}\text { Neuronal net } \\
\text { excitability s }\end{array}$ \\
\hline & & $\begin{array}{l}12-15 \text { months, NFTs throughout the } \\
\text { brain. }\end{array}$ & \\
\hline $\begin{array}{l}\text { Marinković et al. } \\
\qquad \text { (2019) }\end{array}$ & $\begin{array}{l}\text { P301S } \\
\text { (htau P301S) }\end{array}$ & $\begin{array}{l}2 \mathrm{~m} \text {, injected with tau preformed fi- } \\
\text { brils for NFTs seeding, evaluated } \\
\text { for cortical activity up to } 50 \mathrm{~d} \\
\text { after injections }\end{array}$ & Decreased \\
\hline $\begin{array}{l}\text { Mondragón- } \\
\text { Rodríguez et al. } \\
\text { (2018b) }\end{array}$ & $\begin{array}{l}\text { 3xTg-AD } \\
\text { (htau P301L, hAPP Swedish, } \\
\quad \text { hPSEN1) }\end{array}$ & $\begin{array}{l}1 \text { month, increased phospho-tau, in- } \\
\text { traneuronal APP/A } \beta \text {, prior to cog- } \\
\text { nitive impairment. }\end{array}$ & Decreased \\
\hline
\end{tabular}

Ahnaou et al. (2017) Tg tau P301L (h tau P301L)
3 months, injected with preformed Normal tau fibrils to induce tau aggregation.
EC-htau (h $\tau$ P301L) EC-hAPP (hAPP) EC-hAPP/htau (hAPP, h $\tau$ P301L)
EC-htau: 2.5-3.5 months, htau and phospho-tau accumulation in EC. EC-hAPP: 2.5-3.5 months, soluble $\mathrm{A} \beta$. resistance to induced-hyperexcitability in EChtau mice
Experimental paradigm/neuronal network excitability observation(s)

Findings: increased PTZ-induced seizure susceptibility in young (3-month-old) tau58/4 mice as compared with age-matched WT littermates. Young tau58/4 animals displayed more severe seizures and had a reduced latency to the first seizure compared with WTs. While, age-related differences in susceptibility could be demonstrated for both genotypes, old tau58/4 did not exhibit a significantly higher seizure susceptibility as compared with WT mice.

Experimental paradigm: in vivo two-photon $\mathrm{Ca}^{2+}$ imaging of neurons in layer $2 / 3$ of the cortex in awake, head-fixed mice. Findings: strong reduction in cortical activity, independent of NFTs presence, suggesting the impairing role of soluble, mutated tau protein species.

Experimental paradigm: in vitro whole cell patch clamp recordings from hippocampal CA1 pyramidal neurons; in vitro LFPs recordings from hippocampal slices.

Findings: no difference in amplitude and frequency of action potentials between $3 \times \mathrm{Tg}-\mathrm{AD}$ and non-Tg CA1 pyramidal neurons. Overall, the young $3 \times \mathrm{Tg}-\mathrm{AD}$ mice showed less excitable hippocampal network activity, likely related to abnormally hyperphosphorylated tau at microtubule domain region (MDr).

Experimental paradigm: in vivo EEG recordings. Network oscillations, phase amplitude cross frequency coupling, mismatch negativity (MMN) of event related brain potentials, and coherence was analyzed.

Findings: weakening of $\theta$ oscillations, drastic impairments in $\theta-\gamma$ oscillations phase-amplitude cross frequency coupling and disrupted MMN complex amplitude (all vital for memory and learning performance) induced by tau seeding. No epileptiform activity or network hyperexcitability.

Experimental paradigm: in vitro hippocampal EC/subiculum electrophysiology recordings: single electrode evoked and sEFPs, single neuron patch clamp, and extracellular multielectrode recordings.

Findings: mutated htau induced resistance to EC-hippocampus hyperexcitability in EC-htau mice evidenced by resistance to increased network activity evaluated by sEFP durations after $\mathrm{GABA}_{\mathrm{A}}$ blockade with picrotoxin. Increased neuronal excitability in EC in EC-hAPP mice evidenced by higher frequency of relatively prolonged sEFPs in lateral EC and epileptiform-ictal like discharges in medial EC. While no differences were observed in sEFPs duration and frequency in EC/CA1/subiculum regions (using multielectrode recordings) between EC-hAPP/htau mice and WT mice, a smaller percentage of slices displayed epileptiform discharges. Co-expression of hAPP and htau produced an intermediate phenotype, mostly driven by tau

Experimental paradigm: in vivo EEG recordings in awake behaving mice; epileptic spikes quantification both at baseline and after injection of non-convulsive dose of PTZ.

Findings: increased epileptic spike counts both at baseline and after PTZ injection in htau-A152T mice as compared with non-Tg controls. 
Table 2: Continued

\begin{tabular}{|c|c|c|c|c|}
\hline $\begin{array}{l}\text { Author(s) and publi- } \\
\text { cation year }\end{array}$ & Mouse model/transgene(s) & Age/stage of pathology & $\begin{array}{l}\text { Neuronal network } \\
\text { excitability status }\end{array}$ & $\begin{array}{l}\text { Experimental paradigm/neuronal network excitability observa- } \\
\text { tion(s) }\end{array}$ \\
\hline Decker et al. (2016) & htau-A152T & $\begin{array}{l}\text { 12-14 months, accumulation of hy- } \\
\text { perphosphorylated and missorted } \\
\text { tau, neurodegeneration, and syn- } \\
\text { aptic loss in hippocampal CA3 re- } \\
\text { gion. Increased phospho-tau in } \\
\text { hippocampal slice cultures at DIV } \\
10 .\end{array}$ & Increased & $\begin{array}{l}\text { Experimental paradigm: in vivo EEG recordings in awake be- } \\
\text { having mice; epileptic spikes quantification both at baseline } \\
\text { and after injection of non-convulsive dose of PTZ. } \\
\text { Findings: enhanced basal synaptic transmission in CA3 region } \\
\text { of the hippocampus in htau-A152T mice (increased fEPSPs } \\
\text { in mossy fiber pathway in acute slices from 12-month-old } \\
\text { mice and increased somatic field potentials in stratum pyra- } \\
\text { midale of area CA3 in organotypic hippocampal slices at DIV } \\
\text { 30. Increase in picrotoxin-induced epileptiform burst fre- } \\
\text { quency as well as in firings per burst in organotypic slice cul- } \\
\text { tures expression htau-A152T mutation (both at DIV } 10 \text { and } \\
\text { 30) which was prevented by ceftriaxone (stimulates astro- } \\
\text { cytic glutamate uptake via the transporter EAAT2/GLT1). }\end{array}$ \\
\hline Das et al. (2018) & htau-A152T & 4-6 months; soluble tau & Increased & $\begin{array}{l}\text { Experimental paradigm: in vivo EEG recordings; epileptic spikes } \\
\text { quantification. } \\
\text { Findings: increased epileptic spike counts at resting state in } \\
\text { htau-A152T mice as compared with non-Tg controls. } \\
\text { Antiepileptic drug levetiracetam treatment reduced epileptic } \\
\text { spike counts in htau-A152T mice. }\end{array}$ \\
\hline $\begin{array}{l}\text { García-Cabrero et al. } \\
\text { (2013) }\end{array}$ & $\begin{array}{l}\text { FTDP-17 mice } \\
\text { (htau G272V, P301L, and R406W; } \\
\text { Overexpression of human tau iso- } \\
\text { form with } 2 \text { N-terminal inserts, 4- } \\
\text { microtubule-binding-repeat } \\
\text { elements) }\end{array}$ & $\begin{array}{l}1-5,6-14 \text {, and } 15-22 \text { months; mu- } \\
\text { tant tau transgene overexpressed } \\
\text { at } 3 \mathrm{~m} \text { of age, activated microglia } \\
\text { at } 4 \text { months, reactive astrocytes } \\
\text { at } 9 \text { months, and phospho-tau } \\
\text { aggregates at } 18-20 \text { months }\end{array}$ & Increased & $\begin{array}{l}\text { Experimental paradigm: in vivo video EEG recordings and PTZ- } \\
\text { seizure susceptibility testing. } \\
\text { Findings: spontaneous epileptiform activity and epileptic seiz- } \\
\text { ures in } 70 \% \text { of FTDP- } 17 \text { mice at the age of } 5.5 \mathrm{~m} \text { and there- } \\
\text { after. } \\
\text { Increased PTZ-induced seizures susceptibility at } 6-14 \text { months } \\
\text { of age and thereafter. }\end{array}$ \\
\hline
\end{tabular}

$\mathrm{A} \beta$, amyloid $\beta$; EC, entorhinal cortex; DIV, days in vitro; EAAT2, excitatory amino acid transporter 2; EEG, electroencephalogram; fEPSPs, field EPSPs; FTDP, frontotemporal dementia with parkinsonism; GLT1, glutamate transporter 1; hAPP, human amyloid $\beta$ precursor protein; hPSEN, human presenilin; LFPs, local field potentials; mEPSCs, miniature EPSCs; NFTs, neurofibrillary tangles; PTZ, phenylenetetrazole; sEFPs, spontaneous extracellular field potentials; sEPSCs, spontaneous EPSCs; SWDs, spike-wave discharges; SWRs, sharp-wave ripples; Tg, transgenic; WT, wild type.

demands. In fact, the reverse seems to be true, namely that hyperexcitability is an early-onset pathologic process in $A D$ and plays a critical role in memory dysfunction.

\section{The Role of tau in Neuronal Network Excitability: The Enhancement versus Suppression Conundrum}

\section{tau, AD, and neuronal network excitability}

tau is a neuronal microtubule-associated protein which plays a key role in microtubule assembly, stabilization, and axonal transport. In AD and other related tauopathies, tau is abnormally hyperphosphorylated which results in reduced binding of tau to microtubules, and subsequent accumulation as NFTs, leading to neurodegeneration and cognitive impairment (Grundke-lqbal et al., 1986a,b; lqbal et al., 2016). tau pathology is known to be better correlated with cognitive deficit in $A D$ than $A \beta$ pathology (Nelson et al., 2012), and tau spread from EC to other cortical areas via connected neuroanatomical circuitry is a critical process in the progression of $A D$ (de Calignon et al., 2012; Liu et al., 2012). Several studies have looked into the role of tau in neuronal network hyperexcitability in AD (Roberson et al., 2007; García-Cabrero et al., 2013; Holth et al., 2013; Angulo et al., 2017; Hatch et al., 2017; Mondragón-Rodríguez et al., 2018b; Busche et al., 2019); however, the data are conflicting with the precise role remaining yet to be elucidated. Table 2 summarizes the studies evaluating neuronal network excitability in taubased mouse models of $A D$.

Tau promotes neuronal network hyperexcitability both in early stages before NFTs and at advanced stages of tau pathology

tau and epilepsy

tau has classically been considered to promote neuronal network hyperexcitability and to have an enabling role for epileptogenesis (Vossel et al., 2017; Sánchez et al., 2018). Hyperphosphorylated tau deposits were reported in epilepsy patients' brains (Thom et al., 2011; Tai et al., 2016). Additionally, tau hyperphosphorylation was also demonstrated in experimental rodent models of epilepsy (Crespo-Biel et al., 2007; Tian et al., 2010). Interestingly, hyperphosphorylated tau in patients with refractory TLE was reported to correlate with accelerated cognitive decline (Tai et al., 2016). A recent study in clinically normal older adults using tau PET scan found that temporal lobe tau accumulation was associated with hippocampal hyperactivity (demonstrated by increased fMRI activity; Huijbers et al., 2019). Similarly, another recent study using task-related fMRI in combination with measures of tau pathology in CSF reported that higher CSF tau levels were related to hippocampal hyperactivity and object mnemonic discrimination in older adults (Berron et al., 2019). Also, accelerated kindling epileptogenesis was observed in rTg4510 mutant human tau mice (with 13-fold 
tau overexpression) but not in tau knock-out mice (Liu et al., 2017). Furthermore, genetic deletion of tau was also shown to attenuate neuronal network hyperexcitability in mouse and Drosophila models of hyperexcitability (Holth et al., 2013). Also, genetic reduction of tau in a mouse model of Dravet syndrome, a severe childhood epilepsy caused by mutations in the human SCN1A gene encoding the voltage-gated sodium channel subunit $\mathrm{Na}_{v} 1.1$, was reported to reduce the frequency of spontaneous and febrile seizures and premature mortality, to decrease epileptic interictal spikes in vivo and drug-induced epileptic activity in brain slices ex vivo, and to ameliorate learning and memory deficits (Gheyara et al., 2014). These data further suggested that cognitive deficit could be directly or indirectly linked to tau-dependent epileptic activity. Taken together these data hint toward a proepileptic role of tau. Recent studies have also shown, in turn, that network hyperexcitability enhances tau propagation and tau pathology (Pooler et al., 2013; Wu et al., 2016). Accordingly, modeling chronic TLE in 3xTg-AD mice (harboring mutant human APP, presenilin and tau proteins) was reported to enhance tau phosphorylation in the temporal lobe structures (Yan et al., 2012). This may potentially be a vicious cycle where early tau deposition enhances neuronal network excitability which in turn further increases tau release and propagation.

\section{High-frequency oscillations or SWRs, epilepsy, and tau}

High-frequency neuronal oscillations (HFOs; 100-250 Hz) in the hippocampus, known as SWRs, synchronize the firing behavior of groups of neurons and are thought to play an important role in driving Hebbian synaptic plasticity and memory consolidation (Buzsáki et al., 1992; Sadowski et al., 2011). Hippocampal SWRs drive the synchronous co-activation of local populations of pyramidal neurons and interneurons (Csicsvari et al., 1999; Klausberger and Somogyi, 2008). Hippocampal SWRs were suggested to be a cognitive biomarker for episodic memory and planning. High-frequency SWRs with spectral frequencies in the range of 250$600 \mathrm{~Hz}$, called fast ripples, have been described in the brains of epileptic patients and rodents (Worrell et al., 2004; Bragin et al., 2010). In animal models of TLE, fast ripples occur in the dentate gyrus, CA1, and CA3 areas of hippocampus, subiculum, and EC in rats that exhibit recurrent spontaneous seizures (Bragin et al., 1999). A recent study reported that early hippocampal SWR abnormality predicts later learning and memory impairments in an AD mouse model (Jones et al., 2019).

Previously, disrupted hippocampal SWR associated spike dynamics (frequency and temporal structures) were reported in a tau-based transgenic mouse model of dementia, i.e., rTg4510 transgenic mice that express aggregating human tau P301L [a frontotemporal lobe dementia (FTD) mutation] and display NFTs but no $\mathrm{A} \beta$ pathology (Witton et al., 2016). On in vivo electrophysiological recordings in the hippocampus of seven- to eight-monthold rTg4510 mice, an age when NFTs are rampant and neurodegeneration is well established in these mice (Ramsden et al., 2005), it was found that excitatory pyramidal neurons were more likely to fire action potentials in a phase locked manner during SWRs; conversely, inhibitory interneurons were less likely to fire phase locked spikes during SWRs (Witton et al., 2016). These data indicated a reduced inhibitory control of hippocampal network events and pointed toward a hyperexcitabilitybased mechanism which may underlie the cognitive impairments in this model of dementia (Witton et al., 2016).

Tau reduction decreases neuronal network hyperexcitability in $A \beta$ mice and reduces seizure susceptibility in WT mice

Table 3 summarizes the studies evaluating the effect of tau reduction on neuronal network excitability in $A \beta$ and WT mice. Previously, genetic reduction of endogenous tau was reported to reduce interictal spiking and spontaneous seizures besides ameliorating cognitive deficit without affecting $A \beta$ pathology in the J20 (hAPP) mouse model of AD (Roberson et al., 2007). In fact, tau reduction also slowed the onset of PTZ-induced seizures and lowered the susceptibility to kainate-induced seizures in WT mice without hAPP (Roberson et al., 2007), suggesting a role for endogenous tau in enhancing neuronal network excitability. Another study in aged tau knock-out mice, further corroborated decreased PTZ-induced seizure susceptibility (Li et al., 2014).

Antisense oligonucleotides-mediated reduction of endogenous tau throughout the entire CNS (brain and spinal cord tissue, interstitial fluid, and CSF) of WT mice was found to reduce seizure susceptibility in two chemicallyinduced seizure models; mice with reduced tau protein had less severe seizures than control mice (DeVos et al., 2013). In fact, total tau protein levels and seizure severity were highly correlated, such that those mice with the most severe seizures also had the highest levels of tau (DeVos et al., 2013). This finding was more important given the fact that in this study tau reduction was achieved in adult mice through antisense oligonucleotides as compared with genetic ablation of tau where a developmental compensation may account for the protection against seizures (DeVos et al., 2013). It was also later shown that the antisense oligonucleotide-mediated tau reduction prevented hippocampal volume loss and neuronal death, extended mouse survival, and reduced pathologic tau seeding in P301S mouse model of tauopathies (DeVos et al., 2017).

Further confirming the role of tau in mediating $\mathrm{A} \beta$-induced hyperexcitability, another study found that tau reduction prevented spontaneous epileptiform activity in multiple lines of hAPP mice (Roberson et al., 2011). tau reduction was also found to reduce the severity of spontaneous and chemically-induced seizures in mice overexpressing $A \beta$ (Roberson et al., 2011). Additionally, whole-cell current recordings from acute hippocampal slices of hAPP mice with tau exhibited increased spontaneous and evoked excitatory currents, reduced inhibitory currents, and NMDAR dysfunction (Roberson et al., 2011). tau reduction increased inhibitory currents and normalized excitation/inhibition (E/I) balance and NMDAR-mediated currents in hAPP mice (Roberson et al., 2011).

tau protein was also reported to be mediating $\mathrm{A} \beta$-induced axonal transport deficits and synaptic long-term potentiation (LTP) alterations in hAPP mice, both of which 
Table 3: Summary of studies analyzing the effect of tau reduction on network excitability in A $\beta$ mice and in WT mice

\begin{tabular}{|c|c|c|c|c|}
\hline $\begin{array}{l}\text { Author(s) and } \\
\text { publication } \\
\text { year }\end{array}$ & $\begin{array}{l}\text { Mouse model/ } \\
\text { transgene(s) }\end{array}$ & Age/stage of pathology & $\begin{array}{l}\text { Baseline neuronal network } \\
\text { excitability status }\end{array}$ & $\begin{array}{l}\text { Experimental paradigm and tau reduction strategy/effect of tau } \\
\text { reduction on neuronal network excitability }\end{array}$ \\
\hline $\begin{array}{l}\text { Roberson et al. } \\
\qquad(2007)\end{array}$ & 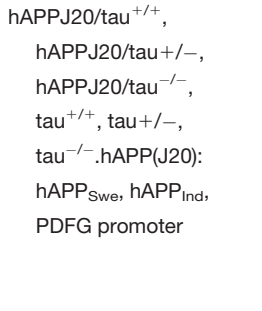 & $\begin{array}{l}\text { hAPP/tau }{ }^{+/+}: 4-7 \text { months, } \mathrm{A} \beta \text { pla- } \\
\text { ques, neurodegeneration }\end{array}$ & Increased in hAPP/tau ${ }^{+/+}$ & $\begin{array}{l}\text { Experimental paradigm: in vivo PTZ-induced and kainate-induced } \\
\text { seizure susceptibility evaluation. tau reduction achieved through } \\
\text { crossing hAPPJ20 line with tau knock-out (tau }{ }^{-/-} \text {). } \\
\text { Findings: tau reduction increased resistance to both PTZ-and kai- } \\
\text { nate-induced seizures. Seizures were less severe in hAPP/tau } \\
\text { and hAPP/tau } \\
\text { also less severe in } \text { tau }^{-/-} \text {mice than in } \operatorname{tau}^{+/+} \text {mice. The onset of } \\
\text { seizure was also delayed by tau reduction. tau reduction also } \\
\text { ameliorated learning and memory deficits in hAPPJ20 mice. }\end{array}$ \\
\hline $\begin{array}{l}\text { Roberson et al. } \\
\qquad(2011)\end{array}$ & $\begin{array}{l}\text { hAPPJ20/tau } \\
\text { hAPPJ20/tau+/-, } \\
\text { hAPPJ20/tau } \\
\text { hAPPJ9/-, } \\
\text { hAu } \\
\text { hAPPJ9/tau } \\
\text { he- } \\
\text { tau }^{+/+}, \mathrm{tau}^{-/-}\end{array}$ & $\begin{array}{l}\text { 7-14 months for in vivo EEG detec- } \\
\text { tion of frequency of epileptiform } \\
\text { spikes: A } \beta \text { plaques, neurodegen- } \\
\text { eration. } \\
\text { 5-8 months for in vivo PTZ-induced } \\
\text { seizure susceptibility evaluation: } \\
\text { A } \beta \text { plaques, neurodegeneration }\end{array}$ & $\begin{array}{l}\text { Increased in hAPPJ20/tau } \\
\text { and hAPPJ9/tau } \\
+/+ \\
\text { mice }\end{array}$ & $\begin{array}{l}\text { Experimental paradigm: in vivo PTZ-induced seizure susceptibility } \\
\text { evaluation. In vivo EEG detection of frequency of epileptiform } \\
\text { spikes in freely moving mice. In vitro epileptiform discharges in } \\
\text { area CA1 of the hippocampus after bicuculline administration in } \\
\text { acute slices. tau reduction achieved via crossing hAPPJ20 or } \\
\text { hAPPJ9 line with tau knock-out }\left(\text { tau }^{-1-} \text { ) mice. }\right. \\
\text { Findings: tau reduction decreased PTZ-induced seizure severity and } \\
\text { frequency of generalized epileptiform spikes in hAPPJ20 mice. } \\
\text { tau reduction also prevented bicuculline-induced epileptiform } \\
\text { bursting in acute hippocampal slices from WT }\left(\operatorname{tau}^{-1-}\right) \text { and } \\
\text { hAPPJ20 mice. }\end{array}$ \\
\hline $\begin{array}{l}\text { DeVos et al. } \\
\qquad(2013)\end{array}$ & $\begin{array}{l}\text { WT (C57BL/6J), } \\
\quad \operatorname{tau}^{-/-}\end{array}$ & $3-5$ months, no pathology & Normal & $\begin{array}{l}\text { Experimental paradigm: in vivo EEG recordings, baseline and after } \\
\text { picrotoxin administered via reverse microdialysis. In vivo PTZ-in- } \\
\text { duced seizure susceptibility evaluation. tau reduction was } \\
\text { achieved via ASOs. } \\
\text { Findings: reduction in normalized spike frequency after picrotoxin } \\
\text { administration in ASO-treated WT mice and tau }{ }^{-/-} \text {as compared } \\
\text { with controls. Total tau protein levels in the hippocampus of mice } \\
\text { highly correlated with normalized spike frequency. PTZ-induced } \\
\text { seizure severity was significantly reduced in ASO-treated WT } \\
\text { mice. Seizure severity and tau protein levels correlated well in all } \\
\text { tested mice. }\end{array}$ \\
\hline Li et al. (2014) & $\begin{array}{l}\operatorname{tau}^{+/+}, \text {tau }+/-, \\
\operatorname{tau}^{-/-} . \\
\text {(all on C57BI/6J } \\
\quad \text { background) }\end{array}$ & $\begin{array}{l}24 \text { months, no pathology, age-ap- } \\
\text { propriate cognitive function }\end{array}$ & Normal & $\begin{array}{l}\text { Experimental paradigm: in vivo PTZ-induced seizure susceptibility } \\
\text { evaluation. tau reduction achieved via genetic homozygous or } \\
\text { heterozygous knock-out. } \\
\text { Findings: PTZ-induced seizure severity was significantly reduced in } \\
\text { tau knock-out aged mice. Also, aged tau } \\
\text { longer seizure latencies than tau } \text { tau }^{+/-} \text {mice. }\end{array}$ \\
\hline $\begin{array}{l}\text { Ittner et al. } \\
\text { (2010) }\end{array}$ & 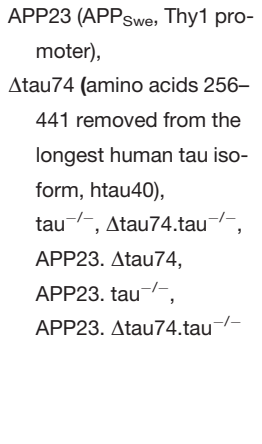 & 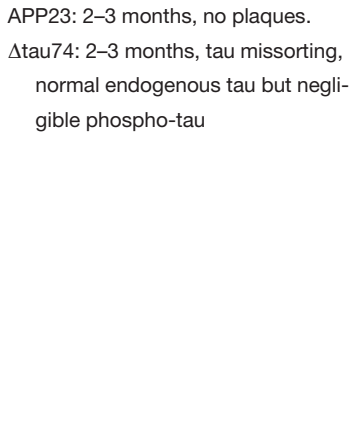 & Increased in APP23 mice & 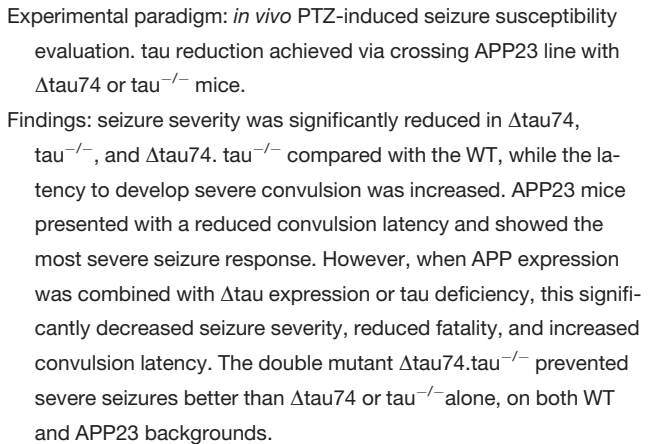 \\
\hline
\end{tabular}

$\mathrm{A} \beta$, amyloid $\beta$; ASOs, antisense oligonucleotides; EEG, electroencephalogram; hAPP, human amyloid $\beta$ precursor protein; PDGF, platelet-derived growth factor; PTZ, phenylenetetrazole; WT, wild type.

were rescued by tau knock-out (Vossel et al., 2010; Shipton et al., 2011). tau-dependent depletion of $\mathrm{K}_{\mathrm{v}} 4.2$ (a dendritic potassium channel important for regulating dendritic excitability and synaptic plasticity) and dendritic hyperexcitability in the CA1 region of the hippocampus were also observed in an AD mouse model overexpressing $A \beta$ (Hall et al., 2015). Additionally, a dendritic function of tau in $\mathrm{A} \beta$-dependent excitotoxicity via postsynaptic targeting of the Src kinase Fyn, a substrate of which is the NMDAR, was previously shown (Ittner et al., 2010). Missorting of tau in transgenic mice expressing truncated tau $(\Delta \mathrm{tau})$ and absence of tau in tau ${ }^{-1}$ mice were both found to disrupt postsynaptic targeting of Fyn, and reduce PTZ-induced seizure susceptibility in mice (Ittner et al., 2010). 
Notably, in APP23 mice, when APP expression was combined with $\Delta$ tau expression or tau deficiency, this significantly decreased seizure severity, reduced fatality, and increased convulsion latency (Ittner et al., 2010). An NMDAR/PSD-95/tau/Fyn complex was shown to mediate $\mathrm{A} \beta$-dependent neuronal network hyperexcitability (Ittner et al., 2010, 2016; Ittner and Götz, 2011). Overall, these data demonstrated that tau protein is an important mediator of $A \beta$-induced neuronal network hyperexcitability.

Expression of ApoE4, an AD risk factor allele, is associated with neuronal network hyperexcitability in mice (Hunter et al., 2012). ApoE4 mice were shown to exhibit GABAergic inhibitory interneuron loss accompanied by cognitive impairments associated with abnormally hyperphosphorylated tau, and this pheontype was rescued by tau reduction (Li et al., 2009; Andrews-Zwilling et al., 2010). These data further suggest a role for tau in ApoE4 mediated neuronal network hyperexcitability in $A D$.

\section{Neuronal network hyperexcitability in mouse models of tauopathies}

Besides $A D$, abnormal forms of hyperphosphorylated tau also accumulate in other tauopathies such as FTD, corticobasal degeneration (CBD), and progressive supranuclear palsy (PSP). The tauopathy mouse models, particularly those carrying FTD mutations, provide a unique opportunity to study AD-like tau pathology (Goedert et al., 2012). Autosomal dominant FTD with parkinsonism linked to chromosome 17 (FTDP-17) is a tauopathy characterized by the presence of abnormally hyperphosphorylated tau deposits in the absence of $\mathrm{A} \beta$ pathology (Foster et al., 1997). Previously, hyperexcitability and epileptic seizures were reported in FTDP-17 mouse model, a transgenic mouse line over-expressing a human tau isoform with 2 $\mathrm{N}$-terminal inserts, 4-microtubule-binding-repeat elements and with the three FTDP-17-linked mutations G272V, P301L, and R406W (Fig. 3A-G; García-Cabrero et al., 2013). Mutant tau transgene was profusely expressed as early as three months of age in these mice, two months before the appearance of spontaneous epileptic activity (García-Cabrero et al., 2013). Thus, human FTDP-17 mutant tau expression in the absence of $\mathrm{A} \beta$ pathology in this model was sufficient to lead to physiological dysfunction which resulted in the epileptic activity and seizures (García-Cabrero et al., 2013). Recently, another FTD-causing tau mutation (V337M) was reported to impair activity-dependent plasticity of the cytoskeleton in the axon initial segment (AIS), and extracellular recordings by multielectrode arrays (MEAs) revealed that the V337M tau mutation in human neurons led to an abnormal increase in neuronal activity in response to chronic depolarization (Sohn et al., 2019).

Previously, employing in vitro intracellular recordings, neuronal network hyperexcitability was reported in rTg4510 human tau transgenic mice (Rocher et al., 2010; Crimins et al., 2011, 2012). It was reported, using whole cell patch clamp recordings, that mutated tau led to increased action potential firing rate in layer three frontal cortical pyramidal neurons in 8.5-month-old rTg4510 mice slices, independent of NFTs formation (Rocher et al., 2010). Another study further corroborated this data, demonstrating increased frequency of spontaneous EPSCs (sEPSCs) in layer three pyramidal neurons of frontal cortical slices of nine-month-old rTg4510 mice, and proposing increased excitability as a compensatory homeostatic response by surviving neurons to neurodegeneration in tauopathies (Fig. 3H,l; Crimins et al., 2011). Interestingly, a subsequent study by the same group found neuronal hyperexcitability in layer three pyramidal neurons of frontal cortical slices in both early (less than four months of age) and late (more than eight months of age) stages of tauopathy in rTg4510 mice (Crimins et al., 2012). The measures of hyperexcitability found in layer three cortical neurons at both early and late stages of tauopathy in $\mathrm{rTg} 4510$ mice included depolarized resting membrane potential, an increased depolarizing sag potential and increased action potential firing rate (Crimins et al., 2012)

A previous study found that the $\mathrm{A} 152 \mathrm{~T}$-variant of human tau (htau-A152T), known to increase the risk for both AD and non-AD tauopathies (Coppola et al., 2012), when expressed in transgenic mice neurons led to not only age-dependent cognitive decline, neurodegeneration, and gliosis, but also caused intermittent epileptic spike activity detectable by EEG (Maeda et al., 2016). The epileptic spikes were more abundant in htau-A152T mice and less abundant in htau-WT mice (carrying human tau overexpression) as compared with non-transgenic controls (Maeda et al., 2016). An earlier in vitro study employing acute hippocampal slice and hippocampal slice cultures found enhanced basal synaptic transmission and an increase in picrotoxin-induced epileptiform burst frequency as well as in action potential firing per burst in the CA3 region of the hippocampus in htau-A152T mice (Decker et al., 2016). Increased extracellular glutamate was also observed in hippocampal slice cultures form htau-A152T mice; the increased picrotoxin-induced epileptiform activity in htauA152T slice cultures was prevented by ceftriaxone which stimulates astrocytic glutamate uptake via the transporter EAAT2/GLT1 (Decker et al., 2016). In another study, the htau-A152T expression in mice brain was also found to increase the power of brain oscillations in the $0.5-$ to $6-\mathrm{Hz}$ range $(\delta-\theta)$ more than the increase induced by only htau expression when compared with non-transgenic controls (Das et al., 2018). These data suggest the possibility that taumediated neuronal network hyperexcitability may not only be dependent on its expression level but also on its sequence. Remarkably, genetic ablation of endogenous tau in $\mathrm{Mapt}^{-1-}$ mice reduced the power of these brain oscillations when compared with WT controls (Das et al., 2018). Additionally, suppression of htau-A152T production in doxycycline-regulatable transgenic mice reversed their abnormal network activity (Das et al., 2018). Also, treatment of htau-A152T mice with the antiepileptic drug levetiracetam persistently reversed their brain dysrhythmia and network hypersynchronization (Das et al., 2018).

A recent study examined PTZ-induced seizure susceptibility in tau58/4 mice expressing the human 4R/0N tau isoform that contains the point mutation of proline-to-serine in codon 301 (P301S) of the MAPT gene (Fig. 3J; Van Erum et al., 2020). Overexpression of human tau is 
A

B
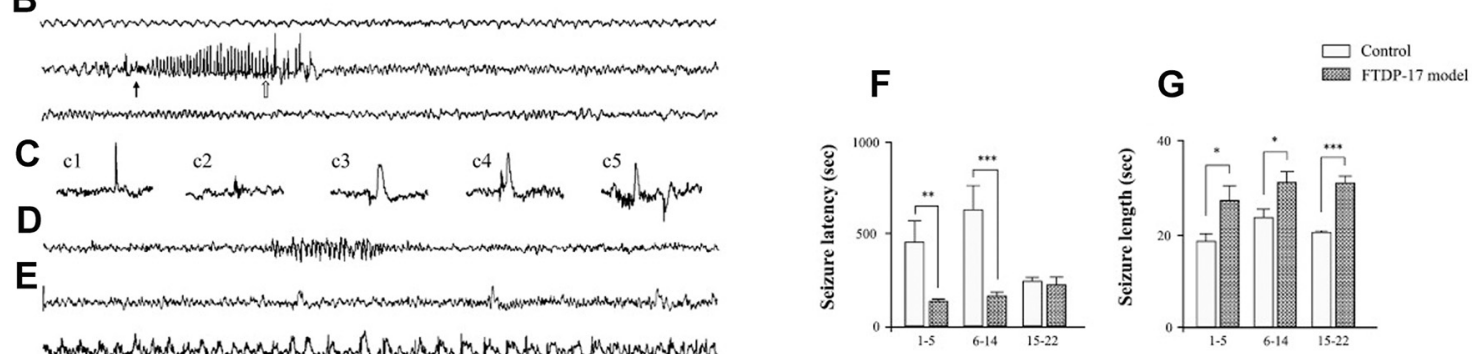

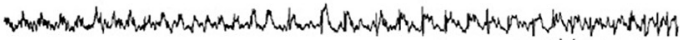

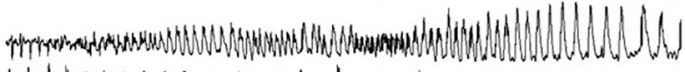

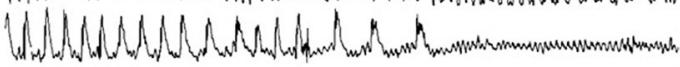

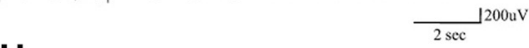

H 2 sec $200 \mathrm{w}$

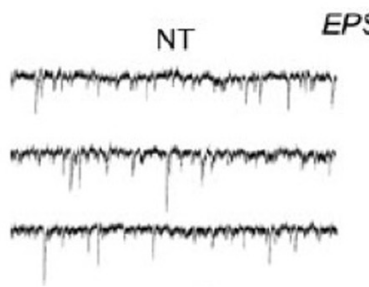

EPSCs
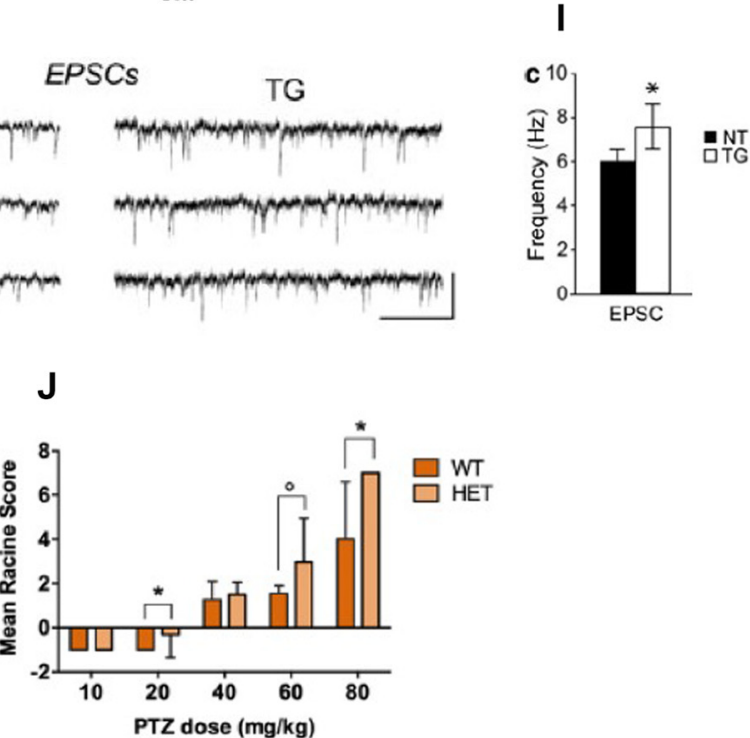

Figure 3. Neuronal network hyperexcitability in tau mouse models. $\boldsymbol{A}-\mathbf{G}$, Hyperexcitability and epileptic seizures in a mouse model of a tauopathy (FTDP-17). Reproduced from García-Cabrero et al. (2013) with permission from Elsevier. $\boldsymbol{A}$, Intracranial recording of background activity $(6-7 \mathrm{~Hz})$ in control mice. $\boldsymbol{B}$, Spindle-shaped polyspike discharge at $8-10 \mathrm{~Hz}$, during an initial tonic phase (thin arrow indicates the beginning) and a short clonic phase (open arrow signals the beginning) in a FTDP-17 mouse. $\boldsymbol{C}$, Spontaneous interictal epileptic activity in FTDP-17 mice corresponding to (c1) single spike, (c2) polyspike, (c3) slow wave, and (c4, c5) polyspikewave discharges. $\boldsymbol{D}$, Nonconvulsive spontaneous seizure with EEG correlates corresponding to rhythmic, spindle-shaped discharges. $\boldsymbol{E}$, Spontaneous generalized tonic-clonic seizure in a FTDP-17 mouse manifested in the EEG record as generalized lowfrequency $(3-6 \mathrm{~Hz})$ poyspike-wave discharge, $36 \mathrm{~s}$ in length. Figure shows the records from monopolar electrodes placed over the left frontal cortex with the reference electrodes implanted posterior to $\lambda$. $\boldsymbol{F}, \mathbf{G}$, Analysis of seizure latency and length of PTZ-induced generalized seizures in FTDP-17 mice. Mice at three different age spans (1-5, 6-14, and 15-22 months) were injected with a convulsive dose of PTZ $(50 \mathrm{mg} / \mathrm{kg})$. $\boldsymbol{F}$, The time interval between drug administration and development of generalized tonic-clonic seizures and $(\boldsymbol{G})$ the seizure length were measured. Data are presented as mean \pm SEM. Student's $t$ test was performed for statistical evaluation; ${ }^{*} p<0.05,{ }^{* *} p<0.01,{ }^{* * *} p<0.001(n=15-24)$. $\boldsymbol{H}$, I, Increased spontaneous synaptic activity in whole-cell patch clamp recordings of layer 3 frontal cortex pyramidal neurons of rTg4510 (hTau P301L) mice. Reproduced with permission from Crimins et al. (2011). Increased frequency of sEPSCs in TG (rTg4510) cells. $\boldsymbol{H}$, Representative sEPSCs from non-transgenic (NT) and TG cells. $\boldsymbol{I}$, Bar graphs of mean frequency sEPSCs in NT and TG cells. $\boldsymbol{J}$, Increased PTZ-induced seizure susceptibility in three-month-old Tau58/4 (htau P301S) mice. Young HET (Tau58/4) mice had higher mean severity scores than WT littermates. Reproduced with permission from Van Erum et al. (2020).

present in these mice from birth in heterozygous animals. In the cerebrum, hyperphosphorylated tau arises at the level of the pons and frontal cortices at three months of age. NFTs formation is observed at the age of six months, and at 12 months; NFTs are diffusely present in the frontal cortex and the pons and also appear in the cerebellum, midbrain, and parietal cerebral cortex (Van Erum et al., 2020). The study found an increased PTZ-induced seizure susceptibility in young (three months old; Fig. 3J), but not in old (12- to 15month-old) tau58/4 mice. Young tau58/4 animals displayed more severe seizures and had a reduced latency to the first seizure compared with WT littermates (Van Erum et al., 2020). Also, age-related differences in 
susceptibility could be demonstrated for both genotypes (Van Erum et al., 2020).

\section{Tau suppresses neuronal network excitability even before development of NFTs: evidence for the counter argument}

In vivo and in vitro electrophysiological evidence of taumediated suppression of neuronal activity in mouse models of tauopathies

Interestingly, in stark contrast to the data supporting the notion that tau promotes neuronal network hyperexcitability in AD, some recent studies demonstrate that tau may actually suppress it. A recent study employing in vivo two-photon $\mathrm{Ca}^{2+}$ imaging of large populations of neurons in layer $2 / 3$ of the neocortex showed that while $A \beta$ promotes neuronal network hyperactivity, tau in fact suppresses the activity (Fig. 4A-F; Busche et al., 2019). The study found neuronal hyperactivity in 6- to 12-month-old plaque-bearing APP/PS1 mice, and a strong reduction of cortical activity levels in age-matched rTg4510 transgenic mice that express aggregating human tau P301L (expression level of human tau 13-fold higher than that of endogenous tau) and display NFTs but no $\mathrm{A} \beta$ pathology (Busche et al., 2019). Interestingly, tau aggregation was not necessary for neuronal silencing as suppression of cortical activity was found in neurons devoid of NFTs (Busche et al., 2019). Furthermore, marked reduction of neuronal activity was found in neurons of rTg21221 mice that overproduce non-aggregating WT human tau at comparable levels to rTg4510 mice but lack NFTs (Busche et al., 2019). These data suggested that impairment of neurons could occur with tau overexpression independent of tau aggregation and NFTs formation. This was further validated by reduction in cortical activity in young age rTg4510 mice (Busche et al., 2019). Soluble, non-aggregated tau was found to be sufficient for neuronal silencing, and NFTs were not required (Busche et al., 2019). Interestingly, on evaluation of $\mathrm{A} \beta$ and tau together, neuronal hyperactivity was not only completely abolished in the crossed APP/PS1-rTg4510 and APP/PS1-rTg21221 mice, but there was also a strong reduction in cortical activity levels, both in old and young mice (Busche et al., 2019). These data suggested that tau blocks $A \beta$-dependent hyperactivity, leading to silencing of circuits when both $A \beta$ and tau are present together in the cortex. While these findings are contradictory to other data showing neuronal network hyperactivity in both young and aged 3xTg-AD mice which harbor both $A \beta$ and tau along with PS1 (Davis et al., 2014; Kazim et al., 2017), they are supported by another study in young 3xTg-AD mice which reported a decrease in neuronal activity in these mice (Mondragón-Rodríguez et al., 2018), this will be discussed in more detail later in the present review (see below, Phosphorylation of tau reduces hippocampal excitability). Remarkably, while suppressing tau transgene expression resulted in reversal of suppression of neural activity in tau mice, it was less effective in rescuing neuronal network impairments in crossed mice containing both $\mathrm{A} \beta$ and tau (Busche et al., 2019), suggesting a complex interaction of $\mathrm{A} \beta$ and tau in neural activity.
Another recent study has reported similar results, i.e., reduced activity of neuronal circuits in a P301S mouse model of tauopathies (Fig. 4G,H; Marinković et al., 2019). By using chronic in vivo two-photon calcium imaging in awake mice, a strong reduction of calcium transient frequency in layer $2 / 3$ cortical neurons of P301S mice, independent of NFTs presence, was found (Marinković et al., 2019). Interestingly, reduced neuronal activity in P301S mice did not change with time and pathology progression (Marinković et al., 2019). Thus, it was concluded that it is soluble, mutated tau protein species, not NFTs, that suppress neuronal activity (Busche et al., 2019; Marinković et al., 2019).

A previous study employing in vivo intracellular and extracellular electrophysiological recordings found that pathologic tau reduced the neocortical activity in rTg4510 mice before significant neurodegeneration and at an age where not all neurons in these mice express pathologic tau (Menkes-Caspi et al., 2015). The changes induced by pathologic tau included slower neuronal oscillations and reduced firing rates, and reduction in reliability of synaptic transmission in the transgenic neocortex (Menkes-Caspi et al., 2015). While the study did not differentiate between the effect of soluble tau and NFTs in suppressing network excitability, it was suggested that pathologic tau may in fact affect neuronal activity at levels below those detectable with routine immunocytochemical and perfusion methods (Menkes-Caspi et al., 2015). It is interesting to note here that these data are in contrast to other studies employing in vitro intracellular recordings in the same mice mentioned before (Rocher et al., 2010; Crimins et al., $2011,2012)$. These differences could potentially be because of the inherent differences between preparations and recording techniques (Menkes-Caspi et al., 2015); however, further investigation is needed to clarify this discrepancy (we will discuss this in detail in Phosphorylation of tau reduces hippocampal excitability; and Perspectives on the Similar versus Divergent Roles of $A \beta$ and tau in Neuronal Network Hyperexcitability in AD: Which One Has a Dominant Effect, $A \beta$ or tau?)

In congruence with the findings of Menkes-Caspi and colleagues (Menkes-Caspi et al., 2015), another in vitro electrophysiological study reported tau-induced suppression of neuronal activity (Angulo et al., 2017). The study evaluated neuronal activity in mutant htau mice, mutant hAPP mice, and combined mutant htau and hAPP mice in the EC, one of the first regions in the brain to be affected by the AD pathology (mainly the tau pathology; Angulo et al., 2017). It was found that mutant EC-hAPP mice exhibited a significant increase in the duration of spontaneous extracellular field potentials (sEFPs) in EC (Angulo et al., 2017). Interestingly, pyramidal neurons of the subiculum in EC-hAPP mice, which are monosynaptically excited by EC layer III neurons, showed mEPSCs with reduced amplitude, suggesting that the increased excitation observed in EC induced a compensatory negative feedback in subicular projection neurons, a process known as synaptic homeostasis, explained by EC interneuron pruning based on computational modeling (Angulo et al., 2017). The physiological changes produced in EC by the expression 
A

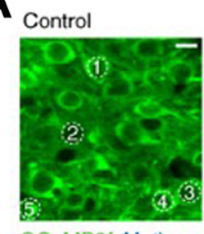

GCaMP6f Methoxy-X04
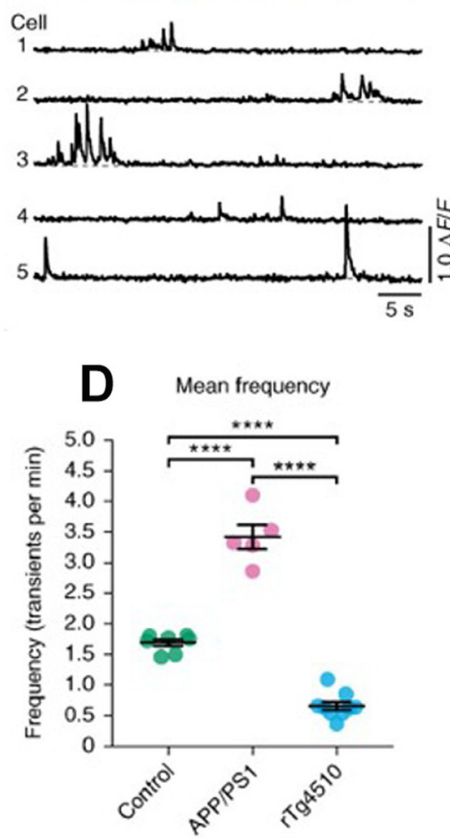

G
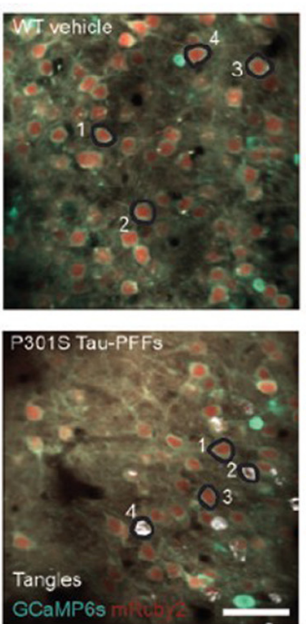

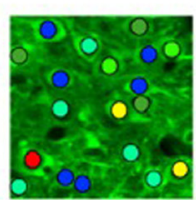

B

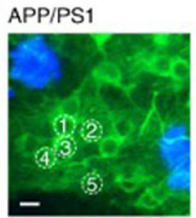

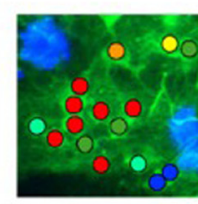
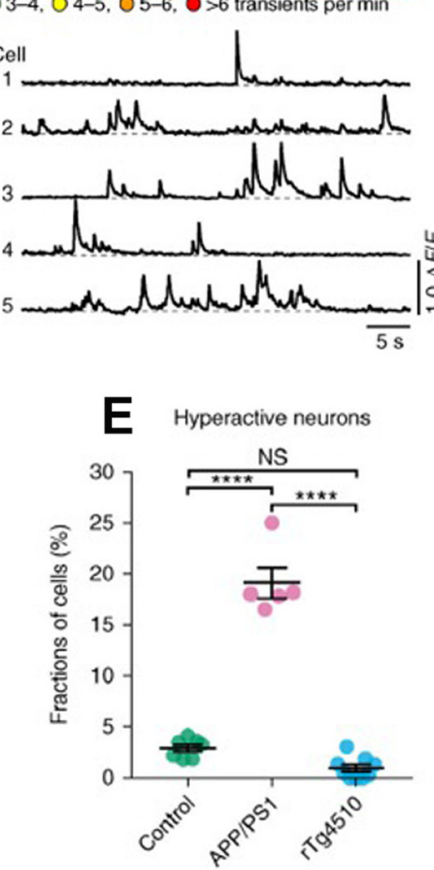

$\mathbf{C}_{\text {rT } T 4510}$

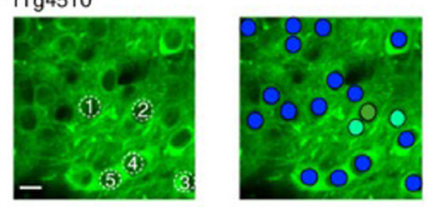

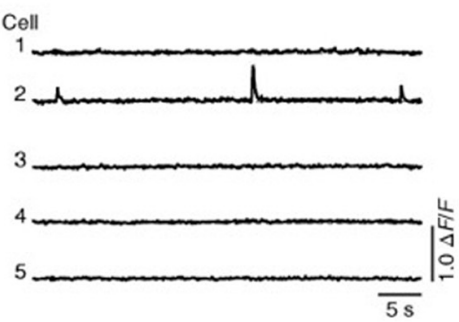

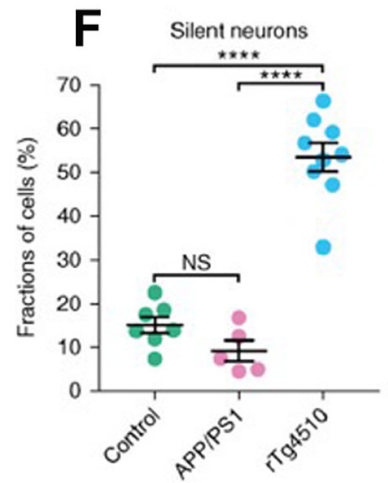

$\mathrm{H}$
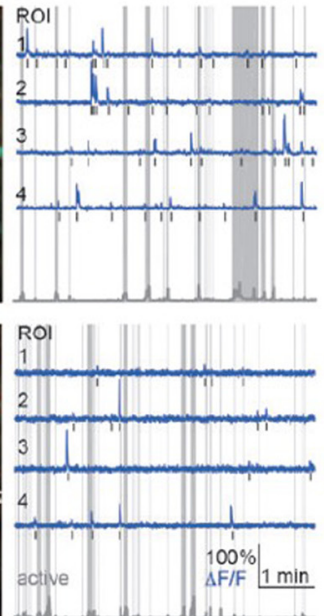

OWT vehicle OP301S vehicle N. NFT-free

o WT Tau-PFFs • P301S Tau-PFFs $\Delta$ NFT-bearing

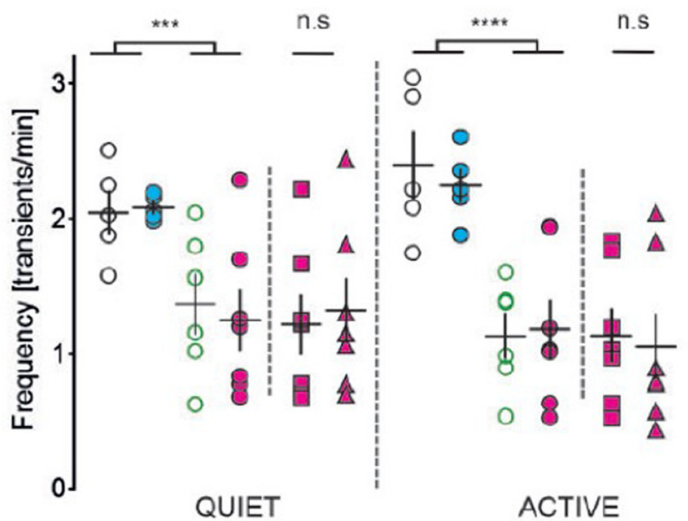

Figure 4. In vivo evidence of suppression of neuronal activity in tau mouse models. $\boldsymbol{A}-\boldsymbol{F}$, Neuronal silencing in rTg4510 mice as compared with neuronal hyperactivity in APP/PS1 mice. Reproduced with permission from Busche et al. (2019). A-C, top, In vivo two-photon fluorescence images of GCaMP6f-expressing (green) layer 2/3 neurons in the parietal cortex and corresponding activity maps from WT controls $(\boldsymbol{A})$, APP/PS1 $(\boldsymbol{B})$, and $\mathrm{rTg} 4510(\boldsymbol{C})$ mice. In APP/PS1 mice, plaques were labeled with methoxy-X04 (blue); in the activity maps, neurons were color-coded as a function of their mean $\mathrm{Ca}^{2+}$ transient activity. Scale bars: $10 \mu \mathrm{m}$. Bottom, spontaneous $\mathrm{Ca}^{2+}$ transients of neurons indicated in the top panel. $\boldsymbol{D}$, Mean neuronal frequencies for controls $(1.69 \pm 0.05$ transients per minute), APP/PS1 (3.42 \pm 0.20 transients per minute), and $r$ Tg4510 (0.66 \pm 0.07 transients per minute); $F_{(2,18)}=171.2, p=1.93-$ $\times 10^{-12}$. All post hoc multiple comparisons between genotypes were highly significant: $p=5.42 \times 10^{-9}$ for controls versus APP/PS1, $p=1.38 \times 10^{-6}$ for controls versus $\mathrm{rTg} 4510$, and $p=1.01 \times 10^{-12}$ for APP/PS1 versus rTg4510. $\boldsymbol{E}$, Fractions of hyperactive neurons. Controls: $2.91 \pm 0.35 \%$, APP/PS1: $19.11 \pm 1.50 \%$, rTg4510: $0.93 \pm 0.35 \% ; F_{(218)}=176.2, p=1.51 \times 10^{-12}$. Post hoc multiple comparisons were $p=2.84 \times 10^{-11}$ for controls versus APP/PS1, $p=1.64 \times 10^{-12}$ for APP/PS1 versus rTg4510 and not significant, $p=0.1045$, for controls versus rTg4510. $\boldsymbol{F}$, Fractions of silent neurons. Controls: $15.05 \pm 1.87 \%$, APP/PS1: 9.20 $\pm 2.36 \%, r T g 4510$ : 


\section{continued}

$53.48 \pm 3.24 \% ; F_{(2,18)}=77.18, p=1.48 \times 10^{-9}$. Post hoc multiple comparisons were $p=2.02 \times 10^{-8}$ for controls versus $r$ Tg4510 and $p=1.08 \times 10^{-8}$ for APP/PS1 versus rTg4510 and not significant, $p=0.3972$, for controls versus APP/PS1. Each solid circle represents an individual animal (controls, $n=7$; APP/PS1, $n=5$; rTg4510, $n=9$ ), and all error bars reflect the mean \pm SEM; the differences between genotypes were assessed by one-way ANOVA followed by Tukey's multiple comparisons test, ${ }^{* \star \star} p<0.0001$. NS, not significant. $\boldsymbol{G}, \boldsymbol{H}$, Neuronal activity is reduced in P301S mice independently of presence of NFTs. Reproduced with permission from Marinković et al. (2019). G, left, Representative in vivo recordings from WT vehicle and P301S tau-PFFs (tau preformed fibrils-injected) mice. AAV1 transduced neurons are labeled with mRuby2 (red) and GCaMP6s (green). NFTs are labeled with FSB (white). Images are made by averaging 450 time-series frames acquired in vivo at $410 \mathrm{~Hz}$ with two-photon lasers tuned to $940 \mathrm{~nm}$ for CGaMP6s/mRuby2 and to $750 \mathrm{~nm}$ for FSB. Scale bar: $50 \mathrm{~mm}$. Right, Traces (blue) extracted from annotated regions of interest (black) during quiet and active (gray shade) behavioral states classified based on changes in whisking movement (gray trace in the bottom). Note that traces 2 and 4 in P301S tau-PFFs group are from NFT-bearing neurons. Black bars mark detected calcium transients. $\boldsymbol{H}$, Mean frequency of calcium transients during quiet and active states of all neurons detectable in three or more time points. WT vehicle (black), WT tau-PFFs (cyan), P301S vehicle (green), all P301S tau-PFFs: all neurons are denoted as magenta circles, with NFT-free as magenta squares and NFT-bearing as magenta triangles. Data points represent individual mice, $n=5-7$ mice per group; black lines represent mean value $\pm \mathrm{SEM}$; ${ }^{\star \star \star} p<0.001,{ }^{\star \star \star \star} p<0.0001$, WT versus P301S (two-way ANOVA, genotype factor, not significant; Student's $t$ test).

of mutant tau protein (P301L) manifested as resistance to $\mathrm{GABA}_{\mathrm{A}}$ receptor antagonist-induced hypersynchrony (Angulo et al., 2017). However, the human tau mutation, by itself, did not produce any significant spontaneous activity changes in EC-hippocampus circuits. Remarkably, mice exhibiting both $A \beta$ and tau pathologies displayed an intermediate and subtler phenotype, which was predominantly driven by tau pathology. These data suggested divergent roles of $A \beta$ and tau in neuronal excitability with $\mathrm{A} \beta$ promoting hyperexcitability and tau suppressing excitability and tau exerting a dominant effect in the presence of both pathologies. These data are in congruence with a recent in vivo study discussed earlier (Busche et al., 2019).

\section{Phosphorylation of tau reduces hippocampal excitability}

Phosphorylation of tau has been considered the most critical posttranslational modification in taupathies and neurodegenerative diseases (Busche and Hyman, 2020). tau protein contains 85 potential tyrosine $(Y)$, threonine $(T)$, and serine (S) phosphorylation sites. A comprehensive analysis of phosphorylation sites of tau protein has revealed $>40$ phosphorylation sites in $A D$ (Morishima-Kawashima et al., 1995; Hanger et al., 2007). Accumulating evidence indicate that different phosphorylation sites result in changes in synaptic function, axonal initial segment, which ultimately precipitates to abnormal neuronal excitability and network dysfunction (Ittner et al., 2016; Mondragón-Rodríguez et al., 2018b; Hill et al., 2019). A study employing patch-clamp electrophysiology of hippocampal CA1 neurons in two tau pathology mouse models, the rTg4510 strain and a second model, pR5, that also expresses P301L mutant tau, although at much lower levels, showed that hyperphosphorylated tau before neurodegeneration induced a more depolarized threshold for action potential initiation and reduced firing in hippocampal CA1 neurons, an effect that was rescued by the suppression of transgenic tau (Hatch et al., 2017). The authors found that this reduction in neuronal excitability resulted from the relocation of the AIS down the axon in a tau phosphorylation-dependent manner, which was microtubule dependent. Interestingly, the authors found that the shift of AIS is correlated with phosphorylation of tau at pThr231/pSer235 and pSer262/pSer356, but not pSer396/pSer404, indicating that the sites of phosphorylation is critical for mediating reduction of hyperexcitability (Hatch et al., 2017).

A more recent study by Lennart and his colleagues demonstrated, by using P301L pR5 mouse model, that hyperphosphorylation of tau resulted in increase in stubby spines and filopodia, reduction of total dendritic length of hippocampal pyramidal neurons. The authors also found that the neuronal atrophy resulted in a significant reduction of LTP in CA1, depolarized threshold for action potential initiation, and an increased current of inward rectifying potassium channels (Müller-Thomsen et al., 2020). As results, hyperphosphorylation of tau lead to decreased excitability of CA1 neurons.

While these data are in contrast to other in vitro studies reporting hyperexcitability in rTg4510 mice (Rocher et al., 2010; Crimins et al., 2011, 2012), it must be noted that those previous studies analyzed excitability in cortical pyramidal neurons as compared with this study which evaluated CA1 hippocampal neurons. These observations also raise the possibility that neuronal dysfunction resulting from tau hyperphosphorylation may occur in a brain region-specific manner. Nonetheless, as mentioned before, recent in vivo studies have also found reduced excitability in the neocortex of $r \mathrm{Tg} 4510$ mice (Menkes-Caspi et al., 2015; Busche et al., 2019).

Previously, also in rTg4510 mice, it was found that tau was aberrantly targeted to dendritic spines by the P301L mutation, before overt neurodegeneration and synaptic loss (Hoover et al., 2010). It was reported that phosphorylation controlled tau mislocalization to dendritic spines, and once mislocalized to spines, tau suppressed excitatory synaptic transmission and caused loss of surface AMPA receptors in spines (Hoover et al., 2010). These findings were reported both in $\mathrm{rTg} 4510$ mice cultured cortical neurons and in rat hippocampal neurons with transfected htau-P301L mutation (Hoover et al., 2010).

Remarkably, a protective role of site-specific phosphorylation of tau against $A \beta$ excitotoxicity was recently reported (Ittner et al., 2016), challenging the dogma that tau phosphorylation only mediates toxic processes in $A D$. p38 mitogen-activated protein kinase (p38MAPK) is known to phosphorylate tau (Goedert et al., 1997; Feijoo et al., 2005; Cuenda and Rousseau, 2007). Although p38MAPK was reported to contribute to NMDAR- 
mediated toxicity (Mucke and Selkoe, 2012), and its inhibition improved $\mathrm{A} \beta$-induced LTP deficits (Wang et al., 2004), paradoxically, hyperexcitability in APP transgenic mice increased with inhibition of p38MAPK (Ittner et al., 2014). Among different p38MAKs, p38MAPK $\gamma$ was found to localize to dendritic spines and postsynaptic densities (PSDs) of neurons (Ittner et al., 2016). Depletion of postsynaptic p38MAPK $\gamma$ exacerbated neuronal network hyperexcitability in APP23 transgenic mice (Ittner et al., 2016). Furthermore, it was reported that p38MAPK $\gamma$-mediated phosphorylation of tau at threonine 205 (Thr205) disrupted NR/PSD-95/tau/Fyn complexes, and reduced A $\beta$ dependent neuronal network hyperexcitability (Ittner et al., 2016). These data (Ittner et al., 2016), along with earlier data from the same group (Ittner et al., 2010), suggest that while tau may promote neuronal network hyperexcitability, the phosphorylation of tau in fact suppresses excitability and protects against excitotoxicity.

Another recent study also showed reduction in hippocampal excitability by phosphorylation of tau protein (Mondragón-Rodríguez et al., 2018b). The study found that pyramidal neurons in the hippocampus from young 3xTg-AD mice (one-month-old, without any cognitive deficit) accumulated hyperphosphorylated tau at the microtubule domain region (MDr) and exhibited reduced neuronal network excitability and seizure susceptibility. Further analysis showed that phosphorylation site at Ser396 was responsible for changes in network excitability in these mice (Mondragón-Rodríguez et al., 2018). Previously, the same group reported that tau phosphorylation at MDr sites could serve as a regulatory mechanism to prevent overexcitation (Mondragón-Rodríguez et al., 2012). Interestingly, the study also found alterations (increase) in network oscillatory activity at $\theta$ band frequency in young 3xTg-AD mice (Mondragón-Rodríguez et al., 2018). Previously, changes in hippocampal $\theta$ activity were correlated with the cognitive impairment observed during neurodegeneration (Cayzac et al., 2015). Specifically, slowing of hippocampal activity has been correlated with cognitive decline in early onset $A D$ (Engels et al., 2016). It was postulated that the increase in $\theta$ activity observed at a young age in 3xTg-AD mice before any cognitive deficit and neurodegeneration could be an early compensatory response, and may contribute to early network dysfunction in these mice and $A D$ (MondragónRodríguez et al., 2018). Nonetheless, as 3xTg-AD mice also harbor APP and PS1 mutations in addition to a tau mutation, it is difficult to ascertain whether this increase in $\theta$ oscillations was a result of tau and its phosphorylation or APP/A $\beta$ overexpression. In fact, a recent study showed early weakening of $\theta$ oscillations and drastic impairments in $\theta-\gamma$ oscillations phase-amplitude cross frequency coupling induced by tau seedings in a P301L human mutant tau mouse model (Ahnaou et al., 2017). Interestingly, the study failed to find any epileptiform activity or network hyperexcitability in these mice with tau aggregates induced by seeding, and argued toward a causal relationship between the early disruption in functional networks (but not neuronal network hyperexcitability) and tau aggregation (Ahnaou et al., 2017). Along similar lines, two recent studies showed that inducing $\gamma$ oscillations via sensory stimulation ( $\gamma$ entrainment using sensory stimulus or GENUS) not only benefited cognition but also ameliorated $A \beta$ and tau pathologies in 5XFAD and P301S mouse models of AD, respectively (Adaikkan et al., 2019; Martorell et al., 2019).

\section{Perspectives on the Similar versus Divergent Roles of $A \beta$ and tau in Neuronal Network Hyperexcitability in AD: Which One Has a Dominant Effect, A $\beta$ or tau?}

The presence of neuronal network hyperexcitability in human $\mathrm{MCl} / \mathrm{AD}$ patients and animal models of the disease is well documented (Palop et al., 2007; Crimins et al., 2011, 2012; Bakker et al., 2012, 2015; Vossel et al., 2013, 2016, 2017; Davis et al., 2014; Bezzina et al., 2015; Kazim et al., 2017). While routine scalp EEG recordings cannot always accurately detect epileptiform activity originating from the mesiotemporal region (including the hippocampal formation; Clemens et al., 2003; Nilsson et al., 2009) and carries low yield of identifying network hyperexcitability in AD (Horváth et al., 2016), neuronal hyperactivity, silent seizures, and spikes have been reported in the $\mathrm{MCl}$ patients' hippocampus using techniques with better detection properties such as fMRI (Bakker et al., 2012, 2015) and foramen ovale electrode (Lam et al., 2017). As discussed in detail in this review, while the causal relationship between $\mathrm{A} \beta$ and network hyperexcitability remains to be established in human $A D$ patients, the role of $A \beta$ (even before the formation of plaques, i.e., intraneuronal hAPP/A $\beta$ and soluble $A \beta$ ) in promoting neuronal network hyperexcitability has been consistently reported in animal model studies (Palop et al., 2007; Busche et al., 2008, 2012; Minkeviciene et al., 2009; Palop and Mucke, 2010a, b; Sanchez et al., 2012; Verret et al., 2012; Born et al., 2014; Bezzina et al., 2015; Kazim et al., 2017). However, the role of tau in network excitability in $A D$ remains yet to be precisely delineated as different animal model studies reported divergent effects (Roberson et al., 2007; Crimins et al., 2011, 2012; Roberson et al., 2011; García-Cabrero et al., 2013; Menkes-Caspi et al., 2015; Angulo et al., 2017; Mondragón-Rodríguez et al., 2018b; Busche et al., 2019; Van Erum et al., 2020). Nonetheless, recent human studies have reported a correlation between temporal lobe tau accumulation, CSF tau levels and hippocampal hyperactivity (Berron et al., 2019; Huijbers et al., 2019), suggesting a proepileptic effect of tau. Importantly, as in human $A D$ brain, the $A \beta$ and tau pathologies co-exist and potentially both contribute to neurodegeneration, a highly relevant question that remains to be answered is how the two histopathological hallmarks interact to affect the neuronal network activity in AD brains, and which one has a dominant effect, $A \beta$ or tau?

With subclinical epileptiform activity and network hyperactivity demonstrated in human $\mathrm{MCl} / \mathrm{AD}$ patients (Bakker et al., 2012, 2015; Vossel et al., 2013, 2016; Lam et al., 2017), it seems plausible that either $\mathrm{A} \beta$ and tau cooperate to lead to neuronal network hyperexcitability (Fig. 
A Hypothesis \# 1: $A \beta$ and tau cooperate to lead to neuronal network hyperexcitability

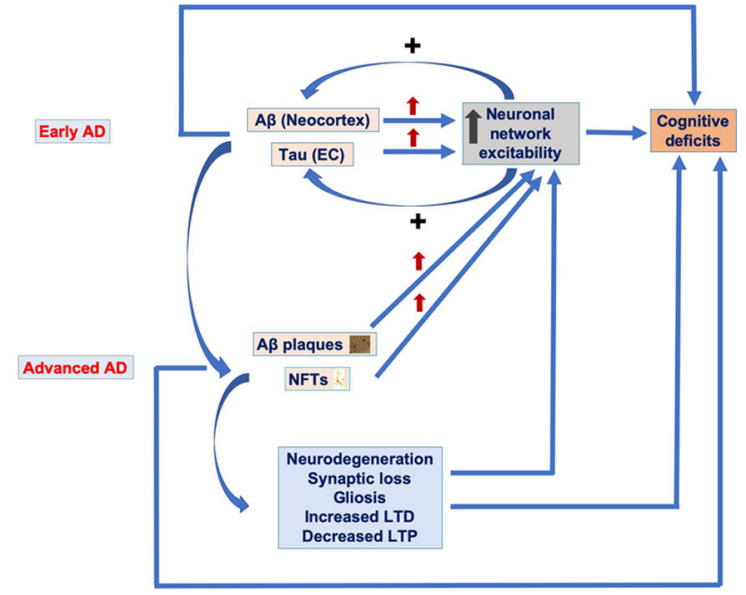

B Hypothesis \# 2: Neuronal network hyper-excitability promoting effect of $A \beta$ dominates over the suppressing effect of tau

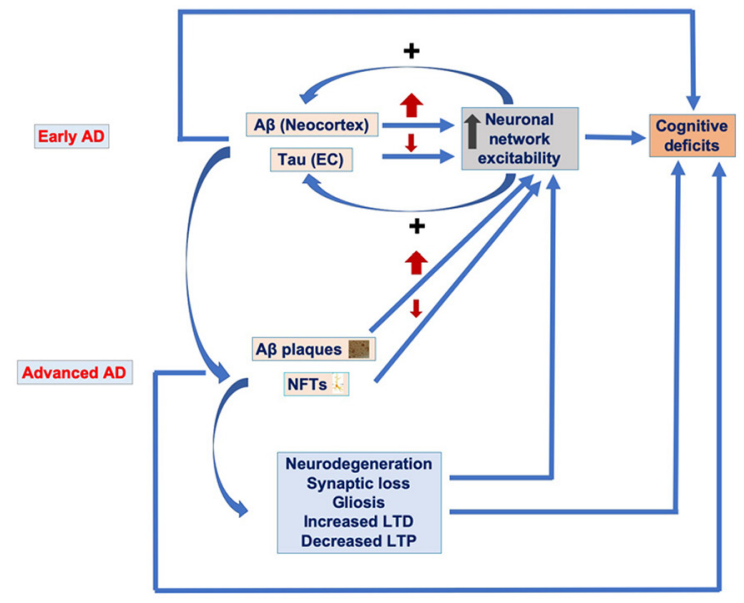

\section{Hypothesis \# 3: Tau suppresses neuronal network excitability and dominates over the effect of $A \beta$}

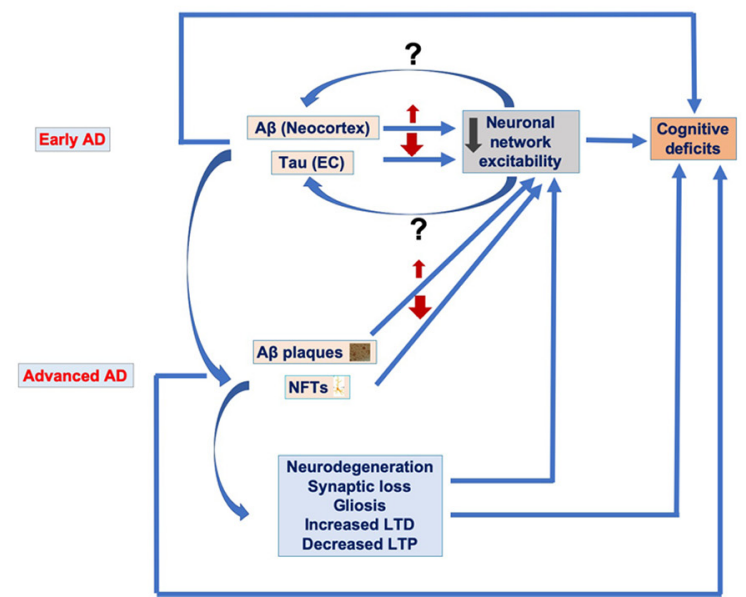

Figure 5. Hypotheses regarding the possible effects of $\mathrm{A} \beta$ and
$5 A$, hypothesis \#1) or the neuronal network hyperexcitability promoting effect of $A \beta$ dominates over the suppressing effect of tau (Fig. $5 B$, hypothesis \#2; if tau suppresses neuronal network activity as suggested by recent animal model studies; Hatch et al., 2017; Mondragón-Rodríguez et al., 2018b; Busche et al., 2019; Marinković et al., 2019). In support of both the first and second hypotheses, few studies in AD transgenic mice harboring both $\mathrm{A} \beta$ and tau (3xTg-AD) have reported hyperexcitability in these mice both at early and late stages of the pathology (Davis et al., 2014; Kazim et al., 2017). In agreement with the first hypothesis, tau reduction in hAPP mice has been reported to decrease neuronal network excitability (Roberson et al., 2007; Ittner et al., 2010; Roberson et al., 2011).

Alternatively, another line of evidence suggests that tau may be the dominant protein over $\mathrm{A} \beta$, and that it causes overall suppression of neuronal hyperexcitability. This was demonstrated by Busche and colleagues, who used in vivo calcium imaging of cortical neurons from APP/

\section{continued}

tau on neuronal network excitability in AD. $\boldsymbol{A}$, Hypothesis \#1, $\mathrm{A} \beta$ and tau cooperate to lead to neuronal network hyperexcitability in $A D$. At early stages of $A D, A \beta$ is more abundant in the neocortex whereas tau is localized to EC. Both $A \beta$ and tau at early $A D$ stages promote neuronal network hyperexcitability which not only contributes to cognitive impairments but also reciprocally increases $A \beta$ deposition and tau release and spread to other cortical areas across connected neuroanatomical circuitry. Also, at advanced $\mathrm{AD}$ stages, both $\mathrm{A} \beta$ and tau promote neuronal network hyperexcitability, thus leading to cognitive deficit. Furthermore, $\mathrm{A} \beta$-induced and tau-induced neuronal and synaptic loss, gliosis, and impaired synaptic plasticity (decreased LTP and increased LTD) contribute to neuronal network hyperexcitability and to cognitive deficits, effects also at play in scenarios illustrated in $\boldsymbol{B}, \boldsymbol{C}$. $\boldsymbol{B}$, Hypothesis \#2, $\mathrm{A} \beta$ enhances neuronal network hyperexcitability whereas tau suppresses excitability; the overall phenotype is hyperexcitability as $A \beta$ effect dominates over tau effect. $A \beta$ at early $A D$ stages promotes neuronal network hyperexcitability which not only contributes to cognitive impairments but also increases $A \beta$ deposition and tau release and spread to other cortical areas across connected neuroanatomical circuitry. However, tau at early AD stages suppresses neuronal activity, thus leading to silencing of neuronal networks which could also contribute to AD-related network dysfunction and cognitive deficit. Also, at advanced AD stages, $\mathrm{A} \beta$ enhances and tau suppresses neuronal network excitability, both leading to cognitive deficits. This could also be the case in $\mathrm{AD}$ patients with higher $\mathrm{A} \beta$ deposits than NFTs in their brains. C, Hypothesis \#3, tau suppresses neuronal network excitability, whereas $\mathrm{A} \beta$ enhances it; the overall phenotype is suppressed excitability as tau suppressive effect dominates over $\mathrm{A} \beta$ enhancing effect. Tau both at early and advanced AD stages suppresses neuronal excitability thus leading to silencing of neuronal networks contributing to $A D$ cognitive deficits. Contrarily, $A \beta$ both at early and advanced $A D$ stages promotes neuronal network hyperexcitability however this is dominated by tau suppressive effect. However, this hypothesis cannot explain the tau spread from EC to other cortical areas as increased neuronal activity has been identified to promote propagation of tau. Nonetheless, there could be other mediators of tau spread besides neuronal network hyperexcitability. 
PS1-rTg4510 and APP/PS1-rTg21221 mice (Busche et al., 2019).

Neuropathological autopsy studies and more recently neuroimaging (PET scan) studies have shown plaques and NFTs deposition in AD brains differ both spatially and temporally from each other (Arnold et al., 1991; Braak and Braak, 1991, 1995, 1996; Schöll et al., 2016). In AD brains, the $\mathrm{A} \beta$ plaques first form in the neocortex and other cortical areas and then spread inward to deeper brain regions, whereas NFTs first form in the EC within the hippocampal formation and limbic areas, and from there they spread outward to the neocortex and other cortical areas (Arnold et al., 1991; Braak and Braak, 1991, 1995, 1996; Schöll et al., 2016). Neuronal activity was reported to enhance tau release and propagation (Pooler et al., 2013; Wu et al., 2016). Accumulating evidence supports the notion that the spread of tau from EC and limbic regions to other neocortical areas coincides with the appearance of cognitive impairment in AD (Wang et al., 2016; Bejanin et al., 2017; Pontecorvo et al., 2017; Jagust, 2018). Despite being a neuropathological hallmark of $A D, A \beta$ correlates weakly with neurodegeneration; rather, it is tau that is associated with brain atrophy and hypometabolism, which, in turn, are related to cognition (Nelson et al., 2012; Bejanin et al., 2017; Jagust, 2018). It thus remains possible that in human AD brains, $A \beta$-induced neuronal network hyperexcitability enhances propagation of tau from EC to $A \beta$ bearing neocortex which leads to emergence of cognitive deficit.

While several studies over the past two decades have demonstrated that the interaction between $\mathrm{A} \beta$ and tau leads to increased pathology (Götz et al., 2001; Lewis et al., 2001; Hurtado et al., 2010; Wang et al., 2016; Bennett et al., 2017; Pontecorvo et al., 2017; Jacobs et al., 2018), the physiological consequences of this interaction on neuronal network excitability in $A D$ is a matter of debate. As discussed before, there is strong experimental evidence for neuronal network hyperexcitability enhancing the effects of both $\mathrm{A} \beta$ and tau. In this context, how can we explain the neuronal activity suppressing effect of tau demonstrated in recent animal model studies? As discussed by Busche et al. (2019), studies have also showed a progressive reduction in whole-brain activity in $A D$ patients (Silverman et al., 2001; Alexander et al., 2002; Greicius et al., 2004) and regional cerebral blood flow (Bradley et al., 2002) as well as an EEG slowing (Jelic et al., 1997), all of which could be explained by a dominant neuronal activity suppressive effect of tau. Furthermore, the dominant role of tau along with the well-reported data that tau correlates with cognitive decline better than $\mathrm{A} \beta$ (Nelson et al., 2012) could also explain the failure of a number of $A \beta$-based $A D$ clinical trials. Nonetheless, as mentioned before, subclinical epileptiform activity and neuronal network hyperactivity have been well documented in human MCl/AD patients (Bakker et al., 2012, 2015; Vossel et al., 2013, 2016; Lam et al., 2017). As neuronal network hyperexcitability is more clearly linked to A $\beta$ (Palop and Mucke, 2010a,b, 2016; Zott et al., 2018), it is possible that epileptiform activity (as detected by EEG) is more prominent in $A D$ patients who have comparatively higher $\mathrm{A} \beta$ than tau levels, or are at early stages of the disease when $\mathrm{A} \beta$ is present in the cortex but tau is limited to EC and limbic areas. Also, in this context, it must be mentioned here that the predominant subconvulsive epileptiform activity phenotype observed in mice carrying hAPP mutation(s), could primarily be because of transgenic mutant APP, as suggested by some studies (Born et al., 2014; Kazim et al., 2017).

It is prudent to mention here that there a few other factors that need to be taken into consideration when evaluating the conflicting data from animal models regarding the roles of $A \beta$ and tau in neuronal network hyperexcitability in AD. First, it is important to consider at what level of the brain organization hierarchy (neuronal, synaptic, circuit, or network) the evaluation was performed. The single-neuron data may differ from a neuronal population circuit or network data. A good example of differential effects at different levels of organization is synaptic depression versus aberrant excitatory network activity induced by $\mathrm{A} \beta$ (Palop and Mucke, 2010a,b). In AD experimental models, pathogenic $A \beta$ reduces glutamatergic transmission and enhances LTD at the synaptic level (Hsia et al., 1999; Kamenetz et al., 2003; Hsieh et al., 2006; Palop et al., 2007) whereas at the network level, $A \beta$ causes dysrhythmias, including neuronal synchronization, epileptiform activity, and seizures (Palop et al., 2007; Busche et al., 2008). Both synaptic depression and aberrant network synchronization probably interfere with activity-dependent synaptic regulation, essential for learning and memory (Palop and Mucke, 2010a,b). Similarly, tau causes synaptic loss (Forner et al., 2017) and impairs LTP (Fá et al., 2016; Puzzo et al., 2017) at the synapse level which would lead to slowed neuronal activity, whereas at the network level both increase and decrease of network activity have been reported in tau mouse models of $A D$ (as discussed before in this review). Second, the extent and exact sites of tau phosphorylation may have to be taken into account to determine whether its overall effect opposes or contributes to the neuronal network hyperexcitability. A third important factor to consider when interpreting neuronal network hyperexcitability in AD studies is to take into account the role of other pathophysiological features of $A D$ such as neuronal loss, gliosis, and E/I imbalance in enhancing hyperexcitability (Miranda and Brucki, 2014; Busche and Konnerth, 2016; Zott et al., 2018; Vico Varela et al., 2019).

\section{Future Directions and Concluding Remarks}

Neuronal network hyperexcitability has been identified as an important component of $A D$ pathophysiology and potentially contributes to cognitive deficit in AD. Evidence for $A \beta$ promoting neuronal network hyperexcitability in $\mathrm{AD}$, demonstrated by both in vitro and in vivo models, strongly suggest network hyperexcitability role of $A \beta$. However, the role tau, either by itself or in combination with $A \beta$, on network excitability in $A D$ need to be more carefully elucidated. To this end, there has been a significant effort to create humanized animal models of tau and $A \beta$, which have become invaluable tools to recapitulate tau 
pathology in AD. Many recent studies use these models, where tau extracted from brains of $A D$ patients is injected into the brains of humanized tau mice. Such studies, combined with in vivo and in vitro electrophysiology, should provide insight into potential role of tau in network excitability. Furthermore, we discussed that an incongruity among studies addressing the role of tau in enhancement versus suppression of neuronal network excitability come from brain region and cell type specificity; studies for network enhancement use cortical neurons, while studies for network suppression come from hippocampal neurons (Ittner et al., 2010, 2016; Crimins et al., 2012, 2013; Kopeikina et al., 2013; Mondragón-Rodríguez et al., 2018b). It is entirely possible that the impact of tau on network excitability is brain region dependent; in vivo experiments with multiple tau injections at different brain regions, paired with in vivo calcium imaging and electrophysiology may provide insight into region-specific effect of tau on network excitability. This area of investigation may provide the necessary knowledge to develop more effective and refined strategies for prevention, diagnosis, and management of $A D$ and related dementias.

\section{References}

Adaikkan C, Middleton SJ, Marco A, Pao P-C, Mathys H, Kim DN-W, Gao F, Young JZ, Suk H-J, Boyden ES, McHugh TJ, Tsai LH (2019) Gamma entrainment binds higher-order brain regions and offers neuroprotection. Neuron 102:929-943.e8.

Ahnaou A, Moechars D, Raeymaekers L, Biermans R, Manyakov NV, Bottelbergs A, Wintmolders C, Van Kolen K, Van De Casteele T, Kemp JA, Drinkenburg WH (2017) Emergence of early alterations in network oscillations and functional connectivity in a tau seeding mouse model of Alzheimer's disease pathology. Sci Rep 7:14189.

Aimone JB, Wiles J, Gage FH (2006) Potential role for adult neurogenesis in the encoding of time in new memories. Nat Neurosci 9:723-727.

Aimone JB, Deng W, Gage FH (2010) Adult neurogenesis: integrating theories and separating functions. Trends Cogn Sci 14:325-337.

Alexander GE, Chen K, Pietrini P, Rapoport SI, Reiman EM (2002) Longitudinal PET evaluation of cerebral metabolic decline in dementia: a potential outcome measure in Alzheimer's disease treatment studies. Am J Psychiatry 159:738-745.

Alzheimer's Association (2019) 2019 Alzheimer's disease facts and figures. Alzheimers Dement 15:321-387.

Amatniek JC, Hauser WA, DelCastillo-Castaneda C, Jacobs DM, Marder K, Bell K, Albert M, Brandt J, Stern Y (2006) Incidence and predictors of seizures in patients with Alzheimer's disease. Epilepsia 47:867-872.

Andrews-Zwilling Y, Bien-Ly N, Xu Q, Li G, Bernardo A, Yoon SY, Zwilling D, Yan TX, Chen L, Huang Y (2010) Apolipoprotein E4 causes age- and tau-dependent impairment of GABAergic interneurons, leading to learning and memory deficits in mice. $J$ Neurosci 30:13707-13717.

Angulo SL, Orman R, Neymotin SA, Liu L, Buitrago L, Cepeda-Prado E, Stefanov D, Lytton WW, Stewart M, Small SA, Duff KE, Moreno $H$ (2017) tau and amyloid-related pathologies in the entorhinal cortex have divergent effects in the hippocampal circuit. Neurobiol Dis 108:261-276.

Arnold SE, Hyman BT, Flory J, Damasio AR, Van Hoesen GW (1991) The topographical and neuroanatomical distribution of neurofibrillary tangles and neuritic plaques in the cerebral cortex of patients with Alzheimer's disease. Cereb Cortex 1:103-116.

Bakker A, Krauss GL, Albert MS, Speck CL, Jones LR, Stark CE, Yassa MA, Bassett SS, Shelton AL, Gallagher M (2012) Reduction of hippocampal hyperactivity improves cognition in amnestic mild cognitive impairment. Neuron 74:467-474.

Bakker A, Albert MS, Krauss G, Speck CL, Gallagher M (2015) Response of the medial temporal lobe network in amnestic mild cognitive impairment to therapeutic intervention assessed by fMRI and memory task performance. Neuroimage Clin 7:688-698.

Ballard C, Gauthier S, Corbett A, Brayne C, Aarsland D, Jones E (2011) Alzheimer's disease. Lancet 377:1019-1031.

Banasr M, Chowdhury GMI, Terwilliger R, Newton SS, Duman RS, Behar KL, Sanacora G (2010) Glial pathology in an animal model of depression: reversal of stress-induced cellular, metabolic and behavioral deficits by the glutamate-modulating drug riluzole. Mol Psychiatry 15:501-511.

Battaglia FP, Benchenane K, Sirota A, Pennartz CM, Wiener SI (2011) The hippocampus: hub of brain network communication for memory. Trends Cogn Sci 15:310-318.

Bejanin A, Schonhaut DR, La Joie R, Kramer JH, Baker SL, Sosa N, Ayakta N, Cantwell A, Janabi M, Lauriola M, O'Neil JP, GornoTempini ML, Miller ZA, Rosen HJ, Miller BL, Jagust WJ, Rabinovici GD (2017) tau pathology and neurodegeneration contribute to cognitive impairment in Alzheimer's disease. Brain 140:32863300.

Bekris LM, Yu C-E, Bird TD, Tsuang DW (2010) Genetics of Alzheimer disease. J Geriatr Psychiatry Neurol 23:213-227.

Bennett RE, DeVos SL, Dujardin S, Corjuc B, Gor R, Gonzalez J, Roe AD, Frosch MP, Pitstick R, Carlson GA, Hyman BT (2017) Enhanced tau aggregation in the presence of amyloid beta. Am $\mathrm{J}$ Pathol 187:1601-1612.

Bero AW, Yan P, Roh JH, Cirrito JR, Stewart FR, Raichle ME, Lee JM, Holtzman DM (2011) Neuronal activity regulates the regional vulnerability to amyloid-beta deposition. Nat Neurosci 14:750756.

Berron D, Cardenas-Blanco A, Bittner D, Metzger CD, Spottke A, Heneka MT, Fliessbach K, Schneider A, Teipel SJ, Wagner M, Speck O, Jessen F, Düzel E (2019) Higher CSF tau levels are related to hippocampal hyperactivity and object mnemonic discrimination in older adults. J Neurosci 39:8788-8797.

Bezzina C, Verret L, Juan C, Remaud J, Halley H, Rampon C, Dahan $L$ (2015) Early onset of hypersynchronous network activity and expression of a marker of chronic seizures in the tg2576 mouse model of Alzheimer's disease. PLoS One 10:e0119910.

Billings LM, Oddo S, Green KN, McGaugh JL, LaFerla FM (2005) Intraneuronal Abeta causes the onset of early Alzheimer's disease-related cognitive deficits in transgenic mice. Neuron 45:675688.

Bookheimer SY, Strojwas MH, Cohen MS, Saunders AM, PericakVance MA, Mazziotta JC, Small GW (2000) Patterns of brain activation in people at risk for Alzheimer's disease. $\mathrm{N}$ Engl $\mathrm{J}$ Med 343:450-456.

Born HA (2015) Seizures in Alzheimer's disease. Neuroscience 286:251-263.

Born HA, Kim JY, Savjani RR, Das P, Dabaghian YA, Guo Q, Yoo JW, Schuler DR, Cirrito JR, Zheng H, Golde TE, Noebels JL, Jankowsky JL (2014) Genetic suppression of transgenic APP rescues hypersynchronous network activity in a mouse model of Alzeimer's disease. J Neurosci 34:3826-3840.

Bossers K, Wirz KTS, Meerhoff GF, Essing AHW, van Dongen JW, Houba P, Kruse CG, Verhaagen J, Swaab DF (2010) Concerted changes in transcripts in the prefrontal cortex precede neuropathology in Alzheimer's disease. Brain 133:3699-3723.

Boyatzis RE, Rochford K, Jack Al (2014) Antagonistic neural networks underlying differentiated leadership roles. Front Hum Neurosci 8:114.

Braak H, Braak E (1991) Neuropathological stageing of Alzheimer-related changes. Acta Neuropathol 82:239-259.

Braak H, Braak E (1995) Staging of Alzheimer's disease-related neurofibrillary changes. Neurobiol Aging 16:271-278; discussion 278284.

Braak H, Braak E (1996) Evolution of the neuropathology of Alzheimer's disease. Acta Neurol Scand Suppl 165:3-12. 
Bradley KM, O'Sullivan VT, Soper NDW, Nagy Z, King EM-F, Smith AD, Shepstone BJ (2002) Cerebral perfusion SPET correlated with Braak pathological stage in Alzheimer's disease. Brain 125:17721781.

Bragin A, Engel J, Wilson CL, Fried I, Mathern GW (1999) Hippocampal and entorhinal cortex high-frequency oscillations $(100-500 \mathrm{~Hz})$ in human epileptic brain and in kainic acid-treated rats with chronic seizures. Epilepsia 40:127-137.

Bragin A, Engel J, Staba RJ (2010) High-frequency oscillations in epileptic brain. Curr Opin Neurol 23:151-156.

Busche MA, Konnerth A (2016) Impairments of neural circuit function in Alzheimer's disease. Philos Trans R Soc Lond B Biol Sci 371:20150429.

Busche MA, Hyman BT (2020) Synergy between amyloid-beta and tau in Alzheimer's disease. Nat Neurosci 23:1183-1193.

Busche MA, Eichhoff G, Adelsberger H, Abramowski D, Wiederhold K-H, Haass C, Staufenbiel M, Konnerth A, Garaschuk O (2008) Clusters of hyperactive neurons near amyloid plaques in a mouse model of Alzheimer's disease. Science 321:1686-1689.

Busche MA, Chen X, Henning HA, Reichwald J, Staufenbiel M, Sakmann B, Konnerth A (2012) Critical role of soluble amyloidbeta for early hippocampal hyperactivity in a mouse model of Alzheimer's disease. Proc Natl Acad Sci USA 109:8740-8745.

Busche MA, Wegmann S, Dujardin S, Commins C, Schiantarelli J, Klickstein N, Kamath TV, Carlson GA, Nelken I, Hyman BT (2019) tau impairs neural circuits, dominating amyloid-beta effects, in Alzheimer models in vivo. Nat Neurosci 22:57-64.

Butovsky O, Jedrychowski MP, Moore CS, Cialic R, Lanser AJ, Gabriely G, Koeglsperger T, Dake B, Wu PM, Doykan CE, Fanek Z, Liu L, Chen Z, Rothstein JD, Ransohoff RM, Gygi SP, Antel JP, Weiner HL (2014) Identification of a unique TGF-beta-dependent molecular and functional signature in microglia. Nat Neurosci 17:131-143.

Buzsáki G, Draguhn A (2004) Neuronal oscillations in cortical networks. Science 304:1926-1929.

Buzsáki G, Horváth Z, Urioste R, Hetke J, Wise K (1992) High-frequency network oscillation in the hippocampus. Science 256:1025-1027.

Buzsáki G ,Anastassiou CA ,Koch C (2012) The origin of extracellular fields and currents-EEG, ECoG, LFP and spikes. Nat Rev Neurosci 13:407-420.

Buzsáki G, Logothetis N, Singer W (2013) Scaling brain size, keeping timing: evolutionary preservation of brain rhythms. Neuron 80:751-764.

Cabrejo L, Guyant-Maréchal L, Laquerrière A, Vercelletto $M$, De la Fournière $F$, Thomas-Antérion $C$, Verny $C$, Letournel $F$, Pasquier $F$, Vital A, Checler F, Frebourg T, Campion D, Hannequin D (2006) Phenotype associated with APP duplication in five families. Brain 129:2966-2976.

Campbell SL, Hablitz JJ, Olsen ML (2014) Functional changes in glutamate transporters and astrocyte biophysical properties in a rodent model of focal cortical dysplasia. Front Cell Neurosci 8:425.

Campion D, Brice A, Dumanchin C, Puel M, Baulac M, De La Sayette V, Hannequin D, Duyckaerts C, Michon A, Martin C, Moreau V, Penet C, Martinez M, Clerget-Darpoux F, Agid Y, Frebourg T (1996) A novel presenilin 1 mutation resulting in familial Alzheimer's disease with an onset age of 29 years. Neuroreport 7:1582-1584.

Campion D, Dumanchin C, Hannequin D, Dubois B, Belliard S, Puel M, Thomas-Anterion C, Michon A, Martin C, Charbonnier F, Raux G, Camuzat A, Penet C, Mesnage V, Martinez M, Clerget-Darpoux F, Brice A, Frebourg T (1999) Early-onset autosomal dominant Alzheimer disease: prevalence, genetic heterogeneity, and mutation spectrum. Am J Hum Genet 65:664-670.

Cayzac S, Mons N, Ginguay A, Allinquant B, Jeantet Y, Cho YH (2015) Altered hippocampal information coding and network synchrony in APP-PS1 mice. Neurobiol Aging 36:3200-3213.

Celone KA, Calhoun VD, Dickerson BC, Atri A, Chua EF, Miller SL, DePeau K, Rentz DM, Selkoe DJ, Blacker D, Albert MS, Sperling RA (2006) Alterations in memory networks in mild cognitive impairment and Alzheimer's disease: an independent component analysis. J Neurosci 26:10222-10231.

Chan J, Jones NC, Bush Al, O'Brien TJ, Kwan P (2015) A mouse model of Alzheimer's disease displays increased susceptibility to kindling and seizure-associated death. Epilepsia 56:e73-e77.

Chao HT, Chen H, Samaco RC, Xue M, Chahrour M, Yoo J, Neul JL, Gong S, Lu H-C, Heintz N, Ekker M, Rubenstein JLR, Noebels JL, Rosenmund C, Zoghbi HY (2010) Dysfunction in GABA signalling mediates autism-like stereotypies and Rett syndrome phenotypes. Nature 468:263-269.

Chin J, Scharfman HE (2013) Shared cognitive and behavioral impairments in epilepsy and Alzheimer's disease and potential underlying mechanisms. Epilepsy Behav 26:343-351.

Ciccone R, Franco C, Piccialli I, Boscia F, Casamassa A, de Rosa V, Cepparulo P, Cataldi M, Annunziato L, Pannaccione A (2019) Amyloid beta-induced upregulation of Nav1.6 underlies neuronal hyperactivity in Tg2576 Alzheimer's disease mouse model. Sci Rep 9:13592.

Cirrito JR, Kang J-E, Lee J, Stewart FR, Verges DK, Silverio LM, Bu G, Mennerick S, Holtzman DM (2008) Endocytosis is required for synaptic activity-dependent release of amyloid-beta in vivo. Neuron 58:42-51.

Clemens Z, Janszky J, Szucs A, Békésy M, Clemens B, Halász P (2003) Interictal epileptic spiking during sleep and wakefulness in mesial temporal lobe epilepsy: a comparative study of scalp and foramen ovale electrodes. Epilepsia 44:186-192.

Cloyd J, Hauser W, Towne A, Ramsay R, Mattson R, Gilliam F, Walczak T (2006) Epidemiological and medical aspects of epilepsy in the elderly. Epilepsy Res 68 [Suppl 1]:S39-S48.

Colonna M, Wang Y (2016) TREM2 variants: new keys to decipher Alzheimer disease pathogenesis. Nat Rev Neurosci 17:201-207.

Coppola G, Chinnathambi S, Lee JJ, Dombroski BA, Baker MC, Soto-Ortolaza Al, Lee SE, Klein E, Huang AY, Sears R, Lane JR, Karydas AM, Kenet RO, Biernat J, Wang LS, Cotman CW, Decarli CS, Levey Al, Ringman JM, Mendez MF, et al. (2012) Evidence for a role of the rare p.A152T variant in MAPT in increasing the risk for FTD-spectrum and Alzheimer's diseases. Hum Mol Genet 21:3500-3512.

Corbett BF, Leiser SC, Ling H-P, Nagy R, Breysse N, Zhang X, Hazra A, Brown JT, Randall AD, Wood A, Pangalos MN, Reinhart PH, Chin J (2013) Sodium channel cleavage is associated with aberrant neuronal activity and cognitive deficits in a mouse model of Alzheimer's disease. J Neurosci 33:7020-7026.

Cornutiu G (2015) The epidemiological scale of Alzheimer's disease. J Clin Med Res 7:657-666.

Crespo-Biel N, Canudas AM, Camins A, Pallàs M (2007) Kainate induces AKT, ERK and cdk5/GSK3beta pathway deregulation, phosphorylates tau protein in mouse hippocampus. Neurochem Int 50:435-442.

Crimins JL, Rocher AB, Peters A, Shultz P, Lewis J, Luebke JI (2011) Homeostatic responses by surviving cortical pyramidal cells in neurodegenerative tauopathy. Acta Neuropathol 122:551-564.

Crimins JL, Rocher AB, Luebke JI (2012) Electrophysiological changes precede morphological changes to frontal cortical pyramidal neurons in the rTg4510 mouse model of progressive tauopathy. Acta Neuropathol 124:777-795.

Crimins JL, Pooler A, Polydoro M, Luebke JI, Spires-Jones TL (2013) The intersection of amyloid beta and tau in glutamatergic synaptic dysfunction and collapse in Alzheimer's disease. Ageing Res Rev 12:757-763.

Csicsvari J, Hirase H, Czurkó A, Mamiya A, Buzsáki G (1999) Oscillatory coupling of hippocampal pyramidal cells and interneurons in the behaving Rat. J Neurosci 19:274-287.

Cuenda A, Rousseau S (2007) p38 MAP-kinases pathway regulation, function and role in human diseases. Biochim Biophys Acta 1773:1358-1375.

D’Amelio M, Cavallucci V, Middei S, Marchetti C, Pacioni S, Ferri A, Diamantini A, De Zio D, Carrara P, Battistini L, Moreno S, Bacci A, Ammassari-Teule M, Marie H, Cecconi F (2011) Caspase-3 
triggers early synaptic dysfunction in a mouse model of Alzheimer's disease. Nat Neurosci 14:69-76.

Danbolt NC, Storm-Mathisen J, Kanner BI (1992) An [Na+ + K+] coupled L-glutamate transporter purified from rat brain is located in glial cell processes. Neuroscience 51:295-310.

Dargaei Z, Bang JY, Mahadevan V, Khademullah CS, Bedard S, Parfitt GM, Kim JC, Woodin MA (2018) Restoring GABAergic inhibition rescues memory deficits in a Huntington's disease mouse model. Proc Natl Acad Sci USA 115:E1618-E1626.

Das M, Maeda S, Hu B, Yu GQ, Guo W, Lopez I, Yu X, Tai C, Wang X, Mucke $L$ (2018) Neuronal levels and sequence of tau modulate the power of brain rhythms. Neurobiol Dis 117:181-188.

Davis KE, Eacott MJ, Easton A, Gigg J (2013) Episodic-like memory is sensitive to both Alzheimer's-like pathological accumulation and normal ageing processes in mice. Behav Brain Res 254:73-82.

Davis KE, Fox S, Gigg J (2014) Increased hippocampal excitability in the 3xTgAD mouse model for Alzheimer's disease in vivo. PLoS One 9:e91203.

de Calignon A, Polydoro M, Suárez-Calvet M, William C, Adamowicz DH, Kopeikina KJ, Pitstick R, Sahara N, Ashe KH, Carlson GA, Spires-Jones TL, Hyman BT (2012) Propagation of tau pathology in a model of early Alzheimer's disease. Neuron 73:685-697.

Decker JM, Krüger L, Sydow A, Dennissen FJ, Siskova Z, Mandelkow E, Mandelkow E-M (2016) The tau/A152T mutation, a risk factor for frontotemporal-spectrum disorders, leads to NR2B receptor-mediated excitotoxicity. EMBO Rep 17:552-569.

Del Vecchio RA, Gold LH, Novick SJ, Wong G, Hyde LA (2004) Increased seizure threshold and severity in young transgenic CRND8 mice. Neurosci Lett 367:164-167.

Demars M, Hu Y-S, Gadadhar A, Lazarov O (2010) Impaired neurogenesis is an early event in the etiology of familial Alzheimer's disease in transgenic mice. J Neurosci Res 88:2103-2117.

Devi L, Ohno M (2013) Effects of levetiracetam, an antiepileptic drug, on memory impairments associated with aging and Alzheimer's disease in mice. Neurobiol Learn Mem 102:7-11.

DeVos SL, Goncharoff DK, Chen G, Kebodeaux CS, Yamada K, Stewart FR, Schuler DR, Maloney SE, Wozniak DF, Rigo F, Bennett CF, Cirrito JR, Holtzman DM, Miller TM (2013) Antisense reduction of tau in adult mice protects against seizures. J Neurosci 33:12887-12897.

DeVos SL, Miller RL, Schoch KM, Holmes BB, Kebodeaux CS, Wegener AJ, Chen G, Shen T, Tran H, Nichols B, Zanardi TA, Kordasiewicz HB, Swayze EE, Bennett CF, Diamond MI, Miller TM (2017) tau reduction prevents neuronal loss and reverses pathological tau deposition and seeding in mice with tauopathy. Sci Transl Med 9:eaag0481.

Dickerson BC, Salat DH, Bates JF, Atiya M, Killiany RJ, Greve DN, Dale AM, Stern CE, Blacker D, Albert MS, Sperling RA (2004) Medial temporal lobe function and structure in mild cognitive impairment. Ann Neurol 56:27-35.

Dickerson BC, Salat DH, Greve DN, Chua EF, Rand-Giovannetti E, Rentz DM, Bertram L, Mullin K, Tanzi RE, Blacker D, Albert MS, Sperling RA (2005) Increased hippocampal activation in mild cognitive impairment compared to normal aging and AD. Neurology 65:404-411.

Duffy AM, Morales-Corraliza J, Bermudez-Hernandez KM, Schaner MJ, Magagna-Poveda A, Mathews PM, Scharfman HE (2015) Entorhinal cortical defects in Tg2576 mice are present as early as 2-4 months of age. Neurobiol Aging 36:134-148.

Edwards-Lee T, Ringman JM, Chung J, Werner J, Morgan A, St George Hyslop P, Thompson P, Dutton R, Mlikotic A, Rogaeva E, Hardy $J$ (2005) An African American family with early-onset Alzheimer disease and an APP (T714I) mutation. Neurology 64:377-379.

Elder GA, Gama Sosa MA, De Gasperi R (2010) Transgenic mouse models of Alzheimer's disease. Mt Sinai J Med 77:69-81.

Engels MM, Hillebrand A, van der Flier WM, Stam CJ, Scheltens P, van Straaten EC (2016) Slowing of hippocampal activity correlates with cognitive decline in early onset Alzheimer's disease. An MEG study with virtual electrodes. Front Hum Neurosci 10:238
Ezquerra M, Lleó A, Castellví M, Queralt R, Santacruz P, Pastor P, Molinuevo JL, Blesa R, Oliva R (2003) A novel mutation in the PSEN2 gene (T430M) associated with variable expression in a family with early-onset Alzheimer disease. Arch Neurol 60:11491151.

Fá M, Puzzo D, Piacentini R, Staniszewski A, Zhang H, Baltrons MA, Li Puma DD, Chatterjee I, Li J, Saeed F, Berman HL, Ripoli C, Gulisano W, Gonzalez J, Tian H, Costa JA, Lopez P, Davidowitz E, Yu WH, Haroutunian V, et al. (2016) Extracellular tau oligomers produce an immediate impairment of LTP and memory. Sci Rep 6:19393.

Feijoo C, Campbell DG, Jakes R, Goedert M, Cuenda A (2005) Evidence that phosphorylation of the microtubule-associated protein tau by SAPK4/p38delta at Thr50 promotes microtubule assembly. J Cell Sci 118:397-408.

Filippini N, Maclntosh BJ, Hough MG, Goodwin GM, Frisoni GB, Smith SM, Matthews PM, Beckmann CF, Mackay CE (2009) Distinct patterns of brain activity in young carriers of the APOE-epsilon4 allele. Proc Natl Acad Sci USA 106:7209-7214.

Fontana R, Agostini M, Murana E, Mahmud M, Scremin E, Rubega M, Sparacino G, Vassanelli S, Fasolato C (2017) Early hippocampal hyperexcitability in PS2APP mice: role of mutant PS2 and APP. Neurobiol Aging 50:64-76.

Forner S, Baglietto-Vargas D, Martini AC, Trujillo-Estrada L, LaFerla FM (2017) Synaptic impairment in Alzheimer's disease: a dysregulated symphony. Trends Neurosci 40:347-357.

Foster NL, Wilhelmsen K, Sima AA, Jones MZ, D'Amato CJ, Gilman $S$ (1997) Frontotemporal dementia and parkinsonism linked to chromosome 17: a consensus conference. Conference participants. Ann Neurol 41:706-715.

Frazzini V, Guarnieri S, Bomba M, Navarra R, Morabito C, Mariggiò MA, Sensi SL (2016) Altered Kv2.1 functioning promotes increased excitability in hippocampal neurons of an Alzheimer's disease mouse model. Cell Death Dis 7:e2100.

Friedman D, Honig LS, Scarmeas N (2012) Seizures and epilepsy in Alzheimer's disease. CNS Neurosci Ther 18:285-294.

Fries $\mathrm{P}$ (2015) Rhythms for cognition: communication through coherence. Neuron 88:220-235.

Fu CH, lascone DM, Petrof I, Hazra A, Zhang X, Pyfer MS, Tosi U, Corbett BF, Cai J, Lee J, Park J, lacovitti L, Scharfman HE, Enikolopov G, Chin J (2019) Early seizure activity accelerates depletion of hippocampal neural stem cells and impairs spatial discrimination in an Alzheimer's disease model. Cell Rep 27:37413751.e4.

Fu Y, Tucciarone JM, Espinosa JS, Sheng N, Darcy DP, Nicoll RA, Huang ZJ, Stryker MP (2014) A cortical circuit for gain control by behavioral state. Cell 156:1139-1152.

García-Cabrero AM, Guerrero-López R, Giráldez BG, Llorens-Martín M, Avila J, Serratosa JM, Sánchez MP (2013) Hyperexcitability and epileptic seizures in a model of frontotemporal dementia. Neurobiol Dis 58:200-208.

Gheyara AL, Ponnusamy R, Djukic B, Craft RJ, Ho K, Guo W, Finucane MM, Sanchez PE, Mucke L (2014) tau reduction prevents disease in a mouse model of Dravet syndrome. Ann Neurol 76:443-456.

Glenner GG, Wong CW (1984) Alzheimer's disease: initial report of the purification and characterization of a novel cerebrovascular amyloid protein. Biochem Biophys Res Commun 120:885-890.

Goedert M, Hasegawa M, Jakes R, Lawler S, Cuenda A, Cohen P (1997) Phosphorylation of microtubule-associated protein tau by stress-activated protein kinases. FEBS Lett 409:57-62.

Goedert M, Ghetti B, Spillantini MG (2012) Frontotemporal dementia: implications for understanding Alzheimer disease. Cold Spring Harb Perspect Med 2:a006254.

Götz J, Chen F, van Dorpe J, Nitsch RM (2001) Formation of neurofibrillary tangles in P301I tau transgenic mice induced by Abeta 42 fibrils. Science 293:1491-1495.

Govindarajan A, Kelleher RJ, Tonegawa S (2006) A clustered plasticity model of long-term memory engrams. Nat Rev Neurosci 7:575583. 
Greicius MD, Srivastava G, Reiss AL, Menon V (2004) Default-mode network activity distinguishes Alzheimer's disease from healthy aging: evidence from functional MRI. Proc Natl Acad Sci USA 101:4637-4642.

Grundke-lqbal I, Iqbal K, Quinlan M, Tung YC, Zaidi MS, Wisniewski HM (1986a) Microtubule-associated protein tau. A component of Alzheimer paired helical filaments. J Biol Chem 261:6084-6089.

Grundke-lqbal I, lqbal K, Tung YC, Quinlan M, Wisniewski HM, Binder LI (1986b) Abnormal phosphorylation of the microtubuleassociated protein tau (tau) in Alzheimer cytoskeletal pathology. Proc Natl Acad Sci USA 83:4913-4917.

Guerreiro R, Hardy J (2014) Genetics of Alzheimer's disease. Neurotherapeutics 11:732-737.

Guillon J, Attal Y, Colliot O, La Corte V, Dubois B, Schwartz D, Chavez M, De Vico Fallani F (2017) Loss of brain inter-frequency hubs in Alzheimer's disease. Sci Rep 7:10879.

Gurevicius K, Lipponen A, Tanila H (2013) Increased cortical and thalamic excitability in freely moving APPswe/PS1dE9 mice modeling epileptic activity associated with Alzheimer's disease. Cereb Cortex 23:1148-1158.

Gyure KA, Durham R, Stewart WF, Smialek JE, Troncoso JC (2001) Intraneuronal abeta-amyloid precedes development of amyloid plaques in Down syndrome. Arch Pathol Lab Med 125:489-492.

Hall AM, Roberson ED (2012) Mouse models of Alzheimer's disease. Brain Res Bull 88:3-12.

Hall AM, Throesch BT, Buckingham SC, Markwardt SJ, Peng Y, Wang Q, Hoffman DA, Roberson ED (2015) tau-dependent kv4.2 depletion and dendritic hyperexcitability in a mouse model of Alzheimer's disease. J Neurosci 35:6221-6230.

Hanger DP, Byers HL, Wray S, Leung K-Y, Saxton MJ, Seereeram A, Reynolds $\mathrm{CH}$, Ward MA, Anderton BH (2007) Novel phosphorylation sites in tau from Alzheimer brain support a role for casein kinase 1 in disease pathogenesis. J Biol Chem 282:23645-23654.

Hatch RJ, Wei Y, Xia D, Götz J (2017) Hyperphosphorylated tau causes reduced hippocampal CA1 excitability by relocating the axon initial segment. Acta Neuropathol 133:717-730.

Haugeto O, Ullensvang K, Levy LM, Chaudhry FA, Honoré T, Nielsen M, Lehre KP, Danbolt NC (1996) Brain glutamate transporter proteins form homomultimers. J Biol Chem 271:27715-27722.

Hauser WA, Morris ML, Heston LL, Anderson VE (1986) Seizures and myoclonus in patients with Alzheimer's disease. Neurology 36:1226-1230.

Helmstaedter C, Elger CE (2009) Chronic temporal lobe epilepsy: a neurodevelopmental or progressively dementing disease? Brain 132:2822-2830.

Hill E, Karikari TK, Moffat KG, Richardson MJE, Wall MJ (2019) Introduction of tau oligomers into cortical neurons alters action potential dynamics and disrupts synaptic transmission and plasticity. eNeuro 6:ENEURO.0166-19.2019.

Holth JK, Bomben VC, Reed JG, Inoue T, Younkin L, Younkin SG, Pautler RG, Botas J, Noebels JL (2013) tau loss attenuates neuronal network hyperexcitability in mouse and Drosophila genetic models of epilepsy. J Neurosci 33:1651-1659.

Hoover BR, Reed MN, Su J, Penrod RD, Kotilinek LA, Grant MK, Pitstick R, Carlson GA, Lanier LM, Yuan LL, Ashe KH, Liao D (2010) tau mislocalization to dendritic spines mediates synaptic dysfunction independently of neurodegeneration. Neuron 68:1067-1081.

Horváth A, Szücs A, Barcs G, Noebels JL, Kamondi A (2016) Epileptic seizures in Alzheimer disease: a review. Alzheimer Dis Assoc Disord 30:186-192.

Houlden H, Crook R, Dolan RJ, McLaughlin J, Revesz T, Hardy J (2001) A novel presenilin mutation (M233V) causing very early onset Alzheimer's disease with Lewy bodies. Neurosci Lett 313:93-95.

Hsia AY, Masliah E, McConlogue L, Yu GQ, Tatsuno G, Hu K, Kholodenko D, Malenka RC, Nicoll RA, Mucke L (1999) Plaque-independent disruption of neural circuits in Alzheimer's disease mouse models. Proc Natl Acad Sci USA 96:3228-3233.
Hsiao K, Chapman P, Nilsen S, Eckman C, Harigaya Y, Younkin S, Yang F, Cole G (1996) Correlative memory deficits, Abeta elevation, and amyloid plaques in transgenic mice. Science 274:99102.

Hsieh H, Boehm J, Sato C, Iwatsubo T, Tomita T, Sisodia S, Malinow R (2006) AMPAR removal underlies Abeta-induced synaptic depression and dendritic spine loss. Neuron 52:831-843.

Huijbers W, Schultz AP, Papp KV, LaPoint MR, Hanseeuw B, Chhatwal JP, Hedden T, Johnson KA, Sperling RA (2019) tau accumulation in clinically normal older adults is associated with hippocampal hyperactivity. J Neurosci 39:548-556.

Hunsberger HC, Weitzner DS, Rudy CC, Hickman JE, Libell EM, Speer RR, Gerhardt GA, Reed MN (2015) Riluzole rescues glutamate alterations, cognitive deficits, and tau pathology associated with P301L tau expression. J Neurochem 135:381-394.

Hunsberger HC, Hickman JE, Reed MN (2016) Riluzole rescues alterations in rapid glutamate transients in the hippocampus of rTg4510 mice. Metab Brain Dis 31:711-715.

Hunt RF, Girskis KM, Rubenstein JL, Alvarez-Buylla A, Baraban SC (2013) GABA progenitors grafted into the adult epileptic brain control seizures and abnormal behavior. Nat Neurosci 16:692-697.

Hunter JM, Cirrito JR, Restivo JL, Kinley RD, Sullivan PM, Holtzman DM, Koger D, Delong C, Lin S, Zhao L, Liu F, Bales K, Paul SM (2012) Emergence of a seizure phenotype in aged apolipoprotein epsilon 4 targeted replacement mice. Brain Res 1467:120-132.

Hurtado DE, Molina-Porcel L, Iba M, Aboagye AK, Paul SM, Trojanowski JQ, Lee VM-Y (2010) A $\beta$ accelerates the spatiotemporal progression of tau pathology and augments tau amyloidosis in an Alzheimer mouse model. Am J Pathol 177:1977-1988.

laccarino HF, Singer AC, Martorell AJ, Rudenko A, Gao F, Gillingham TZ, Mathys H, Seo J, Kritskiy O, Abdurrob F, Adaikkan C, Canter RG, Rueda R, Brown EN, Boyden ES, Tsai L-H (2016) Gamma frequency entrainment attenuates amyloid load and modifies microglia. Nature 540:230-235.

lqbal K, Liu F, Gong CX (2016) tau and neurodegenerative disease: the story so far. Nat Rev Neurol 12:15-27.

Ittner LM, Götz J (2011) Amyloid-beta and tau-a toxic pas de deux in Alzheimer's disease. Nat Rev Neurosci 12:65-72.

Ittner LM, Ke YD, Delerue F, Bi M, Gladbach A, van Eersel J, Wölfing H, Chieng BC, Christie MJ, Napier IA, Eckert A, Staufenbiel M, Hardeman E, Götz J (2010) Dendritic function of tau mediates amyloid-beta toxicity in Alzheimer's disease mouse models. Cell 142:387-397.

Ittner AA, Gladbach A, Bertz J, Suh LS, Ittner LM (2014) p38 MAP kinase-mediated NMDA receptor-dependent suppression of hippocampal hypersynchronicity in a mouse model of Alzheimer's disease. Acta Neuropathol Commun 2:149.

Ittner A, Chua SW, Bertz J, Volkerling A, van der Hoven J, Gladbach A, Przybyla M, Bi M, van Hummel A, Stevens $C H$, Ippati S, Suh LS, Macmillan A, Sutherland G, Kril JJ, Silva APG, Mackay JP, Poljak A, Delerue F, Ke YD, et al. (2016) Site-specific phosphorylation of tau inhibits amyloid-beta toxicity in Alzheimer's mice. Science 354:904-908.

Jacobs HIL, Hedden T, Schultz AP, Sepulcre J, Perea RD, Amariglio RE, Papp KV, Rentz DM, Sperling RA, Johnson KA (2018) Structural tract alterations predict downstream tau accumulation in amyloid-positive older individuals. Nat Neurosci 21:424-431.

Jacobsen JS, Wu C-C, Redwine JM, Comery TA, Arias R, Bowlby M, Martone R, Morrison JH, Pangalos MN, Reinhart PH, Bloom FE (2006) Early-onset behavioral and synaptic deficits in a mouse model of Alzheimer's disease. Proc Natl Acad Sci USA 103:51615166.

Jagust W (2018) Imaging the evolution and pathophysiology of Alzheimer disease. Nat Rev Neurosci 19:687-700.

Janssen JC, Beck JA, Campbell TA, Dickinson A, Fox NC, Harvey RJ, Houlden H, Rossor MN, Collinge J (2003) Early onset familial Alzheimer's disease: mutation frequency in 31 families. Neurology 60:235-239. 
Jayadev S, Leverenz JB, Steinbart E, Stahl J, Klunk W, Yu CE, Bird TD (2010) Alzheimer's disease phenotypes and genotypes associated with mutations in presenilin 2. Brain 133:1143-1154.

Jelic V, Julin P, Shigeta M, Nordberg A, Lannfelt L, Winblad B, Wahlund LO (1997) Apolipoprotein E epsilon4 allele decreases functional connectivity in Alzheimer's disease as measured by EEG coherence. J Neurol Neurosurg Psychiatry 63:59-65.

Jolas T, Zhang X-S, Zhang Q, Wong G, Del Vecchio R, Gold L, Priestley $T$ (2002) Long-term potentiation is increased in the CA1 area of the hippocampus of APP(swe/ind) CRND8 mice. Neurobiol Dis 11:394-409.

Jones EA, Gillespie AK, Yoon SY, Frank LM, Huang Y (2019) Early hippocampal sharp-wave ripple deficits predict later learning and memory impairments in an Alzheimer's disease mouse model. Cell Rep 29:2123-2133.e4.

Jun H, Bramian A, Soma S, Saito T, Saido TC, Igarashi KM (2020) Disrupted place cell remapping and impaired grid cells in a knockin model of Alzheimer's disease. Neuron 107:1095-1112.e6.

Kam K, Duffy ÁM, Moretto J, LaFrancois JJ, Scharfman HE (2016) Interictal spikes during sleep are an early defect in the Tg2576 mouse model of beta-amyloid neuropathology. Sci Rep 6:20119.

Kamenetz F, Tomita T, Hsieh H, Seabrook G, Borchelt D, Iwatsubo T, Sisodia S, Malinow R (2003) APP processing and synaptic function. Neuron 37:925-937.

Kazim SF, Chuang SC, Zhao W, Wong RK, Bianchi R, Iqbal K (2017) Early-onset network hyperexcitability in presymptomatic Alzheimer's disease transgenic mice is suppressed by passive immunization with anti-human APP/Abeta antibody and by mGluR5 blockade. Front Aging Neurosci 9:71.

Kennedy AM, Newman S, McCaddon A, Ball J, Roques P, Mullan M, Hardy J, Chartier-Harlin M-C, Frackowiak RSJ, Warrington EK, Rossor MN (1993) Familial Alzheimer's disease. A pedigree with a mis-sense mutation in the amyloid precursor protein gene (amyloid precursor protein 717 valine->glycine). Brain 116:309-324.

Keren-Shaul H, Spinrad A, Weiner A, Matcovitch-Natan O, DvirSzternfeld R, Ulland TK, David E, Baruch K, Lara-Astaiso D, Toth B, Itzkovitz S, Colonna M, Schwartz M, Amit I (2017) A unique microglia type associated with restricting development of Alzheimer's disease. Cell 169:1276-1290.e1217.

Kim JH, Anwyl R, Suh Y-H, Djamgoz MBA, Rowan MJ (2001) Usedependent effects of amyloidogenic fragments of (beta)-amyloid precursor protein on synaptic plasticity in rat hippocampus in vivo. J Neurosci 21:1327-1333.

Klausberger T, Somogyi P (2008) Neuronal diversity and temporal dynamics: the unity of hippocampal circuit operations. Science 321:53-57.

Koenig T, Prichep L, Dierks T, Hubl D, Wahlund LO, John ER, Jelic V (2005) Decreased EEG synchronization in Alzheimer's disease and mild cognitive impairment. Neurobiol Aging 26:165-171.

Koh MT, Haberman RP, Foti S, McCown TJ, Gallagher M (2010) Treatment strategies targeting excess hippocampal activity benefit aged rats with cognitive impairment. Neuropsychopharmacology 35:1016-1025

Kopeikina KJ, Polydoro M, Tai HC, Yaeger E, Carlson GA, Pitstick R, Hyman BT, Spires-Jones TL (2013) Synaptic alterations in the rTg4510 mouse model of tauopathy. J Comp Neurol 521:13341353.

Kunz L, Schröder TN, Lee H, Montag C, Lachmann B, Sariyska R, Reuter M, Stirnberg R, Stöcker T, Messing-Floeter PC, Fell J, Doeller CF, Axmacher N (2015) Reduced grid-cell-like representations in adults at genetic risk for Alzheimer's disease. Science 350:430-433.

Lai F, Williams RS (1989) A prospective study of Alzheimer disease in Down syndrome. Arch Neurol 46:849-853.

Lalonde R, Dumont M, Staufenbiel M, Strazielle C (2005) Neurobehavioral characterization of APP23 transgenic mice with the SHIRPA primary screen. Behav Brain Res 157:91-98.

Lam AD, Deck G, Goldman A, Eskandar EN, Noebels J, Cole AJ (2017) Silent hippocampal seizures and spikes identified by foramen ovale electrodes in Alzheimer's disease. Nat Med 23:678680.

Lapray D, Lasztoczi B, Lagler M, Viney TJ, Katona L, Valenti O, Hartwich K, Borhegyi Z, Somogyi P, Klausberger T (2012) Behavior-dependent specialization of identified hippocampal interneurons. Nat Neurosci 15:1265-1271.

Larkum ME, Nevian T (2008) Synaptic clustering by dendritic signalling mechanisms. Curr Opin Neurobiol 18:321-331.

Larner AJ, Doran M (2006) Clinical phenotypic heterogeneity of Alzheimer's disease associated with mutations of the presenilin-1 gene. J Neurol 253:139-158.

Leonard AS, McNamara JO (2007) Does epileptiform activity contribute to cognitive impairment in Alzheimer's disease? Neuron 55:677-678.

Lewis J, Dickson DW, Lin WL, Chisholm L, Corral A, Jones G, Yen SH, Sahara N, Skipper L, Yager D, Eckman C, Hardy J, Hutton M, McGowan E (2001) Enhanced neurofibrillary degeneration in transgenic mice expressing mutant tau and APP. Science 293:14871491.

Li B, Yamamori H, Tatebayashi Y, Shafit-Zagardo B, Tanimukai H, Chen S, Iqbal K, Grundke-lqbal I (2008) Failure of neuronal maturation in Alzheimer disease dentate gyrus. J Neuropathol Exp Neurol 67:78-84.

Li G, Bien-Ly N, Andrews-Zwilling Y, Xu Q, Bernardo A, Ring K, Halabisky B, Deng C, Mahley RW, Huang Y (2009) GABAergic interneuron dysfunction impairs hippocampal neurogenesis in adult apolipoprotein E4 knockin mice. Cell Stem Cell 5:634-645.

Li S, Hong S, Shepardson NE, Walsh DM, Shankar GM, Selkoe D (2009) Soluble oligomers of amyloid Beta protein facilitate hippocampal long-term depression by disrupting neuronal glutamate uptake. Neuron 62:788-801.

Li Z, Hall AM, Kelinske M, Roberson ED (2014) Seizure resistance without parkinsonism in aged mice after tau reduction. Neurobiol Aging 35:2617-2624.

Lindquist SG, Nielsen JE, Stokholm J, Schwartz M, Batbayli M, Ballegaard M, Erdal J, Krabbe K, Waldemar G (2008) Atypical early-onset Alzheimer's disease caused by the Iranian APP mutation. J Neurol Sci 268:124-130.

Lithner CU, Hedberg MM, Nordberg A (2011) Transgenic mice as a model for Alzheimer's disease. Curr Alzheimer Res 8:818-831.

Liu L, Drouet V, Wu JW, Witter MP, Small SA, Clelland C, Duff K (2012) Trans-synaptic spread of tau pathology in vivo. PLoS One 7:e31302.

Liu S, Shen Y, Shultz SR, Nguyen A, Hovens C, Adlard PA, Bush Al, Chan J, Kwan P, O'Brien TJ, Jones NC (2017) Accelerated kindling epileptogenesis in Tg4510 tau transgenic mice, but not in tau knockout mice. Epilepsia 58:e136-e141.

Lundqvist M, Rose J, Herman P, Brincat SL, Buschman TJ, Miller EK (2016) Gamma and beta bursts underlie working memory. Neuron 90:152-164.

Maeda S, Djukic B, Taneja P, Yu GQ, Lo I, Davis A, Craft R, Guo W, Wang X, Kim D, Ponnusamy R, Gill TM, Masliah E, Mucke L (2016) Expression of A152T human tau causes age-dependent neuronal dysfunction and loss in transgenic mice. EMBO Rep 17:530-551.

Marcon G, Giaccone G, Cupidi C, Balestrieri M, Beltrami CA, Finato N, Bergonzi P, Sorbi S, Bugiani O, Tagliavini F (2004) Neuropathological and clinical phenotype of an Italian Alzheimer family with M239V mutation of presenilin 2 gene. J Neuropathol Exp Neurol 63:199-209.

Marin O (2012) Interneuron dysfunction in psychiatric disorders. Nat Rev Neurosci 13:107-120.

Marinković P, Blumenstock S, Goltstein PM, Korzhova V, Peters F, Knebl A, Herms J (2019) In vivo imaging reveals reduced activity of neuronal circuits in a mouse tauopathy model. Brain 142:10511062.

Martinez-Losa M, Tracy TE, Ma K, Verret L, Clemente-Perez A, Khan AS, Cobos I, Ho K, Gan L, Mucke L, Alvarez-Dolado M, Palop JJ (2018) Nav1.1-overexpressing interneuron transplants restore brain rhythms and cognition in a mouse model of Alzheimer's disease. Neuron 98:75-89 e75. 
Martorell AJ, Paulson AL, Suk HJ, Abdurrob F, Drummond GT, Guan W, Young JZ, Kim DNW, Kritskiy O, Barker SJ, Mangena V, Prince SM, Brown EN, Chung K, Boyden ES, Singer AC, Tsai L-H (2019) Multi-sensory gamma stimulation ameliorates Alzheimer's-associated pathology and improves cognition. Cell 177:256-271.e22.

McAreavey MJ, Ballinger BR, Fenton GW (1992) Epileptic seizures in elderly patients with dementia. Epilepsia 33:657-660.

McVicker RW, Shanks OEP, McClelland RJ (1994) Prevalence and associated features of epilepsy in adults with Down's syndrome. Br J Psychiatry 164:528-532.

Menkes-Caspi N, Yamin HG, Kellner V, Spires-Jones TL, Cohen D, Stern EA (2015) Pathological tau disrupts ongoing network activity. Neuron 85:959-966.

Minkeviciene R, Rheims S, Dobszay MB, Zilberter M, Hartikainen J, Fülöp L, Penke B, Zilberter Y, Harkany T, Pitkänen A, Tanila H (2009) Amyloid beta-induced neuronal hyperexcitability triggers progressive epilepsy. J Neurosci 29:3453-3462.

Miranda DDC, Brucki SMD (2014) Epilepsy in patients with Alzheimer's disease: a systematic review. Dement Neuropsychol 8:66-71.

Mondragón-Rodríguez S, Trillaud-Doppia E, Dudilot A, Bourgeois C, Lauzon M, Leclerc N, Boehm J (2012) Interaction of endogenous tau protein with synaptic proteins is regulated by $\mathrm{N}$-methyl-D-aspartate receptor-dependent tau phosphorylation. J Biol Chem 287:32040-32053.

Mondragón-Rodríguez S, Gu N, Manseau F, Williams S (2018a) Alzheimer's transgenic model is characterized by very early brain network alterations and beta-CTF fragment accumulation: reversal by beta-secretase inhibition. Front Cell Neurosci 12:121.

Mondragón-Rodríguez S, Salas-Gallardo A, González-Pereyra P, Macías M, Ordaz B, Peña-Ortega F, Aguilar-Vázquez A, OrtaSalazar E, Díaz-Cintra S, Perry G, Williams S (2018b) Phosphorylation of tau protein correlates with changes in hippocampal theta oscillations and reduces hippocampal excitability in Alzheimer's model. J Biol Chem 293:8462-8472.

Morelli L, Prat MI, Levy E, Mangone CA, Castaño EM (1998) Presenilin 1 Met146Leu variant due to an $A->T$ transversion in an early-onset familial Alzheimer's disease pedigree from Argentina. Clin Genet 53:469-473.

Morishima-Kawashima M, Hasegawa M, Takio K, Suzuki M, Yoshida H, Titani K, Ihara Y (1995) Proline-directed and non-proline-directed phosphorylation of PHF-tau. J Biol Chem 270:823-829.

Mu Y, Gage FH (2011) Adult hippocampal neurogenesis and its role in Alzheimer's disease. Mol Neurodegener 6:85.

Mucke L, Selkoe DJ (2012) Neurotoxicity of amyloid beta-protein: synaptic and network dysfunction. Cold Spring Harb Perspect Med 2:a006338.

Mucke L, Masliah E, Yu GQ, Mallory M, Rockenstein EM, Tatsuno G, Hu K, Kholodenko D, Johnson-Wood K, McConlogue L (2000) High-level neuronal expression of abeta 1-42 in wild-type human amyloid protein precursor transgenic mice: synaptotoxicity without plaque formation. J Neurosci 20:4050-4058.

Müller-Thomsen L, Borgmann D, Morcinek K, Schröder S, Dengler B, Moser N, Neumaier F, Schneider T, Schröder H, Huggenberger $S$ (2020) Consequences of hyperphosphorylated tau on the morphology and excitability of hippocampal neurons in aged tau transgenic mice. Neurobiol Aging 93:109-123.

Musaeus CS, Shafi MM, Santarnecchi E, Herman ST, Press DZ (2017) Levetiracetam alters oscillatory connectivity in Alzheimer's disease. J Alzheimers Dis 58:1065-1076.

Nakamura A, Cuesta P, Kato T, Arahata Y, Iwata K, Yamagishi M, Kuratsubo I, Kato K, Bundo M, Diers K, Fernández A, Maestú F, Ito $\mathrm{K}$ (2017) Early functional network alterations in asymptomatic elders at risk for Alzheimer's disease. Sci Rep 7:6517.

Nelson PT, Alafuzoff I, Bigio EH, Bouras C, Braak H, Cairns NJ, Castellani RJ, Crain BJ, Davies P, Del Tredici K, Duyckaerts C, Frosch MP, Haroutunian V, Hof PR, Hulette CM, Hyman BT, Iwatsubo T, Jellinger KA, Jicha GA, Kövari E, et al. (2012) Correlation of Alzheimer disease neuropathologic changes with cognitive status: a review of the literature. $J$ Neuropathol Exp Neurol 71:362-381.

Neves G, Cooke SF, Bliss TVP (2008) Synaptic plasticity, memory and the hippocampus: a neural network approach to causality. Nat Rev Neurosci 9:65-75.

Nilsson D, Fohlen M, Jalin C, Dorfmuller G, Bulteau C, Delalande O (2009) Foramen ovale electrodes in the preoperative evaluation of temporal lobe epilepsy in children. Epilepsia 50:2085-2096.

Noebels J (2011) A perfect storm: converging paths of epilepsy and Alzheimer's dementia intersect in the hippocampal formation. Epilepsia 52 [Suppl 1]:39-46.

Nygaard HB, Kaufman AC, Sekine-Konno T, Huh LL, Going H, Feldman SJ, Kostylev MA, Strittmatter SM (2015) Brivaracetam, but not ethosuximide, reverses memory impairments in an Alzheimer's disease mouse model. Alzheimers Res Ther 7:25.

Oddo S, Caccamo A, Kitazawa M, Tseng BP, LaFerla FM (2003a) Amyloid deposition precedes tangle formation in a triple transgenic model of Alzheimer's disease. Neurobiol Aging 24:1063-1070.

Oddo S, Caccamo A, Shepherd JD, Murphy MP, Golde TE, Kayed R, Metherate R, Mattson MP, Akbari Y, LaFerla FM (2003b) Tripletransgenic model of Alzheimer's disease with plaques and tangles: intracellular Abeta and synaptic dysfunction. Neuron 39:409-421.

Okamoto M, Gray JD, Larson CS, Kazim SF, Soya H, McEwen BS, Pereira AC (2018) Riluzole reduces amyloid beta pathology, improves memory, and restores gene expression changes in a transgenic mouse model of early-onset Alzheimer's disease. Transl Psychiatry 8:153.

Palop JJ, Mucke L (2009) Epilepsy and cognitive impairments in Alzheimer disease. Arch Neurol 66:435-440.

Palop JJ, Mucke L (2010a) Amyloid-beta-induced neuronal dysfunction in Alzheimer's disease: from synapses toward neural networks. Nat Neurosci 13:812-818.

Palop JJ, Mucke L (2010b) Synaptic depression and aberrant excitatory network activity in Alzheimer's disease: two faces of the same coin? Neuromolecular Med 12:48-55.

Palop JJ, Mucke L (2016) Network abnormalities and interneuron dysfunction in Alzheimer disease. Nat Rev Neurosci 17:777-792.

Palop JJ, Chin J, Roberson ED, Wang J, Thwin MT, Bien-Ly N, Yoo J, Ho KO, Yu G-Q, Kreitzer A, Finkbeiner S, Noebels JL, Mucke L (2007) Aberrant excitatory neuronal activity and compensatory remodeling of inhibitory hippocampal circuits in mouse models of Alzheimer's disease. Neuron 55:697-711.

Pereira AC, Gray JD, Kogan JF, Davidson RL, Rubin TG, Okamoto M, Morrison JH, McEwen BS (2017) Age and Alzheimer's disease gene expression profiles reversed by the glutamate modulator riluzole. Mol Psychiatry 22:296-305.

Pereira AC, Lambert HK, Grossman YS, Dumitriu D, Waldman R, Jannetty SK, Calakos K, Janssen WG, McEwen BS, Morrison JH (2014) Glutamatergic regulation prevents hippocampal-dependent age-related cognitive decline through dendritic spine clustering. Proc Natl Acad Sci USA 111:18733-18738.

Pontecorvo MJ, Devous MD Sr, Navitsky M, Lu M, Salloway S, Schaerf FW, Jennings D, Arora AK, McGeehan A, Lim NC, Xiong $H$, Joshi AD, Siderowf A, Mintun MA; 18F-AV-1451-A05 Investigators (2017) Relationships between flortaucipir PET tau binding and amyloid burden, clinical diagnosis, age and cognition. Brain 140:748-763.

Pooler AM, Phillips EC, Lau DHW, Noble W, Hanger DP (2013) Physiological release of endogenous tau is stimulated by neuronal activity. EMBO Rep 14:389-394.

Prince M, Guerchet M, Prina M (2015) The epidemiology and impact of dementia: current state and future trends. Geneva: World Health Organization.

Putcha D, Brickhouse M, O'Keefe K, Sullivan C, Rentz D, Marshall G, Dickerson B, Sperling R (2011) Hippocampal hyperactivation associated with cortical thinning in Alzheimer's disease signature regions in non-demented elderly adults. J Neurosci 31:1768017688.

Puzzo D, Piacentini R, Fá M, Gulisano W, Li Puma DD, Staniszewski A, Zhang H, Tropea MR, Cocco S, Palmeri A, Fraser P, D'Adamio 
L, Grassi C, Arancio O (2017) LTP and memory impairment caused by extracellular Abeta and tau oligomers is APP-dependent. Elife 6:e26991.

Quiroz YT, Budson AE, Celone K, Ruiz A, Newmark R, Castrillón G, Lopera F, Stern CE (2010) Hippocampal hyperactivation in presymptomatic familial Alzheimer's disease. Ann Neurol 68:865875.

Raichle ME, MacLeod AM, Snyder AZ, Powers WJ, Gusnard DA, Shulman GL (2001) A default mode of brain function. Proc Natl Acad Sci USA 98:676-682.

Ramsden M, Kotilinek L, Forster C, Paulson J, McGowan E, SantaCruz K, Guimaraes A, Yue M, Lewis J, Carlson G, Hutton M, Ashe KH (2005) Age-dependent neurofibrillary tangle formation, neuron loss, and memory impairment in a mouse model of human tauopathy (P301L). J Neurosci 25:10637-10647.

Reyes-Marin KE, Nuñez A (2017) Seizure susceptibility in the APP/ PS1 mouse model of Alzheimer's disease and relationship with amyloid beta plaques. Brain Res 1677:93-100.

Risse SC, Lampe TH, Bird TD, Nochlin D, Sumi SM, Keenan T, Cubberley L, Peskind E, Raskind MA (1990) Myoclonus, seizures, and paratonia in Alzheimer disease. Alzheimer Dis Assoc Disord 4:217-225.

Roberson ED, Halabisky B, Yoo JW, Yao J, Chin J, Yan F, Wu T, Hamto P, Devidze N, Yu G-Q, Palop JJ, Noebels JL, Mucke L (2011) Amyloid-beta/Fyn-induced synaptic, network, and cognitive impairments depend on tau levels in multiple mouse models of Alzheimer's disease. J Neurosci 31:700-711.

Roberson ED, Scearce-Levie K, Palop JJ, Yan F, Cheng IH, Wu T, Gerstein H, Yu G-Q, Mucke L (2007) Reducing endogenous tau ameliorates amyloid beta-induced deficits in an Alzheimer's disease mouse model. Science 316:750-754.

Rocher AB, Crimins JL, Amatrudo JM, Kinson MS, Todd-Brown MA, Lewis J, Luebke JI (2010) Structural and functional changes in tau mutant mice neurons are not linked to the presence of NFTs. Exp Neurol 223:385-393.

Romanelli MF, Morris JC, Ashkin K, Coben LA (1990) Advanced Alzheimer's disease is a risk factor for late-onset seizures. Arch Neurol 47:847-850.

Sadowski JHLP, Jones MW, Mellor JR (2011) Ripples make waves: binding structured activity and plasticity in hippocampal networks. Neural Plast 2011:960389.

Sahay A, Scobie KN, Hill AS, O'Carroll CM, Kheirbek MA, Burghardt NS, Fenton AA, Dranovsky A, Hen R (2011) Increasing adult hippocampal neurogenesis is sufficient to improve pattern separation. Nature 472:466-470.

Sánchez MP, García-Cabrero AM, Sánchez-Elexpuru G, Burgos DF, Serratosa JM (2018) tau-induced pathology in epilepsy and dementia: notions from patients and animal models. Int J Mol Sci 19:1092.

Sanchez PE, Zhu L, Verret L, Vossel KA, Orr AG, Cirrito JR, Devidze N, Ho K, Yu G-Q, Palop JJ, Mucke L (2012) Levetiracetam suppresses neuronal network dysfunction and reverses synaptic and cognitive deficits in an Alzheimer's disease model. Proc Natl Acad Sci USA 109:E2895-E2903.

Scarmeas N, Honig LS, Choi H, Cantero J, Brandt J, Blacker D, Albert M, Amatniek JC, Marder K, Bell K, Hauser WA, Stern Y (2009) Seizures in Alzheimer disease: who, when, and how common? Arch Neurol 66:992-997.

Scharfman HE (2012) Alzheimer's disease and epilepsy: insight from animal models. Future Neurol 7:177-192.

Scharfman HE (2012) "Untangling" Alzheimer's disease and epilepsy. Epilepsy Curr 12:178-183.

Scheff SW, Price DA (2003) Synaptic pathology in Alzheimer's disease: a review of ultrastructural studies. Neurobiol Aging 24:10291046.

Scheff SW, Price DA, Schmitt FA, DeKosky ST, Mufson EJ (2007) Synaptic alterations in CA1 in mild Alzheimer disease and mild cognitive impairment. Neurology 68:1501-1508.

Schöll M, Lockhart SN, Schonhaut DR, O'Neil JP, Janabi M, Ossenkoppele R, Baker SL, Vogel JW, Faria J, Schwimmer HD,
Rabinovici GD, Jagust WJ (2016) PET imaging of tau deposition in the aging human brain. Neuron 89:971-982.

Schultz MK, Gentzel R, Usenovic M, Gretzula C, Ware C, Parmentier-Batteur S, Schachter JB, Zariwala HA Jr (2018) Pharmacogenetic neuronal stimulation increases human tau pathology and trans-synaptic spread of tau to distal brain regions in mice. Neurobiol Dis 118:161-176.

Selkoe DJ (2002) Alzheimer's disease is a synaptic failure. Science 298:789-791.

Sepulveda-Falla D, Glatzel M, Lopera F (2012) Phenotypic profile of early-onset familial Alzheimer's disease caused by presenilin-1 E280A mutation. J Alzheimers Dis 32:1-12.

Shi JQ, Wang BR, Tian YY, Xu J, Gao L, Zhao SL, Jiang T, Xie HG, Zhang YD (2013) Antiepileptics topiramate and levetiracetam alleviate behavioral deficits and reduce neuropathology in APPswe/ PS1dE9 transgenic mice. CNS Neurosci Ther 19:871-881.

Shipton OA, Leitz JR, Dworzak J, Acton CEJ, Tunbridge EM, Denk F, Dawson HN, Vitek MP, Wade-Martins R, Paulsen O, VargasCaballero M (2011) tau protein is required for amyloid \{beta\}-induced impairment of hippocampal long-term potentiation. J Neurosci 31:1688-1692.

Shruster A, Melamed E, Offen D (2010) Neurogenesis in the aged and neurodegenerative brain. Apoptosis 15:1415-1421.

Silverman DHS, Small GW, Chang CY, Lu CS, de Aburto MAK, Chen W, Czernin J, Rapoport SI, Pietrini P, Alexander GE, Schapiro MB, Jagust WJ, Hoffman JM, Welsh-Bohmer KA, Alavi A, Clark CM, Salmon E, de Leon MJ, Mielke R, Cummings JL, et al. (2001) Positron emission tomography in evaluation of dementia: regional brain metabolism and long-term outcome. JAMA 286:2120-2127.

Siwek ME, Müller R, Henseler C, Trog A, Lundt A, Wormuth C, Broich K, Ehninger D, Weiergräber M, Papazoglou A (2015) Altered theta oscillations and aberrant cortical excitatory activity in the 5XFAD model of Alzheimer's disease. Neural Plast 2015:1-17.

Snider BJ, Norton J, Coats MA, Chakraverty S, Hou CE, Jervis R, Lendon CL, Goate AM, McKeel DW, Morris JC (2005) Novel presenilin 1 mutation (S170F) causing Alzheimer disease with Lewy bodies in the third decade of life. Arch Neurol 62:1821-1830.

Sohal VS, Zhang F, Yizhar O, Deisseroth K (2009) Parvalbumin neurons and gamma rhythms enhance cortical circuit performance. Nature 459:698-702.

Sohn PD, Huang CTL, Yan R, Fan L, Tracy TE, Camargo CM, Montgomery KM, Arhar T, Mok SA, Freilich R, Baik J, He M, Gong S, Roberson ED, Karch CM, Gestwicki JE, Xu K, Kosik KS, Gan L (2019) Pathogenic tau impairs axon initial segment plasticity and excitability homeostasis. Neuron 104:458-470.e5.

Sperling RA, Laviolette PS, O'Keefe K, O'Brien J, Rentz DM, Pihlajamaki M, Marshall G, Hyman BT, Selkoe DJ, Hedden T, Buckner RL, Becker JA, Johnson KA (2009) Amyloid deposition is associated with impaired default network function in older persons without dementia. Neuron 63:178-188.

Stam CJ, van Cappellen van Walsum AM, Pijnenburg YA, Berendse HW, de Munck JC, Scheltens P, van Dijk BW (2002) Generalized synchronization of MEG recordings in Alzheimer's disease: evidence for involvement of the gamma band. J Clin Neurophysiol 19:562-574.

Stargardt A, Swaab DF, Bossers K (2015) The storm before the quiet: neuronal hyperactivity and Abeta in the presymptomatic stages of Alzheimer's disease. Neurobiol Aging 36:1-11.

Stevens LM, Brown RE (2015) Reference and working memory deficits in the 3xTg-AD mouse between 2 and 15-months of age: a cross-sectional study. Behav Brain Res 278:496-505.

Stewart S, Cacucci F, Lever C (2011) Which memory task for my mouse? A systematic review of spatial memory performance in the Tg2576 Alzheimer's mouse model. J Alzheimers Dis 26:105-126.

Streit WJ (2004) Microglia and Alzheimer's disease pathogenesis. J Neurosci Res 77:1-8.

Sulkava R (1982) Alzheimer's disease and senile dementia of Alzheimer type. A comparative study. Acta Neurol Scand 65:636650. 
Tai XY, Koepp M, Duncan JS, Fox N, Thompson P, Baxendale S, Liu JYW, Reeves C, Michalak Z, Thom M (2016) Hyperphosphorylated tau in patients with refractory epilepsy correlates with cognitive decline: a study of temporal lobe resections. Brain 139:24412455.

Terry RD, Masliah E, Salmon DP, Butters N, DeTeresa R, Hill R, Hansen LA, Katzman R (1991) Physical basis of cognitive alterations in Alzheimer's disease: synapse loss is the major correlate of cognitive impairment. Ann Neurol 30:572-580.

Thom M, Liu JYW, Thompson P, Phadke R, Narkiewicz M, Martinian L, Marsdon D, Koepp M, Caboclo L, Catarino CB, Sisodiya SM (2011) Neurofibrillary tangle pathology and Braak staging in chronic epilepsy in relation to traumatic brain injury and hippocampal sclerosis: a post-mortem study. Brain 134:2969-2981.

Tian FF, Zeng C, Ma YF, Guo TH, Chen JM, Chen Y, Cai XF, Li FR, Wang XH, Huang WJ, Wang YZ (2010) Potential roles of Cdk5/p35 and tau protein in hippocampal mossy fiber sprouting in the PTZ kindling model. Clin Lab 56:127-136.

Tong LM, Djukic B, Arnold C, Gillespie AK, Yoon SY, Wang MM, Zhang O, Knoferle J, Rubenstein JLR, Alvarez-Buylla A, Huang $Y$ (2014) Inhibitory interneuron progenitor transplantation restores normal learning and memory in ApoE4 knock-in mice without or with Abeta accumulation. J Neurosci 34:9506-9515.

Trivedi MA, Schmitz TW, Ries ML, Hess TM, Fitzgerald ME, Atwood CS, Rowley HA, Asthana S, Sager MA, Johnson SC (2008) fMRI activation during episodic encoding and metacognitive appraisal across the lifespan: risk factors for Alzheimer's disease. Neuropsychologia 46:1667-1678.

Van Erum J, Valkenburg F, Van Dam D, De Deyn PP (2020) Pentylenetetrazole-induced seizure susceptibility in the tau58/4 transgenic mouse model of tauopathy. Neuroscience 425:112122.

Verret L, Mann EO, Hang GB, Barth AMI, Cobos I, Ho K, Devidze N, Masliah E, Kreitzer AC, Mody I, Mucke L, Palop JJ (2012) Inhibitory interneuron deficit links altered network activity and cognitive dysfunction in Alzheimer model. Cell 149:708-721.

Vico Varela E, Etter G, Williams S (2019) Excitatory-inhibitory imbalance in Alzheimer's disease and therapeutic significance. Neurobiol Dis 127:605-615.

Vogt DL, Thomas D, Galvan V, Bredesen DE, Lamb BT, Pimplikar SW (2011) Abnormal neuronal networks and seizure susceptibility in mice overexpressing the APP intracellular domain. Neurobiol Aging 32:1725-1729.

Vossel KA, Zhang K, Brodbeck J, Daub AC, Sharma P, Finkbeiner S, Cui B, Mucke L (2010) tau reduction prevents Abeta-induced defects in axonal transport. Science 330:198.

Vossel KA, Beagle AJ, Rabinovici GD, Shu H, Lee SE, Naasan G, Hegde M, Cornes SB, Henry ML, Nelson AB, Seeley WW, Geschwind MD, Gorno-Tempini ML, Shih T, Kirsch HE, Garcia PA, Miller BL, Mucke L (2013) Seizures and epileptiform activity in the early stages of Alzheimer disease. JAMA Neurol 70:1158-1166.

Vossel KA, Ranasinghe KG, Beagle AJ, Mizuiri D, Honma SM, Dowling AF, Darwish SM, Van Berlo V, Barnes DE, Mantle M, Karydas AM, Coppola G, Roberson ED, Miller BL, Garcia PA, Kirsch HE, Mucke L, Nagarajan SS (2016) Incidence and impact of subclinical epileptiform activity in Alzheimer's disease. Ann Neurol 80:858-870.

Vossel KA, Tartaglia MC, Nygaard HB, Zeman AZ, Miller BL (2017) Epileptic activity in Alzheimer's disease: causes and clinical relevance. Lancet Neurol 16:311-322.

Walsh DM, Klyubin I, Fadeeva JV, Cullen WK, Anwyl R, Wolfe MS, Rowan MJ, Selkoe DJ (2002) Naturally secreted oligomers of amyloid beta protein potently inhibit hippocampal long-term potentiation in vivo. Nature 416:535-539.

Wang L, Benzinger TL, Su Y, Christensen J, Friedrichsen K, Aldea P, McConathy J, Cairns NJ, Fagan AM, Morris JC, Ances BM (2016) Evaluation of tau imaging in staging Alzheimer disease and revealing interactions between beta-amyloid and tauopathy. JAMA Neurol 73:1070-1077.

Wang Q, Walsh DM, Rowan MJ, Selkoe DJ, Anwyl R (2004) Block of long-term potentiation by naturally secreted and synthetic amyloid beta-peptide in hippocampal slices is mediated via activation of the kinases c-Jun $\mathrm{N}$-terminal kinase, cyclin-dependent kinase 5 , and p38 mitogen-activated protein kinase as well as metabotropic glutamate receptor type 5. J Neurosci 24:3370-3378.

Webster SJ, Bachstetter AD, Nelson PT, Schmitt FA, Van Eldik LJ (2014) Using mice to model Alzheimer's dementia: an overview of the clinical disease and the preclinical behavioral changes in ten mouse models. Front Genet 5:88.

Westmark CJ, Westmark PR, Beard AM, Hildebrandt SM, Malter JS (2008) Seizure susceptibility and mortality in mice that over-express amyloid precursor protein. Int J Clin Exp Pathol 1:157-168.

Westmark CJ, Westmark PR, Malter JS (2010) Alzheimer's disease and Down syndrome rodent models exhibit audiogenic seizures. $J$ Alzheimers Dis 20:1009-1013.

Witton J, Staniaszek LE, Bartsch U, Randall AD, Jones MW, Brown JT (2016) Disrupted hippocampal sharp-wave ripple-associated spike dynamics in a transgenic mouse model of dementia. J Physiol 594:4615-4630.

Worrell GA, Parish L, Cranstoun SD, Jonas R, Baltuch G, Litt B (2004) High-frequency oscillations and seizure generation in neocortical epilepsy. Brain 127:1496-1506.

Wu JW, Hussaini SA, Bastille IM, Rodriguez GA, Mrejeru A, Rilett K, Sanders DW, Cook C, Fu H, Boonen RACM, Herman M, Nahmani E, Emrani S, Figueroa YH, Diamond MI, Clelland CL, Wray S, Duff KE (2016) Neuronal activity enhances tau propagation and tau pathology in vivo. Nat Neurosci 19:1085-1092.

Yan XX, Cai Y, Shelton J, Deng SH, Luo XG, Oddo S, Laferla FM, Cai H, Rose GM, Patrylo PR (2012) Chronic temporal lobe epilepsy is associated with enhanced Alzheimer-like neuropathology in 3xTgAD mice. PLoS One 7:e48782.

Yu FH, Mantegazza M, Westenbroek RE, Robbins CA, Kalume F, Burton KA, Spain WJ, McKnight GS, Scheuer T, Catterall WA (2006) Reduced sodium current in GABAergic interneurons in a mouse model of severe myoclonic epilepsy in infancy. Nat Neurosci 9:1142-1149.

Ziyatdinova S, Gurevicius K, Kutchiashvili N, Bolkvadze T, Nissinen J, Tanila H, Pitkänen A (2011) Spontaneous epileptiform discharges in a mouse model of Alzheimer's disease are suppressed by antiepileptic drugs that block sodium channels. Epilepsy Res 94:75-85.

Ziyatdinova S, Viswanathan J, Hiltunen M, Tanila H, Pitkänen A (2015) Reduction of epileptiform activity by valproic acid in a mouse model of Alzheimer's disease is not long-lasting after treatment discontinuation. Epilepsy Res 112:43-55.

Zott B, Busche MA, Sperling RA, Konnerth A (2018) What happens with the circuit in Alzheimer's disease in mice and humans? Annu Rev Neurosci 41:277-297.

Zott B, Simon MM, Hong W, Unger F, Chen-Engerer HJ, Frosch MP, Sakmann B, Walsh DM, Konnerth A (2019) A vicious cycle of beta amyloid-dependent neuronal hyperactivation. Science 365:559565. 